\title{
REGULATIONS ON \\ PHOTOVOLTAIC MODULE DISPOSAL AND RECYCLING
}

\author{
Vasilis Fthenakis
}

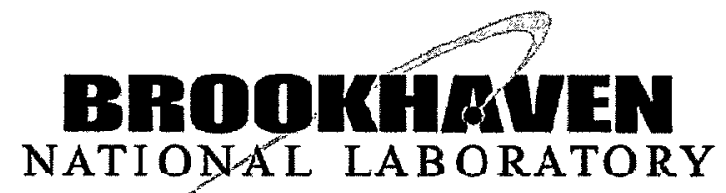

Environmental Research \& Technology Division

Environmental Sciences Department

Brookhaven National Laboratory

Brookhaven Science Associates

Upton, Long Island, New York 11973

Under Contract No. DE-AC02-98CH10886 with the

UNITED STATES DEPARTMENT OF ENERGY 


\section{DISCLAIMER}

This report was prepared as an account of work sponsored by an agency of the United States Government. Neither the United State Government nor any agency thereof, nor any of their employees, not any of their contractors, subcontractors, or their employees, makes any warranty, express or implied, or assumes any legal liability or responsibility for the accuracy, completeness, or usefulness of any information, apparatus, product, or process disclosed, or represents that its use would not infringe privately owned rights. Reference herein to any specific commercial product, process, or service by trade name, trademark, manufacturer, or otherwise, does not necessarily constitute or imply its endorsement, recommendation, or favoring by the United States Government or any agency, contractor, or subcontractor thereof. The vies and opinions of authors expressed herein do not necessarily state or reflect those of the United States Government or any agency, contractor or subcontractor thereof. 


\title{
REGULATIONS ON \\ PHOTOVOLTAIC MODULE DISPOSAL AND RECYCLING*
}

\author{
Vasilis Fthenakis
}

January 29, 2001

Environmental Research \& Technology Division

Environmental Sciences Department

Brookhaven National Laboratory

Brookhaven Science Associates

Upton, Long Island, New York 11973

Under Contract No. DE-AC02-98CH10886 with the

UNITED STATES DEPARTMENT OF ENERGY

"This work was performed under the auspices of the U.S. Department of Energy. 


\section{SUMMARY}

Environmental regulations can have a significant impact on product use, disposal, and recycling. This report summarizes the basic aspects of current federal, state and international regulations which apply to end-of-life photovoltaic (PV) modules and PV manufacturing scrap destined for disposal or recycling. It also discusses proposed regulations for electronics that may set the ground of what is to be expected in this area in the near future. In the United States, several states have started programs to support the recycling of electronic equipment, and materials destined for recycling often are excepted from solid waste regulations during the collection, transfer, storage and processing stages. California regulations are described separately because they are different from those of most other states.

International agreements on the movement of waste between different countries may pose barriers to cross-border shipments. Currently waste moves freely among country members of the Organization of Economic Cooperation and Development (OECD), and between the United Sates and the four countries with which the US has bilateral agreements. However, it is expected, that the United States will adopt the rules of the Basel Convention (an agreement which currently applies to 128 countries but not the United States) and that the Convection's waste classification system will influence the current $O E C D$ waste-handling system. Some countries adopting the Basel Convention consider end-of-life electronics to be hazardous waste, whereas the OECD countries consider them to be non-hazardous.

Also, waste management regulations potentially affecting electronics in Germany and Japan are mentioned in this report.

\section{ACKNOWLEDGMENT}

The contributions of the following individuals are gratefully acknowledged: Chris Eberspacher, Unisun; Mark Hammonds and Ed Mopas, BP. Solar; Hugh Morrow, International Cadmium Association; and Sergio Vasquez, Siemens Solar. 


\section{CONTENTS}

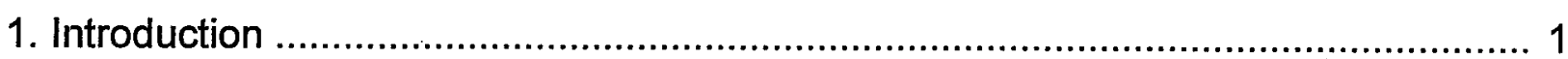

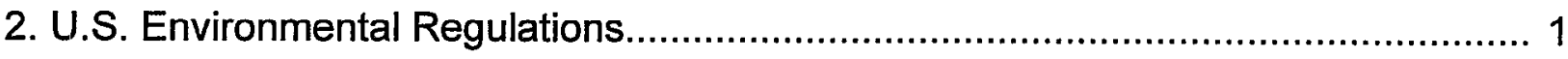

2.1 The Toxicity Characteristics Leaching Procedure ........................................... 2

2.2 Proposed Exceptions from RCRA Solid Waste Characterization ...................... 4

3. State Environmental Regulations .................................................................. 5

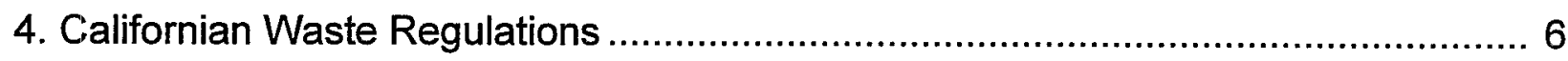

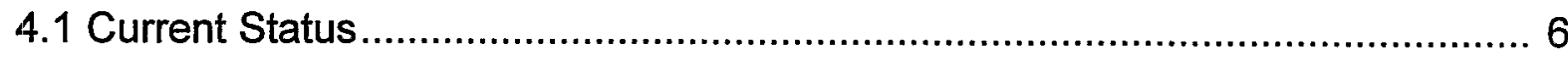

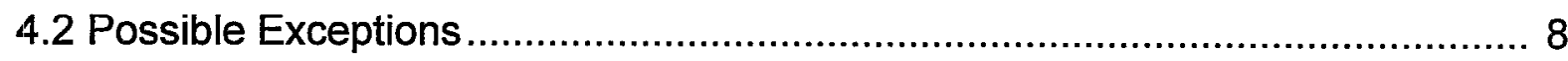

4.3 Proposed Waste Reclassification............................................................... 9

4.4 Preprocessing of PV Waste Intended for Recycling....................................... 10

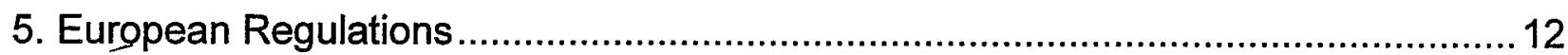

5.1 German Waste Management Regulations.................................................. 12

5.2 Proposed Regulations ........................................................................... 13

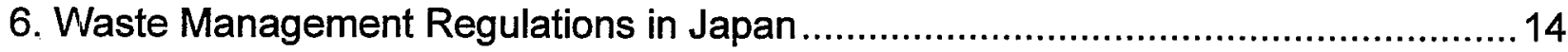

7. Regulations Regarding Movement of Discarded PV products Across National

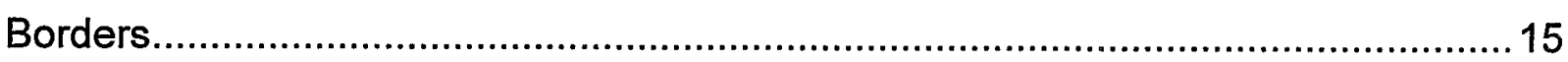

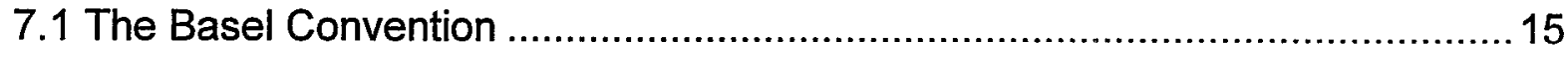

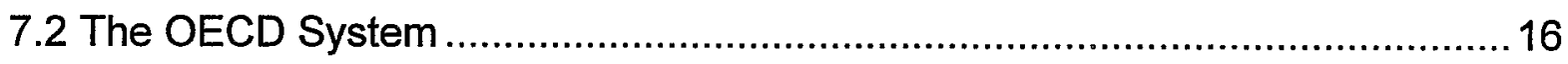

7.3 The European Union Regulation 259/93/EEC ........................................... 16

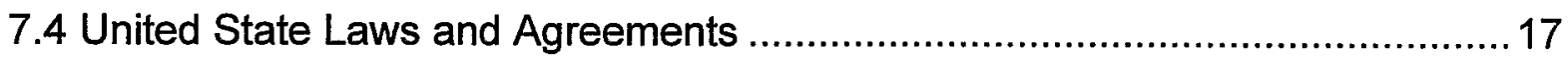

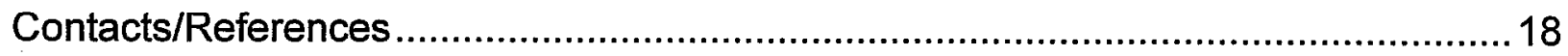

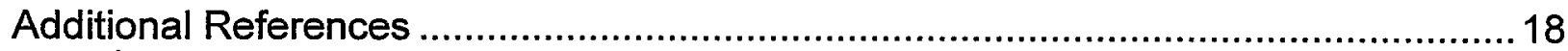

Appendix A. UNISUN's Correspondence with California EPA Regarding

Pretreatment of PV Waste Prior to Recycling ..................................................... 19

Appendix B. The TCLP Metal Extraction Procedure....................................................40

Appendix C. The DEV S4 Metal Extraction Procedure...............................................66

Appendix D. Exports from and Imports to the U.S. Under International and Bilateral

Agreements. 


\section{INTRODUCTION}

Environmental regulations can have a significant impact on the use, disposal, and recycling of products. In this report, I compile the basic aspects of federal, state, and international regulations which potentially apply to end-of life photovoltaic (PV) modules and PV manufacturing scrap destined for disposal or recycling.

Expected changes on regulations regarding electronic waste are also discussed because they set the ground on what is to be expected in the PV area in the near future.

\section{U.S. ENVIRONMENTAL REGULATIONS}

US Regulations applicable to solid-waste management are the Resource Conservation and Recovery Act (RCRA), its various amendments, and corollary State regulations. The $\bar{R} C R A$ defines solid waste as any "discarded material" that is not specifically excluded (Table 1). Neither PVs in general, nor any of the photovoltaic materials in particular (e.g., $\mathrm{Si}, \mathrm{CdTe}, \mathrm{CIS}$ ), are excluded from the general definition of a solid waste. PV materials and modules are not inherently waste material according to RCRA's definitions, but end-of-life PV modules are likely to be categorized as such unless handled in a manner that qualifies them for exclusion. Manufacturing by-products (e.g. defective PV modules, broken module plates, patterning dusts) might be exempted from being handled as solid waste if they are sent for (certain types of) reclamation. One such type that qualifies for exception is the use of PV waste as an ingredient in an industrial process or as a substitute for a commercial product (e.g., using the glass from PV modules as source of silica for fluxing in metal smelters).

To define what is hazardous, RCRA assigns a hazard classification based on four basic characteristics; ignitibility, corrosivity, reactivity, and toxicity. Under RCRA regulations, PV modules (not excluded from classification under the provisions for reclamation of the solid-waste definition) are likely to be classified as non-hazardous if they pass the Toxicity Characteristics Leaching Procedure (TCLP); (Table 2). 
Table 1. Definitions in the U.S. Resource Conservation and Recovery Act (RCRA)

"Waste" = any discarded material that is not specifically excluded. ${ }^{1}$

"discarded" = abandoned, recycled or "inherently waste-like"

"abandoned" = disposed of, incinerated, accumulated for disposal or incineration

"Hazardous waste" = solid waste that pose a substantial hazard to human health and the environment when improperly managed. ${ }^{2}$

listed as "inherently hazardous" or exhibits hazardous characteristics (ignitibility, corrosivity, reactivity, toxicity)

${ }^{1}$ Materials are excluded from solid waste classification if used, reused, or returned to the original process without being reclaimed.

2 Hazardous waste entails high costs of handling, storage, processing, and management, and also, land disposal restrictions

Table 2. RCRA Waste Classification for "Discarded" PV

\begin{tabular}{|l|l|}
\hline Hazardous if it & End-of-Life PV Modules \\
\hline is a solid waste, and & are solid waste, unless recycled and excluded \\
\hline $\begin{array}{l}\text { is not explicitly excluded, } \\
\text { and }\end{array}$ & are not excluded, unless household waste (currently) \\
\hline $\begin{array}{l}\text { is "listed" as inherently } \\
\text { hazardous, or }\end{array}$ & are not listed \\
\hline $\begin{array}{l}\text { it exhibits hazardous } \\
\text { "characteristics" }\end{array}$ & are subject to TCLP testing \\
\hline
\end{tabular}

\subsection{The Toxicity Characteristics Leaching Procedure}

According to the Toxicity Characteristic Leaching Procedure (TCLP), test Method 1311, solid waste is classified as toxic if the extract from a representative sample contains any of the contaminants listed in Table 3 at a concentration equal to, or greater than the TC threshold level given there. Following this procedure, PV waste is crushed into small pieces $\left(1 \mathrm{~cm}^{2}\right.$ area) and subjected for 18 hours to a wet extraction test using a weak 
acid; this procedure is shown in Appendix B. Generators must test solid waste (and wastewater) suspected of containing any of the listed metals (several organic materials also are covered by this procedure but those are not of concern to the PV industry and, therefore, are not listed herein.)

If solid waste is characterized as hazardous, then it must be treated either by extraction, incineration, or immobilization so that the concentrations of leachable hazardous constituents fall below their Universal Treatment Standards (UTSs) (Table 3). The residual waste then can be disposed in controlled landfills. RCRA's land-disposal restrictions forbid the disposal of hazardous waste that has not been treated to levels below the UTS.

Table 3. Toxicity Characteristic (TC) and Universal Treatment Standards (UTS)

\begin{tabular}{|l|l|l|}
\hline Constituent & $\begin{array}{l}\text { TC Threshold level } \\
(\mathrm{mg} / \text { TCLP) }\end{array}$ & $\begin{array}{l}\text { UTS }^{2} \\
(\mathrm{mg} / \text { TCLP) }\end{array}$ \\
\hline Antimony & - & 1.15 \\
\hline Arsenic & 5 & 5 \\
\hline Barium & 100 & \\
\hline Cadmium & 1 & 0.11 \\
\hline Chromium & 5 & 0.6 \\
\hline Lead & 5 & 0.75 \\
\hline Mercury & 0.2 & \\
\hline Nickel & - & 11 \\
\hline Selenium & 3 & 5.7 \\
\hline Silver & 1 & 0.14 \\
\hline Zinc & 5 & 4.3 \\
\hline
\end{tabular}

40 CFR, Ch. 1 (7-1-94 Edition), p. 47

${ }^{2}$ Non-waste-water Standard, Federal Register,Vol. 63, No 100, May 26, 1998.

As shown in Table 3, the UTS level for selenium is greater than its TC level. Thus treated selenium with extract less than $5.7 \mathrm{mg} / \mathrm{l}$, although still hazardous according to the TCLP, can be disposed off in controlled landfills.

In most cases, thin-film photovoltaic modules pass the TCLP test. Table 4 shows the ranges of the results reported to us by various manufacturers from 1994 to1997. 
Table 4. RCRA Leach Testing Results for $\mathrm{x}-\mathrm{Si}$, CdTe, and CIS Modules

\begin{tabular}{|ll|l|l|}
\hline Constituent & $\begin{array}{l}\text { Regulatory TC Limits } \\
(\mathrm{mg} / \mathrm{l})\end{array}$ & $\begin{array}{l}\text { TCLP Results } \\
(\mathrm{mg} / \mathrm{l})\end{array}$ \\
\hline $\mathrm{X}-\mathrm{Si}$ & $\mathrm{Ag}$ & 5 & \\
& $\mathrm{~Pb}$ & 5 & $0-0.1$ \\
& $\mathrm{~Pb}$ & $3-6.6$ \\
\hline $\mathrm{CdTe}$ & & $0.7-9.5$ \\
& $\mathrm{Cd}$ & 1 & $0.04-0.4$ \\
& $\mathrm{~Pb}$ & 5 & $0.4-0.6$ \\
& $\mathrm{Te}$ & - & \\
$\mathrm{ClS}$ & $\mathrm{Zn}$ & - & $2.8-18$ \\
& $\mathrm{Zn}$ & 1 & $0.06-0.5$ \\
& $\mathrm{Se}$ & 1 & $0.028-0.031$ \\
\hline
\end{tabular}

\subsection{Proposed Exceptions from RCRA Solid Waste Characterization}

Two proposed changes in the above regulations might be of interest to the PV industry.

1. The EPA-Science Advisory Board recommended to the EPA that the TCLP be reviewed and improved to account for the following additional parameters: 1) liquid/solid ratio: 2) $\mathrm{pH}$; 3) release rate; 4) colloid formation, and 5) particle size reduction.

If this recommendation is adopted, the TCLP may be replaced with multiple levels of testing reflecting ranges of conditions. It is not known how this may affect the classification of $\mathrm{PV}$ waste.

2. EPA intends to amend the definition of solid waste by excluding from RCRA jurisdiction shredded circuit boards and processed scrap metal destined for metal recovery ${ }^{1}$. The only restrictions to these proposed exclusions are 1) shredded circuit-

\footnotetext{
' In the final rule the Agency clarifies that the exclusion for processed scrap metal being recycled applies to scrap metal that has under gone a processing step regardless of who does the processing. In other words, the generator, an intermediate scrap handler (e.g., broker, scrap processor), or a scrap recycler may perform a processing step. Once the scrap metal has undergone a processing step, it may qualify for the exclusion from the definition of solid waste. Used whole (i.e., intact) circuit boards sent for reclamation may be considered to be scrap metal and may therefore be exempt from RCRA regulation. Shredded circuit boards managed in containers need not be characterized (i.e., analyzed using the TCLP) and that there are no time limitations associated with the storage of shredded circuit boards subject to the exclusion. Under $40 \mathrm{CFR}$ $\$ 262.11$, generators are required to determine if a waste is hazardous only if they generate a solid waste. Therefore, if the shredded circuit boards are in compliance with the exclusion from the definition of solid waste, the generator would not be required to perform a hazardous waste characterization. However, under 40 CFR $\$ 261.2(\mathrm{f})$, if a material is excluded from the definition of solid waste, the claimant must provide appropriate documentation to demonstrate that the material is excluded from regulation and therefore it
} 
boards must be in containers during storage and shipment and, 2) material with "commodity value" should be economically recovered. By minimizing the regulatory and reporting burdens associated with these recoverable materials, the proposed regulatory changes provide an economic impetus that should benefit the regulated community and the recycling industry. This is important not only in the present manufacturing climate, but will become increasingly significant in the years ahead as companies become more involved in the disassembly of end-of-life equipment.

\section{STATE ENVIRONMENTAL REGULATIONS}

Individual states in the United States must, at a minimum, endorse national environmental laws. However, they are allowed to enact and enforce state environmental regulations that are more stringent than the national ones.

Most states have regulations on waste management that essentially mirror the RCRA regulations; a noted exception is California, which has stricter regulations than the national ones.

It appears that several states are easing-up previous regulatory constraints on recycling. In a 1999 conference on recycling electronics (EPR2, Wash. DC, March 23-24, 1999), speakers from Florida, Massachusetts, Minnesota, South Carolina and Wisconsin discussed ongoing or proposed State initiatives on take-back programs, recycling trust funds, landfill bans, and voluntary programs for electronics. All the speakers referred to

need not be characterized. Agency codified the exclusion to state that shredded circuit boards are excluded from the definition of solid waste only if they are stored in containers that are sufficient to prevent a release to the environment. The following is EPA's answer to a question whether volume reduction techniques (such as compacting) are considered treatment: Since the definition of treatment under $\$ 260.10$ is such a broad definition, volume reduction techniques of wastes defined as hazardous could be considered treatment under an implementing agency interpretation. However, when the exclusion for shredded circuit board becomes effective, whole boards destined for recycling will be exempt from the definition of hazardous waste, and shredded boards will be excluded from the definition of solid waste. Assuming that all handlers stay in compliance with the conditions of the exclusion, there will not be any point in the generation and recycling of printed circuit boards that hazardous waste is being handled. If waste defined as hazardous is not being handled, treatment can not occur. The proposed rule would exclude shredded circuit boards from the Resource Conservation and Recovery Act (RCRA) definition of solid waste as long as the boards are destined for metal recovery and are managed in containers during storage and shipment prior to recovery. The proposed rule was published in the Federal Register on January 25, 1996 (61 Fed. Reg. 2338). 
discarded electronic equipment as a "resource" instead of a "waste" and some mentioned that, in practice, their state environmental agencies relax EPA regulations on "hazardous waste" classification (e.g., TCLP testing), for discarded electronic products destined for recycling. In addition, several States have started programs supporting the recycling of electronic equipment. For example, South Carolina introduced legislation in March 18, 1999 on collecting, storing, transporting, processing, and recycling or disposing of scrap electronic equipment, and also established a fund to assist the recycling market and develop the infrastructure for it. The fund draws on state funds and revenues from a $\$ 5$ fee added to the price of new electronic equipment containing cathode ray tube (CRT) displays.

\section{CALIFORNIAN WASTE REGULATIONS}

Californian regulations deserve special attention because they are different from those in most of the other states; they respond to unique or special environmental situations in the state. California has many times initiated regulations, which were later adopted by the federal government. Californian regulations typically allow more flexibility than federal regulations.

\subsection{Current Status}

California's Hazardous Waste Control Law (HWCL) incorporates RCRA and expands the toxicity requirements by adding the requirements of an additional wet extraction test and total allowable concentration of a metal in the waste (Table 5). The thresholds for finding chronic toxicity are measured by both the total concentration of a particular metal constituent (total threshold limit concentration or "TTLC") and the soluble or leachable concentration of that constituent (soluble threshold limit concentration, or "STLC"). Under HWCL regulations, PV modules could be classified as hazardous if they fail either the Toxic Characteristic Procedure (TCLP) or the Soluble Threshold Limit Concentration (STLC) test. Table 6 lists the current limits for inorganic substances. 
Table 5. California-HWCL Waste Classification

\begin{tabular}{|l|l|}
\hline Hazardous if & End-of-Life PV Modules \\
\hline RCRA requirements (listed in Table 2), and & \\
\hline $\begin{array}{l}\text { additional toxicity leaching requirements (STLC), } \\
\text { and mass balance requirements (TTLC) }\end{array}$ & $\begin{array}{l}\text { hazardous according to } \\
\text { TTLC }\end{array}$ \\
\hline
\end{tabular}

Table 6. California Toxicity Leaching Criteria

\begin{tabular}{|l|l|l|}
\hline Substance & $\underline{\text { STLC }\left(\mathrm{mg} / \mathrm{ll}^{1}\right.}$ & ${\text { TLLC }(\mathrm{g} / \mathrm{kg})^{2}}^{2}$ \\
\hline Antimony & 15 & 0.5 \\
\hline Arsenic & 5 & 0.5 \\
\hline Asbestos & & $(1.0 \%)$ \\
\hline Barium & 100 & 10 \\
\hline Beryllium & 0.75 & 0.075 \\
\hline Cadmium & 1 & 0.1 \\
\hline Chromium (VI) & 5 & 0.5 \\
\hline Chromium (III) & 5 & 2.5 \\
\hline Cobalt & 80 & 8 \\
\hline Copper & 25 & 2.5 \\
\hline Fluoride Salts & 180 & 18 \\
\hline Lead & 5 & 1 \\
\hline Mercury & 0.2 & 20 \\
\hline Molybdenum & 350 & 3.5 \\
\hline Selenium & 1 & 0.1 \\
\hline Silver & 5 & 0.5 \\
\hline Thallium & 7 & 0.7 \\
\hline Vanadium & 24 & 2.4 \\
\hline Zinc & 250 & 5. \\
\hline
\end{tabular}

STLC: Soluble Threshold Limit Concentration according to a Waste Extraction Test $(50 \mathrm{~g}$ sample/500 $\mathrm{ml}$ of $0.2 \mathrm{M}$ sodium citrate solution)

TTLC: Total Threshold Limit Concentration

Table 7 gives some comparisons with TTLC levels of the content of PV modules under specific assumptions. It shows that PV modules can fail the TTLC for $\mathrm{Ag}$ and $\mathrm{Pb}(\mathrm{x}-\mathrm{Si}$ cells), $\mathrm{Cd}$ and $\mathrm{Pb}$ (CdTe cells), and $\mathrm{Se}$ (CIS cells). 
Table 7. California TTLC Results for $\mathrm{x}-\mathrm{Si}$, CdTe, and CIS PV Modules

\begin{tabular}{|ll|l|l|}
\hline Constituent & $\begin{array}{l}\text { Regulatory TTLC Limits } \\
\text { (g/kg of waste) }\end{array}$ & $\begin{array}{l}\text { Calculated Content } \\
\text { (g/kg of module) }\end{array}$ \\
\hline $\mathrm{x}-\mathrm{Si}$ & $\mathrm{Ag}$ & 0.5 & $0.65(0.70)$ \\
& & 1 & $0.8 ; 1.25 ; 3.4$ \\
& $\mathrm{~Pb}$ & 2.5 & 1 \\
& $\mathrm{Cu}$ (ribbon) & & 10 \\
\hline $\mathrm{CdTe}$ & $\mathrm{Cd}$ & \\
& $\mathrm{Pb}$ & 1 & 0.32 \\
& $\mathrm{Ni}$ & 2 & 0.05 \\
& $\mathrm{ClS}$ & & 0.02 \\
& $\mathrm{Zn}$ & 5 & \\
& $\mathrm{Se}$ & 0.1 & 0.59 \\
& $\mathrm{Cd}$ & 0.1 & 0.29 \\
& $\mathrm{~Pb}$ & 1 & 0.02 \\
\hline
\end{tabular}

\subsection{Possible Exceptions}

In general, there are two options for obtaining a non-hazardous designation for PV despite its exceeding the TTLC limits for a particular element. First, the California Environmental Protection Agency (Cal-EPA) Department of Toxic Substances Control can be petitioned to re-classify a specific type of PV spent module or scrap as nonhazardous under provisions set forth in the HWCL. Second, Cal-EPA can be formally requested for a rule-making change to its regulations which can grant a generic exclusion for a given material (or a family of materials), independent of the generator. More details about the first option are given below; the second option will be explored in the near future.

Petitioning the Cal-EPA for an exception from TTLC requirements is a straightforward process. The California Health and Safety Code 25143.2 subsection (b) sets the foundation for an exception from TTLC of monolithic products that pass both TCLP and STLC) $)^{2}$.

${ }^{2}$ California Health and Safety Code 25143.2, Subsection (B)

(3) (A) Except as provided in subparagraph (B) below, a waste which would be classified as hazardous solely because it exceeds total threshold limit concentrations, as defined in regulations adopted by the department, shall be excluded from classification as a hazardous waste for purposes of disposal in, and is allowed to be disposed in a disposal unit regulated as a permitted class I, II, or III disposal unit, pursuant to Sections 2532, 2533, and 2541 of Title 23 of the California Code of Regulations, if, prior to disposal, the waste is managed in accordance with the management standards adopted by the department, by regulation, 
The most expedient way for petitioning the Cal-EPA for an exception is for companies to classify their waste themselves based on their specific knowledge and testing, submit supporting documentation to the Cal-EPA, and ask them for a Letter of Concurrence. However, a proposed reclassification of waste is pending in California that may require LD50 or LC50 data for any unlisted material for which exception from TTLP is requested. This is discussed below.

\subsection{Proposed Waste Reclassification}

The California State Department of Toxic Substances Control (DTSC) proposed to the state legislature ${ }^{3}$ a significant change in the method by which the state regulates wastes that are considered hazardous in California (i.e., they fail STLC and/or TTLC), although not hazardous under Federal law. At present, the State regulates these wastes in the same manner as RCRA hazardous waste. The essence of the proposal will be to segment hazardous wastes into two tiers: 1) higher risk wastes that will continue to be regulated the same as RCRA wastes, and 2) lower risk wastes that will be called "special wastes" and will have more relaxed management standards.

The first tier would include "RCRA wastes" (both RCRA-listed waste and waste that fail TCLP). According to this proposal, the STLC wet extraction test is eliminated and only

if any, for this specific type of waste. (B) Subparagraph (A) shall not apply to a hazardous waste that is a liquid, a sludge or sludge-like material, soil, a solid that is friable, powdered, or finely divided, a nonfilterable and nonmillable tarry material, or a waste that contains an organic substance that exceeds the total threshold limit concentration established by the department for that substance.

(C) For purposes of this subparagraph (B), the following definitions shall apply: (i) A waste is liquid if it meet the test specified in subdivision(i) of Section 66268.32 of Title 22 of the California Code of Regulations. (ii) "Sludge or sludge-like material" means any solid, semisolid, or liquid waste generated from a municipal, commercial, or industrial wastewater treatment plant, water supply treatment plant, or air pollution control facility, but does not include the treated effluent from wastewater treatment plants. (iii) "Friable, powdered, or finely divided" shall have the same meaning as used in the regulations adopted by the department pursuant to this chapter. (iv) "Nonfilterable and nonmillable tarry material" shall have the same meaning as used in the regulations adopted by the department pursuant to this chapter. (D) This paragraph does not affect the authority of a city or county regarding solid waste management under existing provisions of law. (c) Any regulations adopted pursuant to subdivision (b) of this section shall be considered by the Office of Administrative Law as necessary for the immediate preservation of the public peace, health and safety, and general welfare, and may be adopted as emergency regulations in accordance with Chapter 3.5 (commencing with Section 11340) of Part 1 of Division 3 of Title 2 of the Government Code.

${ }^{3}$ This proposal is on hold as of October 2000. 
the TCLP test will be used. However, the results of the later would be compared against two regulatory limits (i.e. the RCRA threshold and the Cal-EPA threshold).

The second tier is a new category of "special waste" that do not exceed the chronic or acute toxicity limits set for hazardous wastes, but do exceed new, lower, chronic or acute toxicity limits. The following are the proposed acute toxicity limits for "special waste" status:
a) an oral LD50 of less than $2,500 \mathrm{mg} / \mathrm{kg}$, but over $120 \mathrm{mg} / \mathrm{kg}$,
b) a dermal LD50 of less than $10,800 \mathrm{mg} / \mathrm{kg}$, but over $6,500 \mathrm{mg} / \mathrm{kg}$,
c) a ratio of summed vapor pressures divided by an inhalation LC50 of more than
$0.1 \mathrm{ppm}$ but less than $1 \mathrm{ppm}$, or
d) an aquatic 96 -hour LC50 of less than $500 \mathrm{mg} / \mathrm{liter}$ but over $30 \mathrm{mg} / \mathrm{liter}$.

The new rules will allow "special waste" to be disposed of in non-RCRA landfills, as long as they meet the requirements of the local Water Quality Control Board. Generators of special waste will have to meet record-keeping requirements, obtain an identification number, and meet certain requirements on shipping (e.g., packaging and labeling) and storage.

The status of PV waste and byproducts of manufacturing and recycling could become either more regulated or less regulated, depending on the concentration of the constituent in question.

\subsection{Preprocessing of PV Waste Intended for Recycling}

Besides requesting and receiving an exception, a more definitive way to avoid a hazardous-waste classification of spent PV panels is to separate a listed metal from the glass or plastic substrate. The question is what separations are permitted on site without requiring special waste handling permits.

The answer is found in certain provisions of the U.S. Resource Conservation and Recovery Act and the California Health and Safety Code on materials recycling, including the pretreatment of waste before recycling. These provisions provide a 
regulatory basis for pretreating unused, off-specification thin-film PV products in certain ways without invoking regulation as treatment of a hazardous waste.

Pretreatment before recycling is allowed if it entails physical separation techniques, such as scraping, and grinding; chemical means and an outside supply of heat can not be used. Such pretreatment can remove materials that might otherwise render the modules "hazardous" under federal and/or state regulations. Thus an off-specification module that in its entirety might exhibit the characteristics of a "hazardous waste" is processed to separate from the major part of the plate those fewer materials that cause the whole to be hazardous. This separation reduces the quantity of hazardous waste (up to 3 orders of magnitude for thin-film cells) and therefore, the cost of handling it, and also simplifies handling of the rest of the plate. Furthermore, metal materials removed from off-specification PV plates might be considered scrap metal, and therefore, excluded from certain regulations when recycled (see section 2.2 above). However, such exemption, , will not apply to removed material in "fine powder" form. Fine powder is defined as dry, solid metal having particles smaller than 100 micrometers in diameter. It is likely that the average size of pieces of debris from mechanical stripping of modules will be above 100 microns, and hence, will not be a "fine powder" according to Cal-EPA's definition. Even if it is in "fine powder" form, the material still might be exempt from characterization as solid waste if it is used (recycled) as an ingredient in an industrial process.

Pretreatment of unused off-specification thin-film PV plates provides a pathway for manufacturers of thin-film PV modules in California to significantly reduce the volume of manufacturing wastes and/or to significantly simplify the recycling of certain materials. Under California law, such thin film PV modules are not regulated solid waste provided that they are recycled within one year from the date they were generated. Therefore, a manufacturer can collect PV waste intended for recycling for up to one year to get the advantage of economics of scale. PV plates can be dismantled by the manufacturer, and the metal compounds and glass can be separately reclaimed (e.g., metal by a primary smelter, and glass by the respective industry). Appendix A includes documentation of this approach. ${ }^{4}$

\footnotetext{
${ }^{4}$ Appendix $\mathrm{B}$ includes documents supporting the regulatory basis for why unused, off-specification photovoltaic plates might be pre-treated in certain ways without invoking regulation as treatment of a
} 


\section{EUROPEAN REGULATIONS}

\subsection{German Waste Management Regulations}

The German waste classification system includes a requirement for a wet leaching test simulating landfill conditions, that resembles the one of the United States; to our knowledge, other European countries do not have equivalent tests. This is the DEV S4 wet extraction test and is required for waste that includes listed metals. Although the DEV S4 test is similar to the TCLP, threshold levels for some metals are quite different than those specified by RCRA. These levels and comparisons with leaching tests are shown in Table 8. The procedure of the DEV S4 test is shown in Appendix C.

Table 8. German DEV S4 Results for CdTe and CIS PV Modules

\begin{tabular}{|c|c|c|}
\hline Constituent & $\begin{array}{l}\text { Regulatory DEV Limit } \\
(\mathrm{mg} / \mathrm{l})\end{array}$ & $\begin{array}{l}\text { DEV S4 Results } \\
\text { (mg/l) }\end{array}$ \\
\hline $\begin{array}{r}\text { CdTe } \\
\text { Cd } \\
\text { Te } \\
\mathrm{Al} \\
\mathrm{Ni}\end{array}$ & $\begin{array}{l}0.19 \\
\text { None } \\
\text { None } \\
1\end{array}$ & $\begin{array}{l}0.50 \pm 0.13 \\
0.50 \pm 0.13 \\
0.87 \pm 0.20 \\
0.25 \pm 0.04\end{array}$ \\
\hline $\begin{array}{cc}\text { CIS } & \\
& \mathrm{Zn} \\
& \mathrm{Mo} \\
& \mathrm{Se} \\
& \mathrm{Cd} \\
\mathrm{Cu}\end{array}$ & $\begin{array}{l}2.8 \\
7 \\
0.5 \\
0.028 \\
0.015\end{array}$ & $\begin{array}{l}5 \\
\text { None } \\
\text { None } \\
0.050 \\
1\end{array}$ \\
\hline
\end{tabular}

Results for each element are based on four experiments.

hazardous waste under U.S. Environmental Protection (U.S. EPA) regulations and the California Health and Safety Code. The Appendix contains our regulatory analysis and letters of concurrence from the California Environmental Protection Agency (Cal-EPA). Mr. Andre Amy of Cal-EPA confirmed that Cal-EPA considers unused off-specification photovoltaic products to be retrograde material that is not considered to be a regulated solid waste provided that the materials are recycled within one year after being generated (letter of June 15, 1998). Mr. Ken Payne of Cal-EPA confirmed that off-specification modules could be reclaimed (e.g. as described in the above mentioned policy) under both federal law and California state law (UNISUN's letter of June 22, 1998, Cal-EPA's letter of August 12, 1998 with its enclosures, and UNISUN's comments on the August 12 letter). 


\subsection{Proposed Regulations}

Waste management of all electrical and electronic waste in Europe will be covered by the European Union (EU) DGXI-WEEE Directive, which is pending approval and adoption by the European Union member countries. According to this Directive, the manufacturer has the responsibility for a waste take-back system from business and from private households. The Directive includes provisions that would require manufacturers to certify that products sold in the European market meet certain environmental requirements. It also sets the minimum collection and recycling targets and reporting obligations to the EU nations, which are legally binding.

The draft of this Directive is expected to be introduced for voting to the European Parliament in late 2000, and if and when adopted by the Commission it is expected to take two more years to become a piece of legislature. The Directive has undergone four major revisions as of September 2000. All versions included a ban on the use of lead, mercury, halogenated flame retardants and hexavalent chromium from electrical- and electronic-products. Initially, this ban was proposed as an absolute one, without any exemptions to the proposed bans for materials destined for recycling, or for products containing only small amounts of these metals (even trace amounts of metals can cause the product to be banned). The current fourth draft however, contains a few specific exceptions for mercury and lead in lamps and cathode ray tubes.

In general, the directive requires industry to collect, treat, and dispose of hazardous waste in electrical- or electronic-products and bans the sale of such products containing lead, cadmium, and mercury (with certain exceptions) ${ }^{5}$.

\footnotetext{
${ }^{5}$ Elements of the EU DCXI-WEEE Directive that may become applicable to PV products are listed below:

Definitions and scope (Articles $2 \& 3$ )

The Directive covers small electrical and electronic equipment and equipment for the generation, transfer, and measurement of such currents and fields. It includes (Annex IA): large household appliances, small household appliances, IT and telecommunications equipment, consumer equipment, lighting equipment, electrical and electronic tools, toys, medical equipment systems, monitoring and control instruments, and automatic dispensers. The Directive also covers components, sub-assemblies, and consumables that are part of electrical and electronic equipment.

The Directive covers producers who manufacture and sell electrical and electronic cquipment under their own brand, who resell under their own brand equipment produced by other suppliers, or who import equipment into a member state.
} 


\section{WASTE MANAGEMENT REGULATIONS IN JAPAN}

There is not much information on hazardous-waste regulations in Japan which affect electronic products, and potentially, photovoltaic products. Japan's waste-products system has separate branches for general waste and industrial waste. There are laws governing spent home electrical appliances, but electronic products are not specifically included (as of early 2000). The law requires recycling of electrical appliances in the residential sector, and covers TVs, refrigerators, A/C units, washing and drying machines. The end-users pay the cost for collecting and recycling these items through fees charged by the retailers. The retailers have the obligation to receive discarded products. When a customer disposes of an appliance, the retailer who sold it to customer is required to take it back. If a customer has a used unit, the retailer must take it back when delivering a new unit. The retailers are required to transport the discarded homé appliances to designated collection sites or to commission the transportation. The

Product restrictions (Article 4)

The Directive requires the EU to promote European standards relating to design of equipment to foster reuse, disassembly, and recycling of equipment. It requires member states to ban the sale of products containing lead, mercury, cadmium, hexavalent chromium, and the flame retardants PBB and PBDE by January 1,2008 (The $3^{\text {rd }}$ draft had a phase out date of January 1, 2004). Annex II contains a list of exemptions including: compact fluorescent lamps containing less than $5 \mathrm{mg}$ of mercury, linear fluorescent lamps containing $10 \mathrm{mg}$ of mercury, all other mercury-containing lamps, and lead in glass of cathode ray tubes, light bulbs, and fluorescent tubes. The Commission is authorized to amend this list.

Collection, treatment and recovery (Articles 5-7)

EU countries are responsible for establishing collection points for waste electrical and electronic equipment from private households. Producers are responsible for establishing collection points for waste equipment from all other entities. Collected waste must be treated. Annex III establishes treatment standards for batteries, printed circuit boards, plastics containing halogenated flame retardants, cathode ray tubes, gas discharge lamps, and liquid crystal displays.

Financing (Articles 8-9)

For products put on the market after the Directive goes into effect, producers must provide for financing of collection at government collection facilities, treatment recovery, and environmentally sound disposal. Producers may do this collectively or individually. Five years after the WEEE becomes effective, producers must collectively provide financing for collection, treatment, recovery, and disposal of all products put on the market before the WEEE becomes effective. States must allow producers to use a "visible" fee on new products to cover these costs for ten years. Financing of waste removal from other than private households must be done on a business-to-business basis at the time of the purchase.

Information (Articles 10-12)

Products must include a symbol of a crossed-out trash bin, unless the size or function of the product precludes it. In such case, the symbol must be printed on the packaging of the equipment. 
manufacturers or importers (producers) have the obligation to transport products from the collection sites to recycling facilities and to execute recycling.

In the private sector, some large Japanese companies plan to reduce or phase out their use of lead and cadmium in electronic products, for market acceptance reasons. Hitachi announced a reduction in their usage of lead by one half during 1999 compared to 1997 levels and stated they will stop using lead solder by 2001. NEC Corporation announced their intent to reduce lead use by 2002 to a half of the 1997 levels. NTT Corporation intends to purchase equipment that contains no lead or cadmium by 2001, and Matsushita (Panasonic) aims to stop using lead solder in that same year.

\section{REGULATIONS REGARDING MOVEMENT OF DISCARDED PV PRODUCTS ACROSS NATIONAL BORDERS}

The following are the current applicable international agreements for transboundary waste shipments: 1) The Basel Convention; 2) the Organization of Economic Cooperation and Development (OECD) Council Decision; 3) the European Union Regulation 259/93, and 4) Regional and Bilateral Agreements. International agreements that the United States has signed are recognized as part of the U.S. law and rank above the laws of the states. In addition to international agreements, national laws on exporting, importing, and transit, apply to exports and imports of waste from one country to another.

7.1 The Basel Convention is a global notice and consent system that governs waste shipped from one territory to another for final disposal or recovery/recycling. It is signed by 128 countries but not the United States. It sets requirements for the prior written consent of importing/transit countries, wastes to be managed in an environmentally sound manner, and tracking documents, packaging and labeling. The Basel Convention currently bans trade of the wastes that it covers with non-parties (e.g., the United States), and there is a pending ban on shipments from parties within OECD to less developed countries. The covered waste categories of interest to the PV community are wastes containing lead, cadmium, mercury, or beryllium. In addition, wastes considered hazardous in the exporting, importing or transit countries also are covered. 
7.2 The OECD system rules waste shipments destined for recovery within the 29 OECD countries (OECD includes the United States ${ }^{6}$ ). OECD classifies waste in green, amber, and red lists. Green-list wastes are not subject to any additional controls beyond those imposed on normal international commercial shipments. Amber-list wastes either 1) move on a shipment by shipment basis requiring prior written notification and consent from the importing and transit countries, or 2) move to a facility that is pre-approved by the importing country to accept that type of waste with prior written notification only. Red-list wastes are handled in the same manner as amber-list wastes except that prior written consent for their acceptance is always required from importing and transit countries. Wastes not identified on any list are subject to red-list controls if they are identified or defined as a hazardous waste using a concerned country's national procedures; otherwise, they move as green-list wastes.

Spent electronic assemblies and scrap are currently classified as a "green waste" (nonhazardous waste), and can be shipped freely without any special controls or requirements for waste electronics within the OECD for the purposes of recovery. However, discussions are in progress among OECD governments to adopt the Basel Convention's waste lists, and there is a potential for listing of end-of-life electronics as hazardous waste. Also, movement in some of the OECD countries to ban lead, cadmium, and other metals could cause PV waste, which is currently unlisted, to become red-listed waste because an OECD member has concerns about it.

7.3 The European Union (EU) Regulation 259/93/EEC (Supervision and control of shipments of wastes) covers the movement of all waste within, into and out of the EU. The Regulation implements the Basel Convention and the OECD Decision on the shipment of waste across national boundaries. The shipment of hazardous waste destined for final disposal to non-OECD countries is prohibited, to prevent EU and nonOECD operators from dumping hazardous waste in developing countries. The shipment of waste for disposal or treatment within the EU requires prior authorization. The rules for treatment of waste and recovery operations depend on the listing of the particular

\footnotetext{
${ }^{6}$ OECD member countries currently include Australia, Austria, Belgium, Canada, Czech Republic, Denmark, Finland, France, Germany, Greece, Hungary, Iceland, Italy, Japan, Korea, Luxembourg, Mexico, The Netherlands, New Zealand, Norway, Poland, Portugal, Spain, Sweden, Switzerland, Turkey, The United Kingdom, and The United States.
} 
wastes. Those listed as green will be largely excluded from the regulation; those listed as amber will be subject to a prior notification requirement, and those listed as red will require prior authorization. Regulation 259/93/EEC was recently amended for the export of wastes out of the European Union. The amendment implements into community law the decision taken under the Basel Convention to immediately ban exports of hazardous waste destined for final disposal to non-OECD countries, and to ban all exports of hazardous waste destined for recovery in non-OECD countries.

7.4 United State laws and agreements on exporting, importing and transit. The United States has currently bilateral agreements with Canada, Mexico, Malaysia and Costa-Rica that allow waste to be freely transferred among the United States and the four countries, as long as national laws are not violated. The US-EPA recently made a final ruling on accepting the OECD Decision as legally binding, and asked the EPA to implement this decision. EPA proposed legislation in November 2000, on "Exports from and Imports to the United States under International and Bilateral Waste Agreements", which expands controls on RCRA hazardous waste imports and exports and puts new restrictions on exports of wastes outside of North America. More information on this legislation is given in Appendix D.

Other expected developments include 1) the implementation of the New Basel Convention's waste lists; 2) harmonization of the Basel Convention with the OECD waste lists; and, 3) legislation in the United States regarding implementation of the Basel Convention. The new waste lists cover both hazardous waste (List $A$ ) and nonhazardous waste (List B). List A includes discarded electrical- and electronic-products and batteries containing mercury, cadmium, lead, and PCBs, unless they do not exhibit hazardous characteristics, glass waste from CRTs, and unsorted discarded batteries. List B includes electrical- and electronic-assemblies destined for "direct reuse", and waste not containing cadmium, mercury, lead, or PCBs. There is a general provision to also include waste containing such elements but not possessing hazardous characteristics in List B instead of List A. It is not clear if this exception is related to passing leaching tests, or to named categories. 


\section{CONTACTS / REFERENCES}

EPA Office of Solid Waste http://www.epa.gov/osw

South Carolina Electronic Equipment Recycling Program, SC Department of Commerce www.leginfo.state.sc.us

California Department of Toxic Substances Control, tel. (916)322-7676

http://www.dtsc.ca.gov

Massachusetts Department of Environmental Protection

http://www.state.ma.us/dep/bwp/dswm/dswmpubs.htm

Environmental Business Magazine http://www.ifi.co.uk/m-29rec.htm

EPA Comments on metals, leachability and TCLP

http://www.epa.gov/science1/eecleach.htm

EPA Comments on exception of materials destined for recycling

http://www.epa.gov/epaoswer/hazwaste/ldr/wood/scrap.pdf

-

EPA Transboundary Movement of Waste

http://www.epa.gov/epaoswer/hazwaste/exp-imp/icr.htm

Product Stewardship Advisor http://www.cutter.com

\section{ADDITIONAL REFERENCES}

Eberspacher Chris, , Disposal and Recycling of End-of Life CdTe and Si PV Modules, UNISUN Report for Brookhaven National Laboratory, February 1998.

Hagen Paul, Esq., International Controls on the transboundary movement of electronic scrap, Electronic Product Recovery and Recycling (ERP2) Conference, March 23-24, 1999, Wash. DC.

Electronic Product Recovery and Recycling Baseline Report; Recycling of Selected Electronic Products in the United States, National Safety Council, May 1999

Kosson D. S., Leaching test Methods and Interpretation protocols for Estimating Inorganic and Organic Contaminant Release for Waste Management Decisions, White Paper, Dec. 15, 1997. 


\section{APPENDIX A}

UNISUN's Correspondence with California EPA

Regarding Pretreatment of PV Waste Prior to Recycling 
July 27,1999

Dr. Vasilis Fthenakis

Environmental \& Waste Technology Center

Brookhaven National Laboratory

Upton, NY 11973

re: Pre-treatment of Unused Off-specification PV Plates

Dear Dr. Fthenakis:

As part of its collaboration with Brookhaven National Laboratory on envirónmental, health and safety (EH\&S) issues related to the photovoltaics (PV) industry, UNISUN reviewed certain EH\&S issues related to PV commercialization, including federal and state regulations on wastes and waste handling. Of particular importance for module manufacturers are certain provisions of the U.S. Resource Conservation and Recovery Act and the California Health and Safety Code related to materials recycling, including pretreatment of wastes prior to recycling. These provisions provide a regulatory basis for unused, off-specification thin-film PV products to be pre-treated in certain ways without invoking regulation as treatment of a hazardous waste.

In June 1998 UNISUN assisted a PV module manufacturer in California in drafting a policy for handling unused off-specification thin-film PV plates. A copy of the June 1998 policy edited to remove proprietary and company-specific information is enclosed; see "Pre-treatment of Unused Off-specification Thin-film PV Plates." The policy describes physical separation techniques such as scraping, grinding, etc. through which thin-film PV plates (e.g. unencapsulated thin-film modules) are "pre-treated" prior to recycling. The pre-treatment removes materials (e.g. certain of the thin films) that might otherwise render the plates. "hazardous". under federal and/or state regulations. Thus an off-specification plate that as a whole might exhibit the characteristics of a "hazardous waste" is processed to separate from the majority of the plate those minority materials that would cause the whole to be hazardous, thereby simplifying the handling of the majority and often facilitating the cost-effective recycling of the minority. Thus, the quantity of the waste - in particular hazardous waste - is reduced. 
The policy asserts a regulatory basis for why unused, off-specification photovoltaic plates might be pre-treated in certain ways without invoking regulation as treatment of a hazardous waste under U.S. Environmental Protection (U.S. EPA) regulations and the California Health and Safety Code. Certain aspects of this regulatory analysis were reviewed with U.S. EPA and with the California Environmental Protection Agency (Cal-EPA). Mr. André Amy of Cal-EPA confirmed that Cal-EPA considers unused off-specification photovoltaic products to be retrograde material that is not considered to be a regulated solid waste provided that the materials are recycled within one year after being generated; see as reference the letter of June 15, 1998. Mr. Ken Payne of CalEPA confirmed that off-specification modules could be reclaimed (e.g. as described in the abovementioned policy) under both federal law and California state law; see as references UNISUN's letter of June 22, 1998, Cal-EPA's letter of August 12, 1998 with its enclosures, and UNISUN's comments on the August 12 letter.

Disclaimer on Regulatory Interpretation: This letter and its enclosures reflect UNISUN's best-effort interpretation of existing laws and regulations. The views expressed herein are based on recent copies of the written regulations, on guidelines published by the responsible regulatory agencies, and by direct consultation with persons active in the interpretation and application of these regulations. Manufacturers are advised to seek licensed experts and/or legal counsel on matters of the law.

Pre-treatment of unused off-specification thin-film PV plates provides a pathway for thin-film PV module manufacturers in California to significantly reduce the volume of manufacturing wastes and/or to significantly simplify the recycling of certain materials. These results - while specific to California - provide a basis for seeking corresponding regulatory treatment in other states and regions. Similarly, these results - while specific to thin-film PV plates - provide a basis for developing corollary policies for other PV products.

I appreciate the opportunity to collaborate with Brookhaven National Laboratory in serving the PV industry's needs.

I can be reached at our Camarillo laboratory facility by telephone at (805) $987-7258$, by facsimile at (805) $987-7268$, or by e-mail at "unisun@aol.com".

Sincerely,

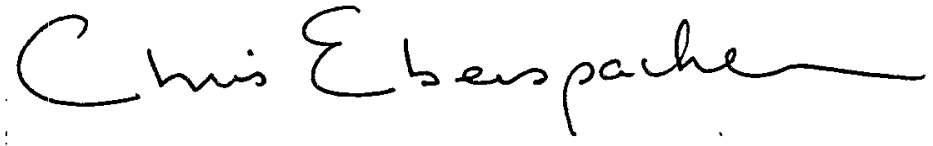

Dr. Chris Eberspacher

Managing Director 


\section{Pre-treatment of Unused Off-specification Thin-film PV Plates}

Over the past two decades the photovoltaics (PV) industry has developed new solar technologies based on thin films of photoactive materials deposited on inexpensive substrates such as window glass. In a typical thin-film photovoltaics design, a glass "substrate" is coated with a sequence of thin films to form a "plate", a second piece of glass is laminated to the plate to form a "laminate", and a mounting frame and electrical connectors are attached to a laminate to form a completed "module." In routine production of thin-film modules, some partial or completed plates are found to be off-specification and not suitable for further processing or for sale. This document summarizes a policy on handling unused off-specification plates.

A thin-film solar plate typically consists of $2-5 \mathrm{~mm}$ thick window glass onto which a sequence of thin photoactive films are deposited. The total thickness of the thin films is typically less than $0.010 \mathrm{~mm}$, and the thin films constitute less than $1 \%$ by weight of the completed plate. The exact composition of the thin-film layers is generally a proprietary trade secret.

In manufacturing thin-film solar products, some plates may be found to be offspecification and unsuitable for further processing or for sale. Off-specification unused plates can be recycled. For example, plates and/or the glass and thin-film materials that constitute the plates can be used or reused as ingredients in industrial processes to make products, or can be used or reused as safe and effective substitutes for commercial products. It is useful to facilitate recycling by pre-treating the plates by physical separation techniques to separate thin-film materials from the bulky glass substrate. Such a separation is easily effected using simple mechanical grinding or scraping techniques without the addition of external heat or any chemicals.

The handling of unused off-specification plates varies depending on whether the plate meets the definition of a hazardous waste under federal or state regulations. For example, if the processing of a plate is terminated at some intermediate point, then the partially-completed thin-film plate may contain sufficient concentrations of certain materials to meet the definition of a "hazardous waste" under the Resource Conservation and Reclamation Act (RCRA) and hence of a "RCRA hazardous waste" under the California Hazardous Waste Control Law (HWCL), or may meet the definition of a "nonRCRA hazardous waste" under the California HWCL. Similarly, depending on the exact processing parameters used to fabricate a complete plate, a complete plate may or may not meet the definitions of a hazardous waste.

Plates that do not meet the definition of a hazardous waste under RCRA (ergo do not meet the definition of a "RCRA hazardous waste" under HWCL), are recycled or disposed of as regular garbage. Any manner of processing is allowable to facilitate recycling or disposal, including crushing, grinding, etc. 
Plates that do not meet the definition of a hazardous waste under RCRA but do meet the classification of a "non-RCRA hazardous waste" under California HWCL are pre-treated by physical separation techniques without the addition of external heat or any chemicals, and the separated materials are sent for thirdparty recycling. Provided that any discharges to air from the pre-treatment do not contain constituents which are hazardous wastes and comply with applicable air pollution control laws, such pre-treatment is allowed under Section 25143.2 of the California Hazardous Waste Control Law, Chapter 6.5, Division 20, Health and Safety Code which excludes from classification as a solid waste a recyclable material which meets the definition of a non-RCRA hazardous waste when the material is used or reused as an ingredient in an industrial process to make a product or as a safe and effective substitute for commercial products. Non-RCRA waste is pre-treated by physical separation techniques to yield film materials that are subsequently recycled by outside entities and glass that can be recycled or otherwise disposed of. Such pre-treatment of such materials does not constitute hazardous waste treatment, and no special California state permits are required for such in-house pre-treatment of such materials when recycled.

Plates that meet the definition of a hazardous waste under RCRA--hence are "RCRA hazardous waste" under California HWCL-are handled as secondary I retrograde materials that are recycled as non-listed commercial chemical products. Under 40 CFR 261.2(c)(3), unused off-specification commercial chemical products listed in 40 CFR 261.33 are not solid wastes when sent for reclamation; the status of non-listed materials is the same as for listed materials (see 50 FR 14219, April 11, 1985). Paralleling the determination that unused printed circuit boards are secondary materials considered to be non-listed commercial chemical products that are not solid wastes when reclaimed (see, for example, June 5, 1990 McManus memo), unused off-specification plates are considered to be non-listed commercial chemical products, and thus, are not solid wastes--ergo not hazardous wastes--under RCRA when reclaimed. Similarly, unused off-specification plates are considered to be retrograde material, and thus, are not wastes regulated under HWCL when recycled within one year of being generated. Unused off-specification plates are pre-treated to facilitate cost-effective recycling prior to being sent off-site for reclamation. The pre-treatment process involves physical separation of plates into film materials that are subsequently recycled by outside entities and glass that can be recycled or otherwise disposed of.

Disclaimer on Regulatory Interpretation: This policy reflects a best-effort interpretation of existing laws and regulations. Manufacturers are advised to seek licensed experts and/or legal counsel on matters of the law. 


\section{MEMORANDUM}

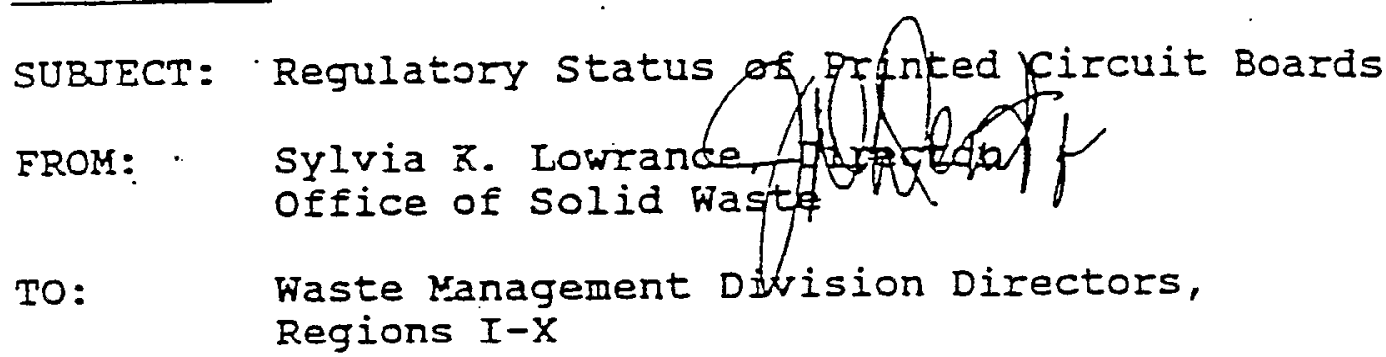

Printed electronic circuit boards are major comporents of personal computers in widespread use in the U.S. today. As updated computer equipment becomes available, the older (but still usable) equipment is often placed into surplus, or is reclaimed/reused. The old equipment may be disassembled and the usable parts salvaged. Parts may also be scrapped and processed for metal values due to tieir obsolescence, even tho.. - noy are still usable. -

After the printed circuit boards themselves are disassembled, recovering usable components, the boards are often shredded or otherwise processed, and/or burned as part of the reclamation process. Later, base metals (lead, copper) or precious metals (e.g., gold; silver, or platinum) can be reclaimed through additional processing.

The International Precious Metals Institute (IPMI) has written to EPA and requesied a determination under RCRA subtițle C for the status of used printed circuit boards. The regulatory status of unused circuit bcards (considered commercial chemical products) and by-product wastes from circuit board production are not affected by this mezorandum. The Agency is planning to study the area of used printed circuit boards in more depth; however, our interim interpretation is discussed below.

The EPA believes that based upon the way in which used printed circuit boarjs ine originally generated, these materials most clearly jeet the definition of spent materials (5 261.1(c)( (1)). However, we have Eurther examined whether these boards can also be classified as sciap metal under $\S 261.1(c)(6)$. Scrap metal is defined based i:- Iazge part on the physical appearance of a secondazl mazerial, dependent on the presence of metal, and includes secsndiz laterials that would otherwise be spent materiais of by-z=oducts. 
As a matter of policy, the Agency has decided that unprocessed, spent (i.e., used) printed circuit boards are subject to regulation as scrap metal for the purposes of $\$ 261.6(a)$ (3)(iv), and are therefore exempt frod RCRA subtitle $C$ regulation when recycled. The Agency has made this determination largely because 1) metals can be recovered from the pieces of metal parts that are an integral part of these circuit boards, and 2) unprocessed circuit boards are in a physical state similar to the type of recycled materials the Agency intended to be exempted by providing examples in the scrap metal definition (e.g., "metal parts . . which when worn or superfluous can be recycled"). The physical state of the unprocessed spent circuit boards limits the dispersion of metal constituents during the handling and transport of the spent printed circuit boards similar to the materials defined as scrap metal in the regulatory language. (Note that this determination is limited to spent circuit boards and does not apply to other spent materials.)

After the boasus are processed (including shredding, grinding, burning or smelting), the resulting material (e.g., shredded pieces, sweeps/ash, filuf, or baghouse dust) may no longer be similar to the materials that meet the definition of a scrap metal. The Agency believes that certain materials generated from the frocessing of spent printed circuit boards may be in a physical state which is inherently different from the more "traditional" scrap metal materials, the latter of which includes bars, turnings, rods, sheets, wire, bolts, etc. Spent circuit board processing, particularly those reclamation steps that do not involve simple physical processing, may generate materials in a form which allows the dispersion of hazardous constituents during subsequent handling. Therefore, some of these materials may not meet the definition of, nor the intent of, the scrap metal definition (analogous to the fluff generated by the shredding of scrap automobiles). Thus, at this point, the processed material may no longer be exempt from regulation as scrap metal, and could be subject to regulation as a spent material (e.g. shredded boards derived from spent circuit boards), a by-product (e.g. sweeps/ash), or a sludge (e.g. baghouse dust).

The processor must determine whether the processed material is a solid waste, and if so, whetier it exhibits a characteristic o a hazardous waste, and manage the material accordingly (assuming the material no longer meets the definition of scrap metal). IE the generacor/processor detegines that a material meets the regulatory definition of solid waste but believes the prngessed (i.e., partially reclaimed) zaterial should be classified as a product rather than a solid waste, an application can be made $t=$ the Regional Administrator or authorized state regulatory agenc: for a case-jy-case variance under section 260.30 (C) of RCRA. I:addition, if. the processed caterial is a hazardous waste tha: contains economicaliy significant amounts of recoverable precious metals then the materials would be subject to reduced regulations 
under Part 266, Subpart F.

This determination is Iimited to circuit boards. For further inforation about this interpretation, please contact Allen Maples or Ross Elliott of the Regulatory Development Branch at (202) 2608551 .

CC: RCRA Enforcement Branch Chiefs, Regions I-X

NEIC

OWPE

OE

IPMI 


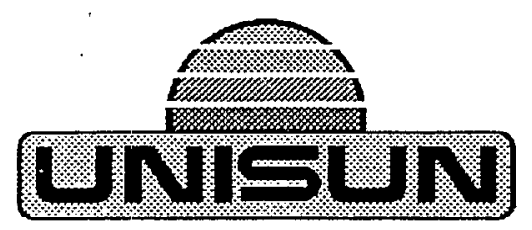

June 15, 1998

Mr. André Amy

California Environmental Protection Agency

Department of Toxic Substances Control

1011 N. Grandview Avenue

Glendale, CA 91201

Dear Mr. Amy:

Enclosed are photocopies of two EPA memos related to waste classification of printed circuit boards. The first is the McManus memo from 1990 in which unused offspecification boards are described as secondary materials that are considered to be nonlisted commercial chemical products that are not considered to be solid wastes when sent for reclaimation. The second is the Lowrance memo from 1992 in which used printed circuit boards are deemed to be scrap metal provided they have not be processed, e.g. shredded.

Thank you again for clarifying that the California Environmental Protection Agency considers unused off-specification photovoltaic products to be retrograde material that is not considered to be regulated solid waste provided that the materials are recycled within one year after being generated.

Sincerely,

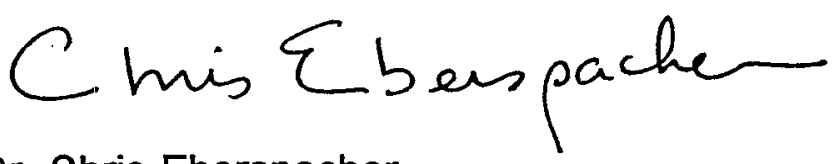

Dr. Chris Eberspacher Managing Director 


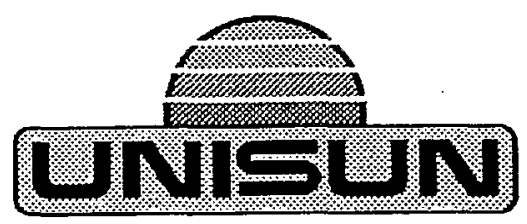

June 22, 1998

Ms. Claudia Moore

California Environmental Protection Agency

Resource Recovery Unit

Department of Toxic Substances Control

P.O. Box 806

Sacramento, CA 95812-0806

Dear Ms. Moore:

I am writing today to seek your concurrence on a matter related to classification and recycling of retrograde materials resulting from the manufacture of photovoltaic solar energy products.

Over the past two decades the photovoltaics industry has developed new solar technologies based on thin films of photoactive materials deposited on inexpensive substrates such as window glass. In thin-film photovoltaics, a glass "substrate" is coated with a sequence of thin films to form a "plate"; and a second piece of glass is laminated to the plate and a mounting frame and electrical connectors are attached to form a completed "module."

In routine production of thin-film modules, some partial or completed plates are found to be off-specification and not suitable for further processing or for sale. We consider unused off-specification plates to be retrograde material that is not a regulated solid waste provided that the material is recycled within one year after being generated.

We, would appreciate your written concurrence on this matter. Thank you.

Sincerely,

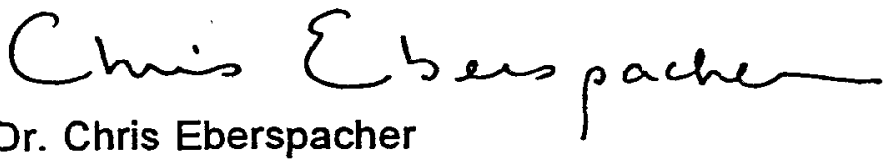

Managing Director

cc: Mr. André Amy, Cal-EPA, Glendale

UNISUN

587-F North Ventu Park Road, Suite 124

Newbury Park, California 91320 USA
Phone (805) 499-7840

FAX (805) 499-8350

UNISUN@aol.com 


\section{Department of Toxic Substances Control}

Jesse R. Huff, Director

400 P Street, 4th Floor, P.O. Box 806

Sacramento, California 95812-0806

Peter M. Rooney

Secretary for

Environmental

Protection

August 12, 1998

Dr. Chris Eberspacher

Unisun

587-F North Ventu Park Road, Suite 124

Newbury Park, California 91320

\section{RECYCLING UNUSED OFF-SPECIFICATION THIN-FILM PHOTOVOLTAIC MODULES}

Dear Dr. Eberspacher:

This letter is in response to your June 22, 1998 letter to the Department of Toxic Substances Control (DTSC) regarding the recycling of unused off-specification or damaged thinfilm photovoltaic modules that are produced by your company, and perhaps others. You asked DTSC to concur with your finding that your off-specification, or damaged, modules, which were unsuitable for further processing or for sale, would be considered retrograde material, and therefore not regulated as waste, provided that the material is recycled within one year after being generated.

\section{Background}

In your letter, you stated that in the production of thin-film photovoltaics, a glass "substrate" is coated with a sequence of thin films to form a "plate", and a second piece of glass is laminated to the plate. Finally, a mounting frame and electrical connectors are attached to form a completed "module". You also stated that in routine production some of these modules are found to be off-specification and unsuitable for further processing or for sale. At this point, you stated that your company, and the industry in general, would like to reclaim the constituent parts of these modules. In addition, you stated that these modules would be dismantled by the manufacturer and that the separate components, metal compounds and glass, would be separately reclaimed (metal by a primary smelter and glass by the respective industry). Pursuant to a 
Dr. Chris Eberspacher

August 12, 1998

Page 2

subsequent telephone conversation with you on July 13,1998, it is my understanding that subject modules will not be recycled onsite, but that, onsite, the photovoltaic film will be physically separated from the module glass, and that the "fine powder" metal components will be recycled separately from the glass. You stated that the results of this inquiry could have industry-wide application within California for the recycling of component parts of thin-film photovoltaic modules.

\section{Status of the Material under Federal Law}

Under current federal law, these off-specification modules would be considered discarded commercial chemical products. As discarded commercial chemical products, thin-film photovoltaic modules are excluded from the definition of solid waste when reclaimed [Title 40 of the Code of Federal Regulations section 261.2(c)(3)]. This means that under federal law offspecification modules could be reclaimed without regard to hazardous waste regulations.

\section{Status of the Material under State Law}

Under California law, the thin-film photovoltaic modules described above would be considered retrograde material at the point of disassembly by the manufacturer (i.e., components (metal and glass) physically separated for further reclamation). As retrograde material, these modules would not be regulated as a hazardous waste, according to Health and Safety Code section $25120.5(\mathrm{e})$, unless they have not been reclaimed by the original manufacturer within one year of the date the material became a retrograde material. In the next phase of reclamation, when these components are shipped from the manufacturing facility to respective reclamation facilities for further reclamation, the metal components would be considered scrap metal, unless they are themselves fine powder (as defined in section 66260.10 of Title 22 of the California Code of Regulations) or are contaminated with a sufficient quantity of fine powder, or other hazardous waste, which renders the metal component characteristically hazardous. Similarly, the glass component would be considered non-hazardous (thus unregulated), unless it is characteristically hazardous (e.g., lead containing). If the glass destined for reclamation exhibits a characteristic of a hazardous waste (e.g., lead) and is applied to the land or used to produce a product that is applied to the land (e.g., antiskid material), the glass would be used in a manner constituting disposal and therefore not be excluded from hazardous waste regulations.

The determinations stated in the foregoing are based on the information you provided either in your letter or by telephone and may not be valid if the information changes or is incorrect. Based upon the information we received, restated herein, the initial stages of the reclamation of thin-film photovoltaic modules by the manufacturer would not be regulated by DTSC, except in the instances described above. 
Dr. Chris Eberspacher

August 12, 1998

Page 3

A copy of the State laws and regulations referenced herein are enclosed for your information. I trust that your concerns about the reclamation of thin-film photovoltaic modules have been clarified. If you need additional information or have further questions, please contact me at (916) $327-4502$ or at the letterhead address.

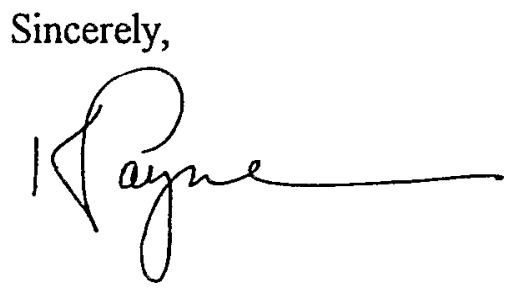

Ken Payne

Resource Recovery Section

Enclosures

cc: Mr. Steven C. Kephart (w/o. enclessures)-

Ventura County Environmental Health

800 South Victoria Avenue

Ventura, California 93009-1730

Mr. Rich Vaille, Chief (w/o enclosures)

RCRA Compliance Branch

U.S. Environmental Protection Agency

Region IX (H-4)

75 Hawthorne Street

San Francisco, California 94105

Ms. Arlene Kabei (w/o enclossures)

Compliance Monitoring and Enforcement Section

U.S. Environmental Protection Agency

Region IX (WST-3-1)

75 Hawthorne Street

San Francisco, California 94105

Mr. Larry Matz, Chief (w/o enclosures)

Statewide Compliance Division

Hazardous Waste Management Program

Department of Toxic Substances Control

P.O. Box 806

Sacramento, California 95812-0806 
Dr. Chris Eberspacher

August 12, 1998

Page 4

cc: Mr. Donald A. Johnson, Chief (w/o enclosures)

State Regulatory Branch

Hazardous Waste Management Program

Department of Toxic Substances Control

P.O. Box 806

Sacramento, California 95812-0806

Mr. Norman Riley, Chief (w/o enclosures)

Resource Recovery Section

State Regulatory Branch

Hazardous Waste Management Program

Department of Toxic Substances Control

P.O. Box 806

Sacramento, California 95812-0806 
"Extremely hazardous waste" means any hazardous waste or mixture of hazardous wastes which, if human exposure should occur, may likely result in death, disabling personal injury or serious illness caused by the hazardous waste or mixture of hazardous wastes because of its quantity, concentration or chemical characteristics.

"Facility" see "Hazardous waste facility."

"Facility mailing list" means the mailing list for a facility maintained by the Department in accordance with section 66271.9 (c)(1)(D).

"Facility personnel" see "Personnel."

"Federal agency" means any department, agency or other instrumentality of the Federal Government, any independent agency or establishment of the Federal Government including any Government corporation, and the Government Printing Office.

"Federal, State and local approvals or permits necessary to begin physical construction" means permits and approvals required under Federal, State or local hazardous waste control statutes, regulations or ordinances.

"Final closure" means the closure of all hazardous waste management units at the facility in accordance with all applicable closure requirements so that hazardous waste management activities under chapters 14 and 15 of this division are no longer conducted at the facility unless subject to the provisions in section 66262.34.

"Fine powder" means a metal in dry, solid form having a particle size smaller than 100 micrometers $(0.004$ inches) in diameter.

For the purposes of chapters 14 and 15, "First attempt at repair" means to take rapid action to maintain compliance with Section 66265.31, for the purpose of stopping or reducing leakage of organic material to the atmosphere using best practices.

"Fixed Treatment Unit" means any equipment which performs a treatment as defined in this section and which is permanently stationed, or which is periodically assembled for use, at a single facility for the purpose of performing treatment, regardless of the period or frequency of treatment.

For the purposes of chapters 14 and 15, "Flame zone" means the portion of the combustion chamber in a boiler occupied by the flame envelope.

For the purposes of chapters 14 and 15, "Flow indicator" means a device that indicates whether gas flow is present in a vent stream.

"Food-chain crops" means tobacco, crops grown for human consumption and crops grown for feed for animals whose products are consumed by humans.

For the purposes of chapters 14 and 15, "Fractionation operation" means a distillation operation or method used to separate a mixture of several volatile components of different boiling points in successive stages, each stage removing from the mixture some proportion of one of the components.

"Free liquids" means liquids which readily separate from the solid portion of a waste under ambient temperature and pressure. Free liquids are determined by using the paint filter test (EPA Method No. 9095), as modified in section $66264.314(\mathrm{~b})$ of this division.

"Freeboard" means the vertical distance between the top of a tank or surface impoundment dike, and the surface of the waste contained therein.

"Functionally equivalent component" means a component which performs the same function or measurement and which meets or exceeds the performance specifications of another component.

"Generator" or "Producer" means any person, by site, whose act or process produces hazardous waste identified or listed in chapter 11 of this division or whose act first causes a hazardous waste to become subject to regulation.

"Groundwater" means water below the land surface in a zone of saturation. 


\section{Comments on the California Environmental Protection Agency's August 12, 1998 response to UNISUN's letter of June 22, 1998 related to handling off-specification thin-film CIS PV plates}

Cal-EPA's letter of August 12, 1998 notes that metal materials removed from offspecification PV plates might be considered scrap metal, hence excluded from certain regulations when recycled in certain ways under certain circumstances. However, if the removed material is a "fine powder," or is contaminated with a fine powder or a sufficient amount of some other hazardous waste, then the removed material might not qualify for handling as a scrap metal. The August 12 letter contained as an enclosure a page of the California codes where "fine powder" is defined as meaning, "...a metal in dry, solid form having a particle size smaller than 100 micrometers ( 0.004 inches) in diameter." It is likely that debris from mechanical stripping of modules will have average piece sizes above 100 microns, ergo not be a "fine powder" per Cal-EPA's definition. It is also likely that a "fine powder" might be recycled as an ingredient in an industrial process to make products, or as a safe and effective substitute for commercial products, ergo be exempt from being handled as a hazardous waste regardless of otherwise having a characteristic of a hazardous waste.

Disclaimer on Regulatory Interpretation: These comments reflect a besteffort interpretation of existing laws and regulations. Manufacturers are advised to seek licensed experts and/or legal counsel on matters of the law.

July 27,1999 


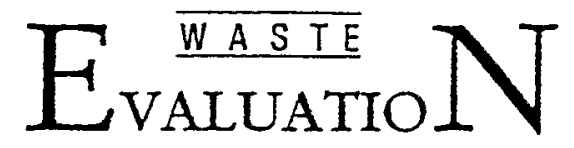

REGULATION GUIDANCE

Department of Toxic Substances Control

\section{USED PRINTED CIRCUIT BOARDS}

(RG Document \#55: Revision 하; Revision Dare: Augurs 19, 1993)

Used printed circuit boards that are recycled for the recovery of components or metals are considered manufactured solid metal objects and meet the definition of scrap metal in section 66260.10 , Title 22, California Code of Regulations, (22 CCR). Scrap metal is excluded from regulation as a hazardous wastes pursuant to section 66261.6(a)(3)(B), 22 CCR. Sludges, semi-solids, or liquid solutions created as a result of the component or metal recovery process would not be considered scrap metal, according to the definition contained in section $66260.10(b)(6), 22$ CCR. If the used printed circuit boards are not recycled, but are disposed of, the boards should be evaluated according to the criteria in Chapter 11, Division 4.5, 22 CCR to determine the appropriate classification of the waste.

\section{See Also: Scrap Metal}

Pursuant to Section 66262.11, Title 22, California Code of Regulations (22 CCR), it is the generator's responsibility to determine if his waste is hazardous or nonhazardous by testing representative samples of the waste using the methods set forth in Chapter 11 , Division 4.5, 22 CCR and/or applying knowledge of the hazardous characteristics of the waste in light of the materials or processes used to generate the waste. If the waste exhibits any of these characteristios, it is classified as a hazardous waste and must be managed as such. The classification of wastes is not to be confused with the establishment of cleanup levels. Waste classification determines only whetber a raste must be managed as a hazardous waste. To obtain further documents relating to the sampling and classification of wastes, call the waste evaluation helpline at (916) 322-7676. Copies of Division 4.5, Title 22, California Code of Regulations are available at most public libraries which contain a government publications section or are available for purchase by calling Barclays Law Publishers at (415) $244-6611$. 


\section{$E_{\text {VAIUATIO }}^{\text {WASTF }}$}

\section{REGULATION GUIDANCE}

Department of Toxic Substances Control

\section{SCRAP METAL}

(RG Document \#44; Revision \#1; Revision Date: August 19, 1993)

Used metal parts or equipment meeting the definition of scrap metal found in section 66260.10, Title 22, California Code of Regulations (22 CCR), may be classified and managed as a nonhazardous waste. The definition includes "manufactured solid metal objects and products" as well as other metal items. Items meeting the definition are excluded from regulation purstiant to section
$66261.6(a)(3)(B), 22$ CCR.

There are several delineated exclusions in section $66260.10(\mathrm{~b}), 22 \mathrm{CCR}$, of the scrap metal definition. Any metal wastes excluded from the definition of scrap metal are subject to the criteria contained in Chapter 11, Division 4.5, 22 CCR.

See Also: No other references.

Pursuant to Section 66262.11, Title 22, California Code of Regulations (22 CCR), it is the generator's responsibility to determine if his waste is hazardous or nonhazardous by testing representative samples of the waste using the methods set forth in Chapter 11 , Division $4.5,22 \mathrm{CCR}$ and/or applying bowledge of the hazardous characteristics of the waste in light of the materials or processes used to generate the waste. If the waste exhibits any of these characteristies, it is classified as 2 bazardous raste and must be managed as such. The classification of prastes is not to be confused with the establishment of cleanup levels. Waste classification determines only whether a waste must be managed 25 a hazardous waste. To obtain further documents relating to the campling and chassilication of wastes, call the waste evaluation belpline at (916) 322-7676. Copies of Division 4.5, Title 22, Californiz Code of Regulations are available at most public lbraries which contain a government publications section or are available for purchase, by calling Barclays Law Publishers at (415) 244-6611. 
JUH 51990

OFGICE OF
SOLIOWATE ANCEMEAGENGY RESPONSE

MEMORANDUM

SUBJECT: Final Monthly Report-RCRA/Superínd Industry Assistance and Emergency Planning and Community Right-To-Know Irormation Hotline Report for March 1990

FROM: Tnea Mekanus, Project Officer Office of Solid Waste

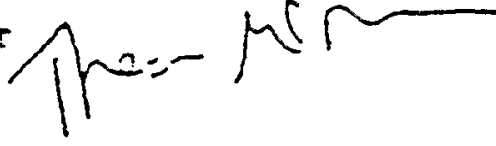

IO: See List of Addresses

Tnis Report is prepared and submitted in support of Contract \#6\&-01-T377.

I. SIGNIFICANT OUESTIONS AND RESOLVED ISSUES-MARCH 1990

\section{A. RCRA}

\section{Clarification of Bv-Product Versus Sqap Metal}

A manufacturer of computer circuit boards sends unused off-specification printed circuit boards and board trimmings from the production process off-site for redamation. The printed creuit boards are made of alternating layers of thin copper and fiberglass plates coated with tin lead; containing approximately $30 \%$ copper, $68 \%$ fiberglass, and $2 \%$ tin lead. How are the unused boards classified under 40 CFR 261.2, and are the trimmings byproducts or scrap metal?.Would these materials be solid wastes under RCRA?

The unused circuit boards are secondary materials. Under 40 CFR 261.2, the Agency designates those secondary materials which are RCRA Subtitle $C$ solid wastes when recycled. According to Section $261.2(\mathrm{c})(3)$, unused off-specification commercial chemical products listed in 40 CFR 261.33 are not considered solid wastes wheñ fent for reclamation. Although the Agency does not directly addressinon listed commercial chemical products in the regulation, their status

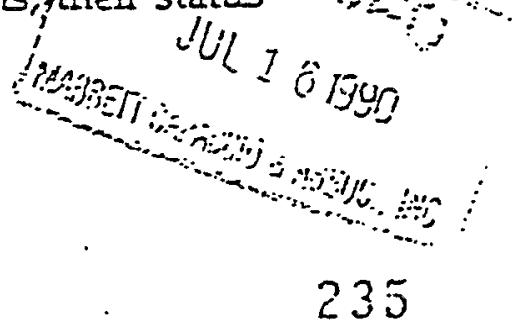




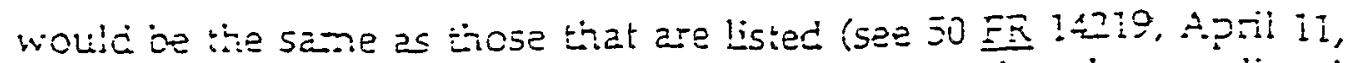
1935). The unlused circlit boards are consiciered to be non-listed commercial chemical producs, and thus, are not solid wastes when recianed. If, however, the circuit boards bad been usad and were no longer fit for luse, tiey would be consicered spert materials and defined as solid wastes when redained.

The timmings are inherently unfit for end use and will be redained. In tive January 4, 1985 Federal Register (50 FR 625), the Agency defines by-producis as materials "that are not produced intentionally or separately, and that are unfit for end use without substantial processing." "The printed circuit board timmings meet the definition of characteristic by-product rather than scap metal, and are not solid wastes when reclained under Section 261.2(c)(3). Although the trimmings are physically similar to scrap metal, to neet the definition of scap metal, the material must have significant metal content, i.e, greater than $50 \%$ metal. In fact, examples given in the Preanble concerning scrap metal were virtually $100 \%$ metal. Materials defined as scrap metal under Section 261.1 are solid wastes when reclained, and, if hazardous, are presently exempt under Section 261.6(a)(3)(iv) from Subtitle C regulation. The Agency has deferied hazarcious scap metal from regulation until appropriate information on types of scap metal and industry management practices is mace available for study.

Source: Mike Petuska, OSW (202) 382-3139

Research: Wally Mon

2. Definition of Regulated Medical Waste Applicable to Intravenous Bags Generated by Veterinarians

A veterinarian sometimes administers sterile saline or dextrose solutions to animals when he treats these arimals for various illnesses (e.g., dehydration). These sterile solutions are contained in intravenous bags which are physically and functionally identical to $\Gamma$ bags that are admiristered to human patients. After the veterinarian's IV bags are empty, can the veterinarian cut the $I V$ bags so that they are no longer recogrizaile and handle them as nonregulated medical waste?

230 
UNITED STATES ENVIRONMENTAL PROTECTION AGENCY

WASHINGTON, D.C. 20450

AUG 281892

OFFICE OF

SOLIO WASTE ANO EMEROENEY RESPONSE

\begin{abstract}
HEMORANDEN
SUBJECT: Follow-up on Yai11e Affldavit

FROK:

Richard J.

Deputy Assiftar

Asaibtant burfor General, uspys

TO: Richard Va1110, Chlef

- State Programa Branch

Hazardous Haste Management Divibion

EPA Region IX
\end{abstract}

Thank you for forwarding to my offlce a copy of your recent letter witich dotalis everis regarding the isaus of solder skimmings (e.g. solder dross) and a laweult brought by the state of Califorria. This memorandum is intended to eliminate any confusion that might exist on the status of Don clay's letters of November 27, 1991 and December 3, 1991 on solder skimmings.

EPA'B current position is that, in light of historlcal events including previous offlcial statements from the Agency and reliance on those official statements, oxidized skimmings from solder baths (Bolder dross) are treated as by-product material. He understand that such skimmings contain base metals like lead and $t$ in as weIl as other matarials, such as luxes. As stated in the November 27 th letter, EPA would need to gather more data on industry practice and undertake the proper rulemaking procedures prior to the time that any change in the atatus of solder skiminga as by-product would occur.

I trust that this information will clarify our position at this:time. Of course, California, as recently authorized to administer the RCRA program, is now fully empowered to make 1ts own prospect1va determiratlont under its own RCRA authority. 


\section{APPENDIX B}

The TCLP Metal Extraction Procedure 


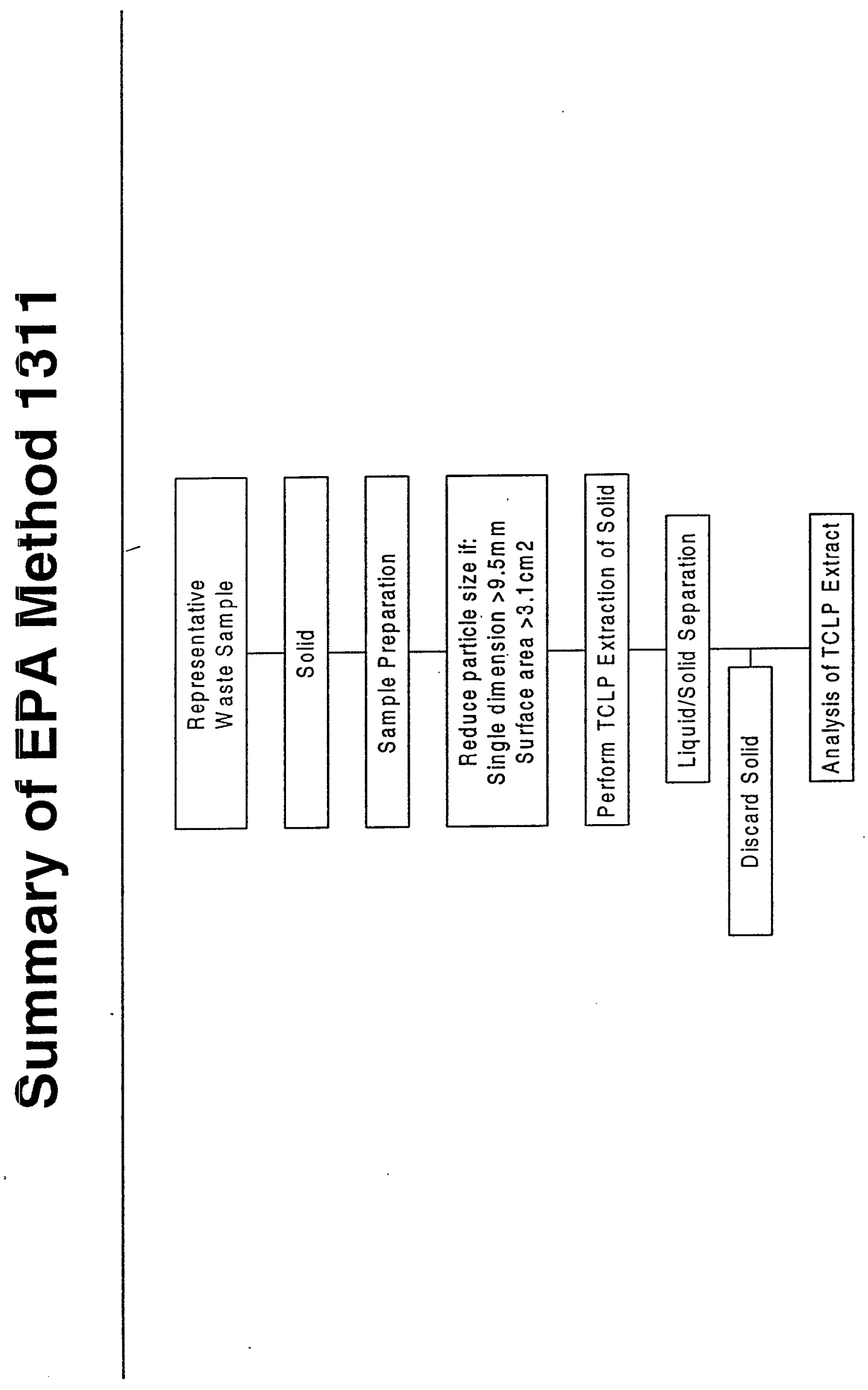




\section{TCLP Laboratory Procedure (40 CFR 261)}

(1) Conduct pre-test to determine proper extraction fluid:

(a) Combine: $5 \mathrm{~g}$ solid material, $96.5 \mathrm{~g}$ water, measure $\mathrm{pH}$.

(b) If $\mathrm{pH} \leq 5.0$, then use extraction fluid \#1.

(c) If $\mathrm{pH}>5.0$, then add $3.5 \mathrm{ml} 1.0 \mathrm{~N} \mathrm{HCl}$, stir 30 seconds, heat to $50^{\circ} \mathrm{C}$ for $10 \mathrm{~min}$, cool to ambient, measure $\mathrm{pH}$ :

(i) If $\mathrm{pH} \leq 5.0$, then use extraction fluid $\# 1$.

(ii) If $\mathrm{pH}>5.0$, then use extraction fluid $\# 2$.

(2) Make up appropriate extraction fluid:

(a) Extraction Fluid \#1 (5.6.1)

Add $5.7 \mathrm{ml}$ glacial HOAc to $500 \mathrm{ml}$ deionized distilled water, add $64.3 \mathrm{ml} 1.0 \mathrm{~N}$ $\mathrm{NaOH}$, dilute to 1 liter volume. $\mathrm{pH}$ will be $4.93 \pm 0.05$.

(b) Extraction Fluid \#2 (5.6.2)

Dilute $5.7 \mathrm{ml}$ glacial HOAc with deionized distilled water to 1 liter volume. $\mathrm{pH}$ will be $2.88 \pm 0.05$.

(3) Weigh out $100 \mathrm{~g}$ of test sample, place in plastic TCLP containers, add 2 liters of appropriate extraction fluid, close lid tightly and secure with tape.

(4) Place in end over end tumbler, lock clasps and secure tightly with bolt and lock nut.

(5) Tumble at $30 \pm 2 \mathrm{rpm}$ for 18 hours.

(6) Filter through $0.6-0.8 \mu \mathrm{m}$ glass fiber filter, reserve approximately $50 \mathrm{ml}$ aliquot of filtrate for analysis.

(7) Analyze for metals (ICP, AA, UV Spectrometer):

(a) If metals concentration (ppm) > allowable TCLP limit, then treat liquid and solid residue as mixed waste.

(b) If metals concentration (ppm) < allowable TCLP limit, then dispose of liquid and solid as radwaste. 
METHOD 1311

\author{
TOXICITY CHARACTERISTIC LEACHING PROCEDURE
}

\title{
1.0 SCOPE AND APPLICATION
}

1.1 The TCLP is designed to determine the mobility of both organic and inorganic analytes present in liquid, solid, and multiphasic wastes.

1.2 If a total analysis of the waste demonstrates that individual analytes are not present in the waste, or that they are present but at such low concentrations that the appropriate regulatory levels could not possibly be exceeded, the TCLP need not be run.

1.3 If an analysis of any one of the liquid fractions of the TCLP extract indicates that a regulated compound is present at such high concentrations that, even after accounting for dilution from the other fractions of the extract, the concentration would be above the regulatory level for that compound. then the waste is hazardous and it is not necessary to analyze the remaining fractions of the extract.

1.4 If an analysis of extract obtained using a bottle extractor shows that the concentration of any regulated volatile analyte exceeds the regulatory level for that compound, then the waste is hazardous and extraction using the ZHE is not necessary. However, extract from a bottle extractor cannot be used to demonstrate that the concentration of volatile compounds is below the regulatory level.

\subsection{SUMMARY OF METHOD}

2.1 For liquid wastes (i.e. those containing less than $0.5 \%$ dry solid material), the waste, after filtration through a 0.6 to 0.8 um glass fiber filter, is defined as the TCLP extract.

2.2 For wastes containing greater than or equal to $0.5 \%$ solids, the liquid, if any, is separated from the solid phase and stored for later analysis: the particle size of the solid phase is reduced, if necessary. The solid phase is extracted with an amount of extraction fluid equal to 20 times the weight of the solid phase. The extraction fluid employed is a function of the alkalinity of the solid phase of the waste. A special extractor vessel is used when testing for volatile analytes (see Table 1 for a list of volatile compounds). Following extraction, the liquid extract is separated from the solid phase by filtration through a 0.6 to $0.8 \mu \mathrm{m}$ glass fiber filter.

2.3 If compatible (i.e., multiple phases will not form on combination), the initial liquid phase of the waste is added to the liquid extract, and these are analyzed together. If incompatible, the liquids are analyzed separately and the results are mathematically combined to yield a volume-weighted average concentration.

CD-ROM

$1311-1$

Revision 0. Ju7y 1992 


\subsection{INTERFERENCES}

3.1 Potential interferences that may be encountered during analysis are discussed in the individual analytical methods.

\subsection{APPARATUS AND MATERIALS}

4.1 Agitation apparatus: The agitation apparatus must be capable of rotating the extraction vessel in an end-over-end fashion (see Figure 1 ) at $30 \pm 2 \mathrm{rpm}$. Suitable devices known to EPA are identified in Table 2 .

\subsection{Extraction Vessels}

4.2.1 Zero-Headspace Extraction Vessel (ZHE). This device is for use only when the waste is being tested for the mobility of volatile analytes (i.e., those listed in Table 1). The ZHE (depicted in Figure 2) allows for liquid/solid separation within the device, and effectively precludes headspace. This type of vessel allows for initial liquid/solid separation, extraction, and final extract filtration without opening the vessel (see Section 4.3.1). The vessels shall have an internal volume of 500-600 mL, and be equipped to accommodate a 90-110 mm filter. The devices contain VITON ${ }^{\otimes 1}$-rings which should be replaced frequently. Suitable ZHE devices known to EPA are identified in Table 3 .

- For the ZHE to be acceptable for use, the piston within the ZHE should be able to be moved with approximately 15 psi or less. If it takes more pressure to move the piston, the 0-rings in the device should be replaced. If this does not solve the problem, the ZHE is unacceptable for TCLP analyses and the manufacturer should be contacted.

The ZHE should be checked for leaks after every extraction. If the device contains a built-in pressure gauge, pressurize the device to 50 psi, allow it to stand unattended for 1 hour, and recheck the pressure. If the device does not have a built-in pressure gauge, pressurize the device to $50 \mathrm{psi}$, submerge it in water, and check for the presence of air bubbles escaping from any of the fittings. If pressure is lost, check all fittings and inspect and replace 0-rings, if necessary. Retest the device. If leakage problems cannot be solved, the manufacturer should be contacted.

Some ZHEs use gas pressure to actuate the ZHE piston, while others use mechanical pressure (see Table 3 ). Whereas the volatiles procedure (see Section 7.3) refers to pounds per square inch (psi), for the mechanically actuated piston, the pressure applied is measured in torque-inch-pounds. Refer to the manufacturer's instructions as to the proper conversion.

1 VITON is a trademark of Du Pont.

CD-ROM : $1311-2$

Revision 0

JuTy 1992 
4.2.2 Bottle Extraction Vessel. When the waste is being evaluated using the nonvolatile extraction, a jar with sufficient capacity to hold the sample and the extraction fluid is needed. Headspace is allowed in this vessel.

The extraction bottles may be constructed from various materials, depending on the analytes to be analyzed and the nature of the waste (see section 4.3.3). It is recommended that borosilicate glass bottles be used instead of other types of glass, especially when inorganics are of concern. Plastic bottles, other than polytetrafluoroethylene, shall not be used if organics are to be investigated. Bottles are available from a number of laboratory suppliers. When this type of extraction vessel is used, the filtration device discussed in Section 4.3 .2 is used for initial liquid/solid separation and final extract filtration.

4.3 Filtration Devices: It is recommended that all filtrations be performed in a hood.

4.3.1 Zero-Headspace Extractor Vessel (ZHE): When the waste is evaluated for volatiles, the zero-headspace extraction vessel described in Section 4.2.1 is used for filtration. The device shall be capable of supporting and keeping in place the glass fiber filter and be able to withstand the pressure needed to accomplish separation (50 psi).

NOTE: - When it is suspected that the glass fiber filter has been ruptured, an in-line glass fiber filter may be used to filter the material within the ZHE.

4.3.2 Filter Holder: When the waste is evaluated for other than volatile analytes, any filter holder capable of supporting a glass fiber filter and able to withstand the pressure needed to accomplish separation may be used. Suitable filter holders range from simple vacuum units to relatively complex systems capable of exerting pressures of up to 50 psi or more. The type of filter holder used depends on the properties of the material to be filtered (see Section 4.3.3). These devices shall have a minimum internal volume of $300 \mathrm{~mL}$ and be equipped to accommodate a minimum filter size of $47 \mathrm{~mm}$ (filter holders having an internal capacity of $1.5 \mathrm{~L}$ or greater, and equipped to accommodate a $142 \mathrm{~mm}$ diameter filter, are recommended). Vacuum filtration can only be used for wastes with low solids content $(<10 \%)$ and for highty granular, liquid-containing wastes. A11 other types of wastes should be filtered using positive pressure filtration. Suitable filter holders known to EPA are shown in Table 4.

4.3.3 Materials of Construction: Extraction vessels and filtration devices shall be made of inert materials which will not leach or absorb waste components. Glass, polytetrafluoroethylene (PTFE), or type 316 stainless steel equipment may be used when evaluating the mobility of both organic and inorganic components. Devices made of high density polyethylene (HDPE), polypropylene (PP), or polyvinyl chloride (PVC) may be used only when evaluating the mobility of metals. Borosili-

CD-ROM $1311-3$

Revision 0 JuTy 1992 
cate glass bottles are recommended for use over other types of glass bottles, especially when inorganics are analytes of concern.

4.4 Filters: Filters shall be made of borosilicate glass fiber, shall contain no binder materials, and shall have an effective pore size of 0.6 to $0: 8 \mu \mathrm{m}$, or equivalent. Filters known to EPA which meet these specifications are identified in Table 5. Pre-filters must not be used. When evaluating the mobility of metals, filters shall be acid-washed prior to use by rinsing with $1 \mathrm{~N}$ nitric acid followed by three consecutive rinses with deionized distilled water (a minimum of $1 \mathrm{~L}$ per rinse is recommended). Glass fiber filters are fragile and should be handled with care.

$4.5 \mathrm{pH}$ Meters: The meter should be accurate to \pm 0.05 units at $25^{\circ} \mathrm{C}$.

4.6 ZHE Extract Collection Devices: TEDLAR ${ }^{\otimes 2}$ bags or glass, stainless steel or PTFE gas-tight syringes are used to collect the initial liquid phase and the final extract of the waste when using the ZHE device. The devices listed are recommended for use under the following conditions:

4.6.1 If a waste contains an aqueous liquid phase or if a waste does not contain a significant amount of nonaqueous liquid (i.e.. < <\% of total waste), the TEDLAR ${ }^{\circledast}$ bag or a $600 \mathrm{~mL}$ syringe should be used to collect and combine the initial liquid and solid extract.

- 4.6.2 If a waste contains a significant amount of nonaqueous liquid in the initial liquid phase (i.e.. $>1 \%$ of total waste), the syringe or the TEDLAR bag may be used for both the initial solid/liquid separation and the final extract filtration. However, analysts should use one or the other. not both.

4.6.3 If the waste contains no initial liquid phase (is $100 \%$ solid) or has no significant solid phase (is $100 \%$ liquid), either the TEDLAR ${ }^{\circledast}$ bag or the syringe may be used. If the syringe is used, discard the first $5 \mathrm{~mL}$ of liquid expressed from the device. The remaining aliquots are used for analysis.

4.7 ZHE Extraction Fluid Transfer Devices: Any device capable of transferring the extraction fluid into the ZHE without changing the nature of the extraction fluid is acceptable (e.g., a positive displacement or peristaltic pump, a gas tight syringe, pressure filtration unit (see Section 4.3.2), or other ZHE device).

4.8 Laboratory Balance: Any laboratory balance accurate to within \pm 0.01 grams may be used (a11 weight measurements are to be within \pm 0.1 grams).

4.9 Beaker or Erlenmeyer flask, glass. $500 \mathrm{~mL}$.

2 TEDLAR ${ }^{\circledast}$ is a registered trademark of Du Pont.

CD-ROM

$1311-4$

Revision 0

July 1992 
flask.

4.10 Watchglass, appropriate diameter to cover beaker or Erlenmeyer

\subsection{Magnetic stirrer.}

\subsection{REAGENTS}

5.1 Reagent grade chemicals shall be used in all tests. Unless otherwise indicated, it is intended that all reagents shall conform to the specifications of the Committee on Analytical Reagents of the American Chemical Society, where such specifications are available. Other grades may be used, provided it is first ascertained that the reagent is of sufficiently high purity to permit its use without lessening the accuracy of the determination.

5.2 Reagent Water. Reagent water is defined as water in which an interferant is not observed at or above the method's detection limit of the analyte(s) of interest. For nonvolatile extractions. ASTM Type II water or equivalent meets the definition of reagent water. For volatile extractions, it is recommended that reagent water be generated by any of the following methods. Reagent water should be monitored periodically for impurities.

5.2.1 Reagent water for volatile extractions may be generated by passing tap water through a carbon filter bed containing about 500 grams of activated carbon (Calgon Corp., Filtrasorb-300 or equivalent).

5.2.2 A water purification system (Millipore Super-0 or equivalent) may also be used to generate reagent water for volatile extractions.

5.2.3 Reagent water for volatile extractions may also be prepared by boiling water for 15 minutes. Subsequentiy, while maintaining the water temperature at $90 \pm 5$ degrees $C$, bubble a contaminant-free inert gas (e.g. nitrogen) through the water for 1 hour. While still hot, transfer the water to a narrow mouth screw-cap bottle under zero-headspace and seal with a Tefion-lined septum and cap.

5.3 Hydrochloric acid (IN), HCl, made from ACS reagent grade.

5.4 Nitric acid (IN), $\mathrm{HNO}_{3}$, made from ACS reagent grade.

5.5 Sodium hydroxide ( $1 N)$, NaOH, made from ACS reagent grade.

5.6 Glacial acetic acid, $\mathrm{CH}_{3} \mathrm{CH}_{2} \mathrm{OOH}$, ACS reagent grade.

\subsection{Extraction fluid.}

5.7.1 Extraction fluid \# 1: Add $5.7 \mathrm{~mL}$ glacial $\mathrm{CH}_{3} \mathrm{CH}_{2} \mathrm{OOH}$ to $500 \mathrm{~mL}$ of reagent water (See Section 5.2 ), add $64.3 \mathrm{~mL}$ of $1 \mathrm{~N} \mathrm{NaOH}$, and dilute to a volume of 1 iiter. When correctly prepared, the $\mathrm{pH}$ of this fluid will be $4.93 \pm 0.05$. 
5.7.2 Extraction fluid 非 2: Dilute $5.7 \mathrm{~mL}$ glacial $\mathrm{CH}_{3} \mathrm{CH}_{2} \mathrm{OOH}$ with reagent water (See Section 5.2) to a volume of 1 liter. When correctly prepared, the $\mathrm{pH}$ of this fluid will be $2.88 \pm 0.05$.

NOTE: These extraction fluids should be monitored frequently for impurities. The $\mathrm{pH}$ should be checked prior to use to ensure that these fluids are made up accurately. If impurities are found or the $\mathrm{pH}$ is not within the above specifications, the fluid shall be discarded and fresh extraction fluid prepared.

5.8 Analytical standards shall be prepared according to the appropriate analytical method.

\subsection{SAMPLE COLLECTION, PRESERVATION, AND HANDLING}

6.1 All samples shall be collected using an appropriate sampling plan.

6.2 The TCLP may place requirements on the minimal size of the field sample, depending upon the physical state or states of the waste and the analytes of concern. An aliquot is needed for preliminary evaluation of which extraction fluid is to be used for the nonvolatile analyte extraction procedure. Another aliquot may be needed to actualiy conduct the nonvolatile extraction (see Section 1.4 concerning the use of this extract for volatile organics). If volatile organics are of concern, another aliquot may be needed. Quality control measures may require additional aliquots. Further, it is always wise to collect more sample just in case something goes wrong with the initial attempt to conduct the test.

6.3 Preservatives shall not be added to samples before extraction.

6.4 Samples may be refrigerated unless refrigeration results in irreversible physical change to the waste. If precipitation occurs, the entire sample (including precipitate) should be extracted.

6.5 When the waste is to be evaluated for volatile analytes, care shall be taken to minimize the loss of volatiles. Samples shall be collected and stored in a manner intended to prevent the loss of volatile analytes (e.g.. samples should be collected in Teflon-lined septum capped vials and stored at 4 - $C$. Samples should be opened only immediately prior to extraction).

6.6 TCLP extracts should be prepared for analysis and analyzed as soon as possible following extraction. Extracts or portions of extracts for metallic anatyte determinations must be acidified with nitric acid to a $\mathrm{pH}<2$, unless precipitation occurs (see Section 7.2.14 if precipitation occurs). Extracts should be preserved for other analytes according to the guidance given in the individual analysis methods. Extracts or portions of extracts for organic analyte determinations shali not be allowed to come into contact with the atmosphere (i.e., no headspace) to prevent losses. See section 8.0 ( $0 \mathrm{~A}$ requirements) for acceptable sample and extract holding times.

CD-ROM

$1311-6$

Revision 0

JuTy 1992 


\subsection{Preliminary Evaluations}

Perform preliminary TCLP evaluations on a minimum 100 gram aliquot of waste. This aliquot may not actually undergo TCLP extraction. These preliminary evaluations include: (1) determination of the percent solids (Section 7.1.1); (2) determination of whether the waste contains insignificant solids and is, therefore, its own extract after filtration (Section 7.1.2): (3) determination of whether the solid portion of the waste requires particle size reduction (Section 7.1.3); and (4) determination of which of the two extraction fluids are to be used for the nonvolatile TCLP extraction of the waste (Section 7.1.4).

7.1.1 Preliminary determination of percent solids: Percent solids is defined as that fraction of a waste sample (as a percentage of the total sample) from which no liquid may be forced out by an applied pressure, as described below.

7.1.1.1 If the waste will obviously yield no liquid when subjected to pressure filtration (i.e., is $100 \%$ solids) proceed to Section 7.1.3.

7.1.1.2 If the sample is liquid or multiphasic, liquid/solid separation to make a preliminary determination of percent solids is required. This involves the filtration device described in Section 4.3.2 and is outlined in Sections 7.1.1.3 through 7.1.1.9.

7.1.1.3 Pre-weigh the filter and the container that will receive the filtrate.

7.1.1.4 Assemble the filter holder and filter following the manufacturer's instructions. Place the filter on the support screcn and sccure.

7.1.1.5 Weigh out a subsample of the waste (100 gram minimum) and record the weight.

7.1.1.6 Allow slurries to stand to permit the solid phase to settle. Wastes that settle slowly may be centrifuged prior to filtration. Centrifugation is to be used only as an aid to filtration. If used, the liquid should be decanted and filtered followed by filtration of the solid portion of the waste through the same filtration system.

7.1.1.7 Quantitatively transfer the waste sample to the filter holder (liquid and solid phases). Spread the waste sample evenly over the surface of the filter. If filtration of the waste at $4{ }^{\circ} \mathrm{C}$ reduces the amount of expressed 1 iquid over what would be expressed at room temperature then allow the sample to warm up to room temperature in the device before filtering.

CD-ROM

$1311-7$

Revision 0

July 1992 
NOTE: If waste material ( $>1 \%$ of original sample weight) has obviously adhered to the container used to transfer the sample to the filtration apparatus, determine the weight of this residue and subtract it from the sample weight determined in Section 7.1.1.5 to determine the weight of the waste sample that will be filtered.

Gradually apply vacuum or gentle pressure of 1-10 psi, until air or pressurizing gas moves through the filter. If this point is not reached under $10 \mathrm{psi}$, and if no additional liquid has passed through the filter in any 2 minute interval, slowly increase the pressure in $10 \mathrm{psi}$ increments to a maximum of 50 psi. After each incremental increase of 10 psi, if the pressurizing gas has not moved through the filter, and if no additional liquid has passed through the filter in any 2 minute interval, proceed to the next 10 psi increment. When the pressurizing gas begins to move through the filter, or when liquid flow has ceased at 50 psi (i.e... filtration does not result in any additional filtrate within any 2 minute period), stop the filtration.

NOTE: Instantaneous application of high pressure can degrade the glass riber filter and may cause premature plugging.

7.1.1.8 The material in the filter holder is defined as the solid phase of the waste, and the filtrate is defined as the liquid phase.

NOTE: Some wastes, such as oily wastes and some paint wastes, will obviously contain some material that appears to be a liquid. Even after applying vacuum or pressure filtration, as outlined in Section 7.1.1.7, this material may not filter. If this is the case, the material within the filtration device is defined as a solid. Do not replace the original filter with a fresh filter under any circumstances. Use only one filter.

7.1.1.9 Determine the weight of the liquid phase by subtracting the weight of the filtrate container (see Section 7.1.1.3) from the total weight of the filtrate-filled container. Determine the weight of the solid phase of the waste sample by subtracting the weight of the liquid phase from the weight of the total waste sample, as determined in Section 7.1 .1 .5 or 7.1 .1 .7 .

Record the weight of the liquid and solid phases. Calculate the percent solids as follows:

Percent solids $=\frac{\text { Weight of solid (Section } 7.1 .1 .9)}{\text { Total weight of waste (Section } 7.1 .1 .5 \text { or } 7.1 .1 .7)} \times 100$

7.1.2 If the percent solids determined in Section 7.1.1.9 is equal to or greater than $0.5 \%$, then proceed either to Section 7.1 .3 to

CD-ROM

$1311-8$

Revision 0 Ju1y 1992 
determine whether the solid material requires particle size reduction or to Section 7.1.2.1 if it is noticed that a smal1 amounl of the filtrate is entrained in wetting of the filter. If the percent solids determined in Section 7.1 .1 .9 is 7 ess than $0.5 \%$, then proceed to Section 7.2 .9 if the nonvolatile TCLP is to be performed and to Section 7.3 with a fresh portion of the waste if the volatile TCLP is to be performed.

7.1.2.1 Remove the solid phase and filter from the filtration apparatus.

7.1.2.2 Dry the filter and solid phase at $100 \pm 20^{\circ} \mathrm{C}$ until two successive weighing yield the same value within $\pm 1 \%$. Record the final weight.

NOTE: $\quad$ Caution should be taken to ensure that the subject solid will not flash upon heating. It is recommended that the drying oven be vented to a hood or other appropriate device.

7.1.2.3 Calculate the percent dry solids as follows:

(Wt. of dry waste + filter) - tared wt. of filter

Percent dry solids $=\frac{\text { Initial wt. of waste (Section 7.1.1.5 or 7.1.1.7) }}{\text { ) }}$

7.1.2.4 If the percent dry solids is less than $0.5 \%$. then proceed to section 7.2.9 if the nonvolatile TCLP is to be performed, and to Section 7.3 if the volatile TCLP is to be performed. If the percent dry solids is greater than or equal to $0.5 \%$, and if the nonvolatile TCLP is to be performed, return to the beginning of this Section (7.1) and, with a fresh portion of waste. determine whether particle size reduction is necessary (Section 7.1.3) and determine the appropriate extraction fluid (Section 7.1.4). If only the volatile TCLP is to be performed, see the note in Section 7.1.4.

7.1.3 Determination of whether the waste requires particle size reduction (particle size is reduced during this step): Using the solid portion of the waste, evaluate the solid for particle size. Particle size reduction is required, unless the solid has a surface area per gram of material equal to or greater than $3.1 \mathrm{~cm}^{2}$, or is smaller than $1 \mathrm{~cm}$ in its narrowest dimension (i.e... is capable of passing through a $9.5 \mathrm{~mm}(0.375$ inch) standard sieve). If the surface area is smalier or the particle size larger than described above, prepare the solid portion of the waste for extraction by crushing, cutting, or grinding the waste to a surface area or particle size as described above. If the solids are prepared for organic volatiles extraction, special precautions must be taken (see Section 7.3.6).

NOTE: Surface area criteria are meant for filamentous (e.g., paper, cloth, and similar) waste materials. Actual measurement of surface area is not required, nor is it recommended. For materials that do not obviously meet 
the criteria, sample specific methods would need to be developed and employed to measure the surface area. Such methodology is currently not available.

7.1.4 Determination of appropriate extraction fluid: If the solid content of the waste is greater than or equal to $0.5 \%$ and if the sample will be extracted for nonvolatile constituents (Section 7.2). determine the appropriate fluid (Section 5.7) for the nonvolatiles extraction as follows:

NOTE: TCLP extraction for volatile constituents uses only extraction fluid \#1 (Section 5.7.1). Therefore, if TCLP extraction for nonvolatiles is not required, proceed to section 7.3 .

7.1.4.1 Weigh out a small subsample of the solid phase of the waste, reduce the solid (if necessary) to a particle size of approximately $1 \mathrm{~mm}$ in diameter or less, and transfer $5.0 \mathrm{grams}$ of the solid phase of the waste to a $500 \mathrm{~mL}$ beaker or Erlenmeyer. flask.

7.1.4.2 Add 96.5 $\mathrm{mL}$ of reagent water to the beaker, cover with a watchglass, and stir vigorously for 5 minutes using a magnetic stirrer. Measure and record the $\mathrm{pH}$. If the $\mathrm{pH}$ is $<5.0$, use extraction fluid 非. Proceed to Section 7.2.

7.1.4.3 If the pH from Section 7.1 .4 .2 is $>5.0$, add $3.5 \mathrm{~mL} 1 \mathrm{~N} \mathrm{HCl}$, slurry briefly, cover with a watchglass, heat to 50 ${ }^{\circ} \mathrm{C}$, and hold at $50{ }^{\circ} \mathrm{C}$ for 10 minutes.

7.1.4.4 Let the solution cool to room temperature and record the $\mathrm{pH}$. If the $\mathrm{pH}$ is $<5.0$, use extraction fluid 非. If the $\mathrm{pH}$ is $>5.0$, use extraction fluid 非. Proceed to Section 7.2.

7.1.5 If the aliquot of the waste used for the preliminary evaluation (Sections $7.1 .1-7.1 .4$ ) was determined to be $100 \%$ solid at Section 7.1.1.1, then it can be used for the section 7.2 extraction (assuming at least 100 grams remain), and the section 7.3 extraction (assuming at least 25 grams remain). If the aliquot was subjected to the procedure in Section 7.1.1.7, then another aliquot shall be used for the volatile extraction procedure in Section 7.3. The aliquot of the waste subjected to the procedure in Section 7.1.1.7 might be appropriate for use for the section 7.2 extraction if an adequate amount of solid (as determined by Section 7.1.1.9) was obtained. The amount of solid necessary is dependent upon whether a sufficient amount of extract will be produced to support the analyses. If an adequate amount of solid remains, proceed to Section 7.2.10. of the nonvolatile TCLP extraction.

\subsection{Procedure When Volatiles are not Involved}

A minimum sample size of 100 grams (solid and liquid phases) is recommended. In some cases, a larger sample size may be appropriate, depending on the

CD-ROM $1311-10$

Revision 0

JuTy 1992 
solids content of the waste sample (percent solids, See Section 7.1.1), whether the initial liquid phase of the waste will be miscible with the aqueous extract of the solid, and whether inorganics, semivolatile organics, pesticides, and herbicides are all analytes of concern. Enough solids should be generated for extraction such that the volume of TCLP extract will be sufficient to support all of the anaiyses required. If the amount of extract generated by a single TCLP extraction will not be sufficient to perform all of the analyses, more than one extraction may bc performed and the extracts from each combined and aliquoted for analysis.

7.2.1 If the waste will obviously yield no liquid when subjected to pressure filtration (i.e.. is $100 \%$ solid. see Section 7.1 .1 ), weigh out a subsample of the waste (100 gram minimum) and proceed to section 7.2.9.

7.2.2 If the sample is liquid or multiphasic, liquid/solid separation is required. This involves the filtration device described in Section 4.3.2 and is outlined in Sections 7.2.3 to 7.2.8.

\subsubsection{Pre-weigh the container that will receive the filtrate.}

7.2.4 Assemble the filter holder and filter following the manufacturer's instructions. Place the filter on the support screen and secure. Acid wash the filter if evaluating the mobility of metals (see Section 4.4).

NOTE: -

Acid washed filters may be used for all nonvolatile extractions even when metals are not of concern.

7.2.5 Weigh out a subsample of the waste (100 gram minimum) and record the weight. If the waste contains $<0.5 \%$ dry solids (Section 7.1 .2 ), the liquid portion of the waste, after filtration, is defined as the TCLP extract. Therefore, enough of the sample should be filtered so that the amount of filtered liquid will support all of the analyses required of the TCLP extract. For wastes containing $>0.5 \%$ dry solids (Sections 7.1.1 or 7.1.2), use the percent solids information obtained in Section 7.1.1 to determine the optimum sample size (100 gram minimum) for filtration. Enough solids should be generated by filtration to support the analyses to be performed on the TCLP extract.

7.2.6 Allow slurries to stand to permit the solid phase to settle. Wastes that settle slowly may be centrifuged prior to filtration. Use centrifugation only as an aid to filtration. If the waste is centrifuged, the liquid should be decanted and filtered followed by filtration of the solid portion of the waste through the same filtration system.

7.2.7 Quantitatively transfer the waste sample (liquid and solid phases) to the filter holder (see Section 4.3.2). Spread the waste sample evenly over the surface of the filter. If filtration of the waste at $4^{\circ} \mathrm{C}$ reduces the amount of expressed liquid over what would be expressed at 
room temperature, then allow the sample to warm up to room temperature in the device before filtering.

NOTE: If waste material ( $>1 \%$ of the original sample weight) has obviously adhered to the container used to transfer the sample to the filtration apparatus, determine the weight of this residue and subtract it from the sample weight determined in Section 7.2.5, to determine the weight of the waste sample that will be filtered.

Gradually apply vacuum or gentle pressure of 1-10 psi, until air or pressurizing gas moves through the filter. If this point is not reached under $10 \mathrm{psi}$, and if no additional liquid has passed through the filter in any 2 minute interval. slowly increase the pressure in 10 psi increments .to a maximum of 50 psi. After each incremental increase of 10 psi, if the pressurizing gas has not moved through the filter, and if no additional liquid has passed through the filter in any 2 minute interval, proceed to the next $10 \mathrm{psi}$ increment. When the pressurizing gas begins to move through the filter, or when the liquid flow has ceased at 50 psi (i.e., filtration does not result in any additional filtrate within a 2 minute period), stop the filtration.

NOTE: Instantaneous application of high pressure can degrade the glass fiber filter and may cause premature plugging.

- 7.2.8 The material in the filter holder is defined as the solid phase of the waste, and the filtrate is defined as the liquid phase. Weigh the filtrate. The liquid phase may now be either analyzed (See Section 7.2.12) or stored at $4{ }^{\circ} \mathrm{C}$ until time of analysis.

NOTE: Some wastes, such as oily wastes and some paint wastes, will obviously contain some material. that appears to be a liquid. Even after applying vacuum or pressure filtration, as outlined in Section 7.2.7, this material may not filter. If this is the case. the material within the filtration device is defined as a solid and is carried through the extraction as a solid. Do not replace the original filter with a fresh filter under any circumstances. Use only one fijter.

7.2.9 If the waste contains $<0.5 \%$ dry solids (see Section 7.1.2), proceed to scction 7.2.13. If the waste contains $>0.5 \%$ dry solids (see Section 7.1.1 or 7.1.2), and if particle size reduction of the solid was needed in Section 7.1.3, proceed to Section 7.2.10. If the waste as received passes a $9.5 \mathrm{~mm}$ sieve, quantitatively transfer the solid material into the extractor bottle along with the filter used to separate the initial liquid from the solid phase, and proceed to Section 7.2.11.

7.2.10 Prepare the solid portion of the waste for extraction by crushing, cutting, or grinding the waste to a surface area or particle size as described in section 7.1.3. When the surface area or particle size has been appropriately altered, quantitatively transfer the solid

CD-ROM $1311-12$

Revision 0

JuTy 1992 
material into an extractor bottle. Include the filter used to separate the initial liquid from the solid phase.

NOTE: Sieving of the waste is not normaliy required. Surface area requirements are meant for filamentous (e.g., paper, cloth) and similar waste materials. Actual measurement of surface area is not recommended. If sieving is necessary, a Teflon coated sieve should be used to avoid contamination of the sample.

7.2.11 Determine the amount of extraction fluid to add to the extractor vessel as follows:

$20 \times$ percent solids (Section 7.1.1) $\times$ weight of waste filtered (Section 7.2 .5 or 7.2 .7 )

Weight of extraction fluid

100

Slowly add this amount of appropriate extraction fluid (see Section 7.1.4) to the extractor vessel. Close the extractor bottle tightly (it is recommended that Teflon tape be used to ensure a tight seal), secure in rotary agitation device, and rotate at $30 \pm 2 \mathrm{rpm}$ for $18 \pm 2$ hours. Ambient temperature (i.e., temperature of room in which extraction takes place) shall be maintained at $23 \pm 2{ }^{\circ} \mathrm{C}$ during the extraction period.

NOTE : -

As agitation continues, pressure may build up within the extractor bottle for some types of wastes (e.q., limed or calcium carbonate containing waste may evolve gases such as carbon dioxide). To relieve excess pressure, the extractor bottle may be periodically opened (e.g., after 15 minutes, 30 minutes, and 1 hour) and vented into a hood.

7.2.12 Following the $18 \pm 2$ hour extraction, separate the material in the extractor vessel into its component liquid and solid phases by filtering through a new glass fiber filter, as outlined in Section 7.2.7. For final fi]tration of the TCLP extract, the glass fiber filter may be changed, if necessary, to facilitate filtration. Filter(s) shall be acid-washed (see Section 4.4) if evaluating the mobility of metals.

\subsubsection{Prepare the TCLP extract as follows:}

7.2.13.1 If the waste contained no initial liquid phase, the filtered liquid material obtained from Section 7.2 .12 is defined as the TCLP extract. Proceed to Section 7.2.14.

7.2.13.2 If compatible (e.g., multiple phases will not result on combination), combine the filtered liquid resulting from Section 7.2.12 with the initial liquid phase of the waste obtained in Section 7.2.7. This combined liquid is defined as the TCLP extract. Proceed to Section 7.2.14. 
7.2.13.3 If the initial liquid phase of the waste, as obtained from Section 7.2.7, is not or may not be compatible with the filtered liquid resulting from Section 7.2.12, do not combine these liquids. Analyze these liquids, collectively defined as the TCLP extract, and combine the results mathematically, as described in Section 7.2.14.

7.2.14 Following collection of the TCLP extract, the pH of the extract should be recorded. Immediately aliquot and preserve the extract for analysis. Metals aliquots must be acidificd with nitric acid to $\mathrm{pH}<2$. If precipitation is observed upon addition of nitric acid to a small aliquot of the extract, then the remaining portion of the extract for metals analyses shall not be acidified and the extract shall be analyzed as soon as possible. All other aliquots must be stored under refrigeration $\left(4{ }^{\circ} \mathrm{C}\right)$ until analyzed. The TCLP extract shall be prepared and analyzed according to appropriate analytical methods. TCLP extracts to be analyzed for metals shall be acid digested except in those instances where digestion causes loss of metallic analytes. If an analysis of the undigested extract shows that the concentration of any regulated metallic analyte exceeds the regulatory level, then the waste is hazardous and digestion of the extract is not necessary. However, data on undigested extracts alone cannot be used to demonstrate that the waste is not hazardous. If the individual phases are to be analyzed separately, determine the volume of the individual phases (to $\pm 0.5 \%$ ), conduct the appropriate analyses, and combine the results mathematically by using a simple volume-weighted average:

Final Analyte Concentration $=\frac{\left(V_{1}\right)\left(C_{1}\right)+\left(V_{2}\right)\left(C_{2}\right)}{V_{1}+V_{2}}$

where:

$V_{1}=$ The volume of the first phase (L).

$C_{1}=$ The concentration of the analyte of concern in the first phase (mg/L).

$V_{2}=$ The volume of the second phase (L).

$\mathrm{C}_{2}=$ The concentration of the analyte of concern in the second phase $(\mathrm{mg} / \mathrm{L})$.

7.2.15 Compare the analyte concentrations in the TCLP extract with the levels identified in the appropriate regulations. Refer to Section 8.0 for quality assurance requirements.

\subsection{Procedure When Volatiles are Involved}

Use the ZHE device to obtain TCLP extract for analysis of volatile compounds only. Extract resulting from the use of the ZHE shall not be used to evaluate the mobility of nonvolatile analytes (e.g., metals, pesticides, etc.).

The ZHE device has approximately a $500 \mathrm{~mL}$ internal capacity. The ZHE can thus accommodate a maximum of 25 grams of solid (defined as that fraction of a

CD-ROM

$1311-14$

Revision 0

July 1992 
sample from which no additional liquid may be forced out by an applied pressure of 50 psi), due to the need to add an amount of extraction fluid equal to 20 times the weight of the solid phase.

Charge the ZHE with sample only once and do not open the device until the final extract (of the solid) has been collected. Repeated filling of the ZHE to obtain 25 grams of solid is not permitted.

Do not allow the waste, the initial liquid phase, or the extract to be exposed to the atmosphere for any more time than is absolutely necessary. Any manipulation of these materials should be done when cold $\left(4^{\circ} \mathrm{C}\right)$ to minimize loss of volatiles.

7.3.1 Pre-weigh the (evacuated) filtrate collection container (See Section 4.6) and set aside. If using a TEDLAR bag, express all liquid from the ZHE device into the bag, whether for the initial or final liquid/solid separation, and take an aliquot from the liquid in the bag for analysis. The containers listed in Section 4.6 are recommended for use under the conditions stated in Sections 4.6.1 - 4.6.3.

7.3.2 Place the ZHE piston within the body of the ZHE (it may be helpful first to moisten the piston 0-rings slightly with extraction fluid). Adjust the piston within the ZHE body to a height that will minimize the distance the piston will have to move once the ZHE is charged - with sample (based upon sample size requirements determined from Section 7.3. Section 7.1.1 and/or 7.1.2). Secure the gas inlet/outlet flange (bottom flange) onto the ZHE body in accordance with the manufacturer's instructions. Secure the glass fiber filter between the support screens and set aside. Set liquid inlet/outlet flange (top flange) aside.

7.3.3 If the waste is $100 \%$ solid (see Section 7.1.1). Weigh out a subsample ( 25 gram maximum) of the waste, record weight, and proceed to Section 7.3 .5 .

7.3.4 If the waste contains $<0.5 \%$ dry solids (Section 7.1 .2 ), the liquid portion of waste, after filtration, is defined as the TCLP extract. Filter enough of the sample so that the amount of filtered liquid will support all of the volatile analyses required. For wastes containing $\geq 0.5 \%$ dry solids (Sections 7.1.1 and/or 7.1.2), use the percent solids information obtained in Section 7.1.1 to determine the optimum sample size to charge into the ZHE. The recommended sample size is as follows:

7.3.4.1 For wastes containing $<5 \%$ solids (see Section 7.1.1), weigh out a 500 gram subsample of waste and record the weight.

7.3.4.2 For wastes containing $\geq 5 \%$ solids (see Section 7.1.1), determine the amount of waste to charge into the ZHE as follows:

CD-ROM

$1311-15$

Revision 0

July 1992 
We'ight of waste to charge $\mathrm{ZHE}=\frac{25}{\text { percent solids (Section 7.1.1) }} \times 100$

Weigh out a subsample of the waste of the appropriate size and record the weight.

7.3.5 If particle size reduction of the solid portion of the waste was required in Section 7.1.3, proceed to Section 7.3.6. If particle size reduction was not required in section 7.1 .3 . proceed to Section 7.3.7.

7.3.6 Prepare the waste for extraction by crushing, cutting, or grinding the solid portion of the waste to a surface area or particle size as described in Section 7.1.3. Wastes and appropriate reduction equipment should be refrigerated, if possible, to $4{ }^{\circ} \mathrm{C}$ prior to particle size reduction. The means used to effect particle size reduction must not generate heat in and of itself. If reduction of the solid phase of the waste is necessary, exposure of the waste to the atmosphere should be avoided to the extent possible.

NOTE: Sieving of the waste is not recommended due to the possibility that volatiles may be lost. The use of an appropriately graduated ruler is recommended as an acceptable alternative. Surface area - requirements are meant for filamentous (e.g., paper, cloth) and similar waste materials. Actual measurement of surface area is not recommended.

When the surface area or particle size has been appropriately altered, proceed to Section 7.3.7.

7.3.7 Waste slurries need not be allowed to stand to permit the solid phase to settle. Do not centrifuge wastes prior to filtration.

7.3.8 Quantitatively transfer the entire sample (liquid and solid phases) quickly to the ZHE. Secure the filter and support screens onto the top flange of the device and secure the top flange to the $\mathrm{ZHE}$ body in accordance with the manufacturer's instructions. Tighten all ZHE fittings and place the device in the vertical position (gas inlet/outlet flange on the bottom). Do not attach the extract collection device to the top plate.

NOTE: If waste material ( $>1 \%$ of original sample weight) has obviously adhered to the container used to transfer the sample to the ZHE, determine the weight of this residue and subtract it from the sample weight determined in Section 7.3.4 to determine the weight of the waste sample that will be filtered.

Attach a gas line to the gas inlet/outlet valve (bottom flange) and, with the liquid inlet/outlet valve (top flange) open, begin applying gentle pressure of 1-10 psi (or more if necessary) to force a 11 headspace 
slowly out of the ZHE device into a hood. At the first appearance of liquid from the liquid inlet/outlet valve, quickly close the valve and discontinue pressure. If filtration of the waste at $4{ }^{\circ} \mathrm{C}$ reduces the amount of expressed liquid over what would be expressed at room temperature, then allow the sample to warm up to room temperature in the device before filtering. If the waste is $100 \%$ solid (see Section 7.1 .1 ), slowly increase the pressure to a maximum of 50 psi to force most of the headspace out of the device and proceed to Section 7.3.12.

7.3.9 Attach the evacuated pre-weighed filtrate collection container to the liquid inlet/outlet valve and open the valve. Begin applying gentle pressure of 1-10 psi to force the liquid phase of the sample into the filtrate collection container. If no additional liquid has passed through the filter in any 2 minute interval. slowly increase the pressure in $10 \mathrm{psi}$ increments to a maximum of $50 \mathrm{psi}$. After each incremental increase of 10 psi, if no additional liquid has passed through the filter in any 2 minute interval, proceed to the next 10 psi increment. When liquid flow has ceased such that continued pressure filtration at 50 psi does not result in any additional filtrate within a 2 minute period. stop the filtration. Close the liquid inlet/outlet valve, discontinue pressure to the piston, and disconnect and weigh the filtrate collection container.

NOTE: Instantaneous application of high pressure can degrade the glass fiber filter and may cause premature plugging.

7.3.10 The material in the ZHE is defined as the solid phase of the waste and the filtrate is defined as the liquid phase.

NOTE: Some wastes, such as oily wastes and some paint wastes, will obviously contain some material that appears to be a liquid. Even after applying pressure filtration, this material will not filter. If this is the case, the material within the filtration device is defined as a solid and is carried through the TCLP extraction as a solid.

If the original waste contained $<0.5 \%$ dry solids (see Section 7.1.2), this filtrate is defined as the TCLP extract and is analyzed directly. . Proceed to Section 7.3.15.

7.3.11 The liquid phase may now be either analyzed immediately (See Sections 7.3 .13 through 7.3 .15 ) or stored at $4{ }^{\circ} \mathrm{C}$ under minima? headspace conditions until time of analysis. Determine the weight of extraction fluid 非 to add to the ZHE as follows:

$20 \times$ percent solids (Section 7.1.1) $\times$ weight of waste filtered (Section 7.3 .4 or 7.3 .8 )

Weight of extraction fluid $=$ 
7.3.12 The following Sections detail how to add the appropriate amount of extraction fluid to the solid material within the ZHE and agitation of the ZHE vessel. Extraction fluid 非 is used in all cases (See Section 5.7).

7.3.12.1 With the ZHE in the vertical position, attach a line from the extraction fluid reservoir to the liquid inlet/outlet valve. The line used shall contain fresh extraction fluid and should be preflushed with fluid to eliminate any air pockets in the line. Release gas pressure on the ZHE piston (from the gas inlet/outlet valve), open the liquid inlet/outlet valve. and begin transferring extraction fluid (by pumping or similar means) into the ZHE. Continue pumping extraction fluid into the ZHE until the appropriate amount of fluid has been introduced into the device.

7.3.12.2 After the extraction fluid has been added. immediately close the liquid inlet/outlet valve and disconnect the extraction fluid line. Check the ZHE to ensure that all valves are in their closed positions. Manually rotate the device in an end-over-end fashion 2 or 3 times. Reposition the ZHE in the vertical position with the liquid inlet/outlet valve on top. Pressurize the ZHE to 5-10 psi (if necessary) and slowly open the liquid inlet/outlet valve to bleed out any headspace (into a hood) that may have been introduced due to the addition of extraction fluid. This bleeding shall be done quickly and shall be stopped at the first appearance of liquid from the valve. Re-pressurize the ZHE with 5-10 psi and check all ZHE fittings to ensure that they are closed.

7.3.12.3 Place the ZHE in the rotary agitation apparatus (if it is not already there) and rotate at $30 \pm 2 \mathrm{rpm}$ for $18 \pm$ 2 hours. Ambient temperature (i.e., temperature of room in which extraction occurs) shall be maintained at $23 \pm 2{ }^{\circ} \mathrm{C}$ during agitation.

7.3.13 Following the $18 \pm 2$ hour agitation period, check the pressure behind the ZHE piston by quickly opening and closing the gas inlet/outlet valve and noting the escape of gas. If the pressure has not been maintained (i.e., no gas release observed), the device is leaking. Check the ZHE for leaking as specified in Section 4.2.1, and perform the extraction again with a new sample of waste. If the pressure within the device has been maintained, the material in the extractor vessel is once again separated into its component liquid and solid phases. If the waste contained an initial liquid phase, the liquid may be filtered directly into the same filtrate collection container (i.e., TEDLAR ${ }^{\circledast}$ bag) holding the initial liquid phase of the waste. A separate filtrate collection container must be used if combining would create multiple phases, or there is not enough volume left within the filtrate collection container. Filter through the glass fiber filter, using the ZHE device as discussed in Section 7.3.9. All extract shall be filtered and collected if the 
TEDLAR bag is used, if the extract is multiphasic, or if the waste contained an initial liquid phase (see Sections 4.6 and 7.3.1).

NOTE: An in-line glass fiber filter may be used to filter the material within the ZHE if it is suspected that the glass fiber filter has been ruptured.

7.3.14 If the original waste contained no initial liquid phase. the filtered liquid material obtained from Section 7.3 .13 is defined as the TCLP extract. If the waste contained an initial liquid phase, the filtered liquid material obtained from Section 7.3.13 and the initial liquid phase (Section 7.3.9) are collectively defined as the TCLP extract.

7.3.15 Following collection of the TCLP extract, immediately prepare the extract for analysis and store with minimal headspace at $4{ }^{\circ} \mathrm{C}$ until analyzed. Analyze the TCLP extract according to the appropriate analytical methods. If the individual phases are to be analyzed separately (i.e.. are not miscible). determine the volume of the individual phases (to $0.5 \%$ ), conduct the appropriate analyses, and combine the results mathematically by using a simple volume-weighted average:

$$
\begin{aligned}
& \text { Final Anatyte } \\
& \text { Eoncentration }
\end{aligned}=\frac{\left(V_{1}\right)\left(C_{1}\right)+\left(V_{2}\right)\left(C_{2}\right)}{V_{1}+V_{2}}
$$

where:

$V_{1}=$ The volume of the first phases (L).

$C_{1}=$ The concentration of the analyte of concern in the first phase $(\mathrm{mg} / \mathrm{L})$.

$V_{2}=$ The volume of the second phase $(L)$.

$\mathrm{C}_{2}=$ The concentration of the analyte of concern in the second phase (mg/L).

7.3.16 Compare the analyte concentrations in the TCLP extract with the levels identified in the appropriate regulations. Refer to Section 8.0 for quality assurance requirements.

\subsection{QUALITY ASSURANCE}

8.1 A minimum of one blank (using the same extraction fluid as used for the samples) must be analyzed for every 20 extractions that have been conducted in an extraction vessel.

8.2 A matrix spike shall be performed for each waste type (e.g... wastewater treatment sludge, contaminated soil, etc.) unless the result exceeds the regulatory level and the data are being used solely to demonstrate that the waste property exceeds the regulatory level. A minimum of one matrix spike must be analyzed for each analytical batch. As a minimum, follow the matrix spike addition guidance provided in each analytical method.

CD-ROM

$1311-19$

Revision 0

JuTy 1992 
8.2.1 Matrix spikes are to be added after filtration of the TCLP extract and before preservation. Matrix spikes should not be added prior to TCLP extraction of the sample.

8.2.2 In most cases, matrix spikes should be added at a concentration equivalent to the corresponding regulatory level. If the analyte concentration is less than one half the regulatory level, the spike concentration may be as low as one half of the analyte concentration, but may not be not less than five times the method detection limit. In order to avoid differences in matrix effects, the matrix spikes must be added to the same nominal volume of TCLP extract as that which was analyzed for the unspiked sample.

8.2.3 The purpose of the matrix spike is to monitor the performance of the analytical methods used, and to determine whether matrix interferences exist. Use of other internal calibration methods, modification of the analytical methods, or use of alternate analytical methods may be needed to accurately measure the analyte concentration in the TCLP extract when the recovery of the matrix spike is below the expected analytical method performance.

formula:

8.2.4 Matrix spike recoveries are calculated by the following

$\% R(\% R e c o v e r y)=100\left(X_{s}-X_{u}\right) / K$

where:

$X_{s}=$ measured value for the spiked sample.

$X_{u}=$ measured value for the unspiked sample, and

$k=$ known value of the spike in the sample.

8.3 All quality control measures described in the appropriate analytical methods shall be followed.

8.4 The use of internal calibration quantitation methods shall be employed for a metallic contaminant if: (1) Recovery of the contaminant from the TCLP extract is not at least $50 \%$ and the concentration does not exceed the regulatory level, and (2) The concentration of the contaminant measured in the extract is within $20 \%$ of the appropriate regulatory level.

8.4.1. The method of standard additions shall be employed as the internal calibration quantitation method for each metallic contaminant.

8.4.2 The method of standard additions requires preparing calibration standards in the sample matrix rather than reagent water or blank solution. It requires taking four identical aliquots of the solution and adding known amounts of standard to three of these aliquots. The forth aliquot is the unknown. Preferably, the first addition should be prepared so that the resulting concentration is approximately $50 \%$ of the expected concentration of the sample. The second and third additions should be prepared so that the concentrations are approximately $100 \%$ and 
$150 \%$ of the expected concentration of the sample. All four aliquots are maintained at the same final volume by adding reagent water or a blank solution, and may need dilution adjustment to maintain the signals in the linear range of the instrument technique. All four aliquots are analyzed.

8.4.3 Prepare a plot, or subject data to linear regression, of instrument signals or external-calibration-derived concentrations as the dependant variable $(y$-axis) versus concentrations of the additions of standard as the independent variable (x-axis). Solve for the intercept of the abscissa (the independent variable, $x$-axis) which is the concentration in the unknown.

8.4.4 Alternately, subtract the instrumental signal or externalcalibration-derived concentration of the unknown (unspiked) sample from the instrumental signals or external-calibration-derived concentrations of the standard additions. Plot or subject to linear regression of the corrected instrument signals or external-calibration-derived concentrations as the dependant variable versus the independent variable. Derive concentrations for unknowns using the internal calibration curve as if it were an external calibration curve.

8.5 Samples must undergo TCLP extraction within the following time periods:

\begin{tabular}{|c|c|c|c|c|}
\hline \multicolumn{5}{|c|}{ SAMPLE MAXIMUM HOLDING TIMES [DAYS] } \\
\hline & $\begin{array}{l}\text { From: } \\
\text { Field } \\
\text { collection } \\
\text { To: } \\
\text { TCLP } \\
\text { extraction }\end{array}$ & $\begin{array}{l}\text { From: } \\
\text { TCLP } \\
\text { extraction } \\
\text { To: } \\
\text { Preparative } \\
\text { extraction }\end{array}$ & $\begin{array}{l}\text { From: } \\
\text { Preparative } \\
\text { extraction } \\
\text { To: } \\
\text { Determinative } \\
\text { analysis }\end{array}$ & $\begin{array}{l}\text { Total } \\
\text { elapsed } \\
\text { time }\end{array}$ \\
\hline $\begin{array}{l}\text { Volatiles } \\
\text { Semi-volatiles } \\
\text { Mercury } \\
\text { Metals, except } \\
\text { mercury }\end{array}$ & $\begin{array}{r}14 \\
14 \\
28 \\
180\end{array}$ & $\begin{array}{l}N \\
N\end{array}$ & $\begin{array}{r}14 \\
40 \\
28 \\
180\end{array}$ & $\begin{array}{r}28 \\
61 \\
56 \\
360\end{array}$ \\
\hline
\end{tabular}

$N A=$ Not applicable

If sample holding times are exceeded, the values obtained will be considered minimal concentrations. Exceeding the holding time is not acceptable in establishing that a waste does not exceed the regulatory level. Exceeding the holding time will not invalidate characterization if the waste exceeds the regulatory level.

CD-ROM $1311-21$

Revision 0

JuTy 1992 


\subsection{METHOD PERFORMANCE}

9.1 Ruggedness. Two ruggedness studies have been performed to determine the effect of various perturbations on specific elements of the TCLP protocol. Ruggedness testing determines the sensitivity of small procedural variations which might be expected to occur during routine laboratory application.

9.1.1 Metals - The following conditions were used when lcaching a waste for metals analysis:

\begin{tabular}{|c|c|}
\hline \multicolumn{2}{|c|}{ Varying Conditions } \\
\hline Liquid/Solid ratio & $19: 1$ vs. $21: 1$ \\
\hline Extraction time & 16 hours vs. 18 hours \\
\hline Headspace & $20 \%$ vs. $60 \%$ \\
\hline Buffer 非 acidity & $190 \mathrm{meq}$ vs. $210 \mathrm{meq}$ \\
\hline Acid-washed filters & yes vs. no \\
\hline Filter type & $\begin{array}{l}0.7 \mu \mathrm{m} \text { glass fiber vs. } 0.45 \mu \mathrm{m} \\
\text { vs. polycarbonate }\end{array}$ \\
\hline Bottle type & borosilicate vs. flint glass \\
\hline
\end{tabular}

of the seven method variations examined, acidity of the extraction fluid had the greatest impact on the results. Four of 13 metals from an API separator sludge/electroplating waste (API/EW) mixture and two of three metals from an ammonia lime still bottom waste were extracted at higher levels by the more acidic buffer. Because of the sensitivity to pH changes, the method requires that the extraction fluids be prepared so that the final $\mathrm{pH}$ is within \pm 0.05 units as specified.

9.1.2 Volatile Organic Compounds - The following conditions were used when leaching a waste for VOC analysis:

\begin{tabular}{|c|c|}
\hline \multicolumn{2}{|c|}{ Varying Conditions } \\
\hline Liquid/Solid ratio & $19: 1$ vs. $21: 1$ \\
\hline Headspace & $0 \%$ VS. $5 \%$ \\
\hline Buffer 非 acidity & $60 \mathrm{meq}$ vs. $80 \mathrm{meq}$ \\
\hline Method of storing extract & Syringe vs. Tedlar bag \\
\hline Aliquotting & yes vs. no \\
\hline Pressure behind piston & 0 psi vs. 20 psi \\
\hline
\end{tabular}

CD-ROM

$1311-22$

Revision 0

July 1992 
None of the parameters had a significant effect on the results of the ruggedness test.

9.2 Precision. Many TCLP precision (reproducibility) studies have been performed, and have shown that, in general, the precision of the TCLP is comparable to or exceeds that of the EP toxicity test and that method precision is adequate. One of the more significant contributions to poor precision appears to be related to sample homogeneity and inter-laboratory variation (due to the nature of waste materials).

9.2.1 Metals - The results of a multi-laboratory study are shown in Table 6, and indicate that a single analysis of a waste may not be adequate for waste characterization and identification requirements.

9.2.2 Semi-Volatile organic compounds - The results of two studies are shown in Tables 7 and 8 . Single laboratory precision was excellent with greater than 90 percent of the results exhibiting an RSD less than 25 percent. Over 85 percent of all individual compounds in the multi-laboratory study fell in the RSD range of 20 - 120 percent. Both studies concluded that the TCLP provides adequate precision. It was also determined that the high acetate content of the extraction fluid did not present problems (i.e., column degradation of the gas chromatograph) for the analytical conditions used.

- 9.2.3 Volatile Organic Compounds - Eleven Taboratories participated in a collaborative study of the use of the ZHE with two waste types which were fortified with a mixture of VOCs. The results of the collaborative study are shown in Table 9. Precision results for Vocs tend to occur over a considerable range. However, the range and mean RSD compared very closely to the same collaborative study metals results in Table 6. Blackburn and Show concluded that at the $95 \%$ level of significance: 1) recoveries among laboratories were statistically similar, 2) recoveries did not vary significantly between the two sample types, and 3 ) each laboratory showed the same pattern of recovery for each of the two samples.

\subsection{REFERENCES}

1. Blackburn, W.B. and Show, I. "Collaborative Study of the Toxicity Characteristics Leaching Procedure (TCLP)." Draft Final Report, Contract No. 6803-1958, S-Cubed, November 1986.

2. Newcomer, L.R., Blackburn, W.B., Kimmel1, T.A. "Performance of the Toxicity Characteristic Leaching Procedure." Wilson Laboratories, S-Cubed, U.S. EPA, December 1986.

3. Williams, L.R., Francis, C.W.: Maskarinec, M.P., Taylor D.R., and Rothman, N. "Single-Laboratory Evaluation of Mobility Procedure for Solid Waste." EMSL. ORNL, S-Cubed, ENSECO.

CD-ROM $1311-23$

Revision 0

July 1992 


\section{APPENDIX C}

The DEV S4 Metal Extraction Procedure

$6 n$ 


\section{Field of application}

The method is applicable to solid, paste-like and sludgelike materials. In the case of sludges which release water when left to stand, i.e. which form a sludge/water interface (dilute sludges), it is advisable to condition such specimens as described in subciausa 6.4 .

\section{Seope}

This method is intended for use in determining from among the materials for examination, those that are dissolved in water under the conditions of this method. Determination of these materials by zype and mass is intended to provide information as to what adverse effects or risks to rivers and lakes oan occur when these materials are stored or dumped in such a manner that they may come into contact with water. The method can however produce values that cannot be obtained under canditions of dumping or only over long intervals of time. The harm caused by mater ial dumped or intended to be dumped cannot be detarmined solely on the basis of analytical values of the eluate.

For assessing the probable behaviour of dumped material and the dumping conditions necessary in order to protecr ground and surface water, it is necessary to take other criteria into account. These include for example the ratio of the leachable portion to the total content of a particular material in the dry residue of the sludge.

Other important factors are the permeability to water of the dumped material and the underiying soil, the probably annual quantity of water seeping through the dumped. material, the quality of the ground water concerned, its level, the thickness of the ground water layer and its direction of flow, and possibly also its velocity of flow. in some cases, it is also necessary to take account of possible interactions with other deposited material or of the seeping water with the underlying soil. The highly complex behaviour of the deposited material can there. fore anly be assessed by a specialist in any particular case.

\section{Principles}

The sample material is leached with water under defined conditions. Then the undissolved components are separated by filuration. The concentrations of the components to be determined are then measured in thie filtrate using the methods of water analysis.

Since the materials, when they are dumped, repeatedly come into contact with fresh rain water or ground wazer, it is sometimes useful to repeat the leaching process several times. When this is done. the following three cases have to be distinguished.

The sample material contains

a) materials that are so readily soluble or present in such small mass that they are already largely leached out after the first leaching process; in such a case one single leaching cycle is sufficient.

b) materials that are less readily soluble or are contained in such large mass that only part of them goes into solution even after several leaching cvcles,

c) materials whose solubility behaviour varies during the examination.

Repeated leaching may be necessary in cases bl ano c) $[1]$

Note. It may be useful, in order to provide an answer to particular questions, to use other leaching liquids than water. Examples of such cases are investigations of the interaction between sedimem and surface water and investigation of possible interactions within the body of the dumped material.

\section{Designation}

The method for determining the leachability by water (S 4) shall be designated as follows:

$$
\text { Method DIN } 38414-54
$$




\section{Apparatus and leaching liquid}

Wide-neck' flasks of glass or plastics, normally with a nominal volume of $2000 \mathrm{ml}$.

Shaking and mixing device.

Filter apparatus, if necessary a pressure fitration apparatus with stirrer (see figure).

Centrifuge.

Device for measuring electrical conductivity; see method DIN 38404 - C8.

pH meter, e.g. as in DIN 19261.

Distilled water or water of equivalent purity.

\section{Preparation of sample}

\subsection{Sampling}

In all cases take care to obtain a representative test portion of the material under examination. For this purpose, the instructions given in sheet $S 1$ of the German Standards Methods [2] shall be complied with.

See [3] and [4] for further material-related information.

\subsection{Size reduction}

In general the material shall be examined in the state in which it is dumped. Size reduction shall only be carried out to the extent necessary for sampling and for carrying out the test; in general, size reduction shall only be carried out if the particle size is more than $10 \mathrm{~mm}$ : on no account shall the material be ground. Any fine particles produced during the size reduetion shall be mixed back inzo the sample.

\subsection{Preparation of solid or paste-like samples}

The initial mass of the original sample for leaching shall be such that it contains about $100 \mathrm{~g}$ of dry mass. It is therefore necessary to make a separate determination of the dry residue by method DIN $38414-S 2$. If a substantially larger quantity of sample is used in the case of inhomogeneous material or lumpy material mix the sample with a correspondingly larger volume of water (see clause 7).

\subsection{Preparation of dilute sludge samples}

Dilute sludges, which generally contain less than $5 \%$ dry residue. lose water when left to stand. If test portions are used, it is necessary to have homogeneous samples: if this condition cannot be met, examine the complete sample. Dilure sludges shall be filtered or centrifuged before leaching: the filtration residue, whose ory mass shall be about $100 \mathrm{~g}$, shall then be leached. The mass of sludge used for the examination will therefore depend on the dry residue of the filtration residue (see method DIN 38414-S 2). The filtrate or supernatant liquor obtained by filtering or centrifuging the dilute sludge shall be clear. Measure the complete volume of the filtrate or the supernatant liquor obtained in the centrifuge tube (sludge liquor) and, if necessary, also its density. Determine the mass of the dried filtration residue or the sediment in the centrifuge tube.

\section{Procedure}

Leaching shall be carried out at room temperature in a $200 \mathrm{ml}$ wide-neck flask. The choice of flask material will depend on the materials being determined. The leaching time shall be 24 hours.

The sample shall be leached one or more times according to the object of the determination.

Note. Reactions occurring during this time need not be recorded separately. By making measurements of electrical conductivity from time to time, it is possible to determine whether further ionogenic substances have dissolved.

\subsection{Single leaching eycle}

Place the original sample or the sample conditioned as described in subclauses 6.2 to 6.4, containing about $100 \mathrm{~g}$ of dry mass, in a wide-neck flask of appropriate volume and weigh it to the nearest $1 \mathrm{~g}$, then dilute with 11 of water (as described in clause 5). Slowly zurn the flask upside down a number of times or shake it so that the sample remains constantly in motion but avoiding as far as possible any further size reduction, for example by abrasion. After the leaching period has elapsed. separate the undissolved residue by filtration or centrifugation. The solid and liquid phases shall be separated as far as possible under the given conditions. It is not permitred to rinse the sample afterwards with water or other liquids. Measure the $\mathrm{pH}$ value and the electrical conductivity of the filtrate or centrifugate.

\subsection{Repeated leaching}

Add a further $1 \mathrm{l}$ of water to the residue of the sample left after following the procedure as described in sub. clause 7.1 ; then follow the procedure again as in subclause 7.1. If necessary. repeat the leaching procedure again one or more times.

\subsection{Further treatment of the eluate}

The eluate obtained as described in subclause 7.1 or 7.2 shall be completely clear. Otherwise, it shall be filtered again through a membrane filter of pore size $0,45 \mu \mathrm{m}$, that has been pre-washed with water las described in clause 5); it may be necessary to use a pressure filter apparatus with a stirrer (see figure) in order to remove finely dispersed matter from the eluate.

Measure the volume of the eluate in each case to the nearest $10 \mathrm{~mL}$.

Determine the concentrations of dissolved matter, using the methods of water analysis.

\section{Evaluation}

8.1 Calculate the proporion by mass of a leached sub. stance. referred to the original sludge, from equation (1):

$$
w_{\mathbb{S S}}=\frac{\beta \cdot V_{\mathrm{E}}}{m_{\mathrm{S}}}
$$

where

$w_{E S}$ is the proportion by mass of a substance leached from the aqueous sludge sample. in $\mathrm{mg} / \mathrm{kg}$ :

$\beta \quad$ is the mass concentration of the leached substance in the eluate, in $\mathrm{mg} / \mathrm{l}$ :

$V_{E}$ is the volume of the filtered eluate, in L;

$m_{\mathrm{S}}$ is the initial mass of the original sample of the aqueous sludge, in $\mathrm{kg}$. 
Note. In the case of repeated leaching, if the eluate is examined each time, $w_{E S}$ is the sum of the individual determinations. In the case of a dilute sludge, if the separated sludge liquor is examined for the proporion by mass of a substance ( $w_{0}$. see table). the mass concentration of this sub. stance in the sludge liquor shall be given in equa. tion (1) for $\beta$, and the volume of the separated sludge liquor for $V_{E}$ and the initial mass of the sample for $m_{S}$.

8.2 Calculate the proportion by mass of the leached substance, referred to the dry residue of the sample from equation (2).

$$
w_{E T}=\frac{w_{E S} \cdot f}{w_{T}}
$$

where

$w_{E T}$ is the proportion by mass of the leached substance in the dry residue of the sample under examination, in $\mathrm{mg} / \mathrm{kg}$ :

$w_{E S}$ is the proportion by mass of the leached substance in the aqueous sample, in $\mathrm{mg} / \mathrm{kg}$;

$w_{T}$ is the dry residue of the sample under examination. in \%:

$f$ is the conversion factor; $f=100 \%$.

8.3 If the ratio of the leachable part of the substance to the total amount of this substance in the dry residue of the sample is of interest, equation (3) applies:

$$
w_{R}=\frac{w_{E T} \cdot f}{w_{G T}}
$$

where

$w_{R}$ is the proportion by mass of the leachable substance, referred to its total mass in the dry residue of the sample, in \%;

$w_{E T}$ is the proportion by mass of the leached substance in the dry residue of the sample. in $\mathrm{mg} / \mathrm{kg}$;
$w_{G T}$ is the total mass of the substance in the dry residue of the non-leached sample, in $\mathrm{mg} / \mathrm{kg}$; it shall be determined by a separate analysis:

$f$ is the conversion factor: $f=100 \%$.

\section{Expression of the result}

Report the proportions by mass in the case of values nat exceeding $1 \mathrm{mg} / \mathrm{kg}$ to 2 significant places at the most. and in the case of values greater than $1 \mathrm{mg} / \mathrm{kg}$ to 3 signif. icant places at the most.

Examples:

Proportion by mass of the leachable zine in the sludge, $w_{E S}=2,2 \mathrm{mg} / \mathrm{kg}$.

Proportion by mass of the leachable 2 inc. referred to the dry residue of the sludge. $w_{\mathrm{ET}}=6.7 \mathrm{mg} / \mathrm{kg}$. Proportion by mass of the leachable zinc, expressed as a percentage of the total zinc content of the dry residue, $\omega_{R}<0,1 \%$.

Refer also to the information given in the sample form (Appendix A).

In addition, the following derails shall be given:

- method of preparation of the sample;

- number of leaching cycles;

- leaching temperature:

- pH value of sludge before leaching;

- pH value and electrical conductivity of the eluate.

All departures from this method. in particular with regard to the preparation of the sample in special cases, and any interference that may occur shall also be reported.

\section{Characteristics of method}

Inter-labcratory test [5j has shown that the margin of error of the various parameters is not small enough to permit differentiation between random errors and errors inherent in the procedure associated with the leaching process. 
Page 4 DIN 38414 Part 4

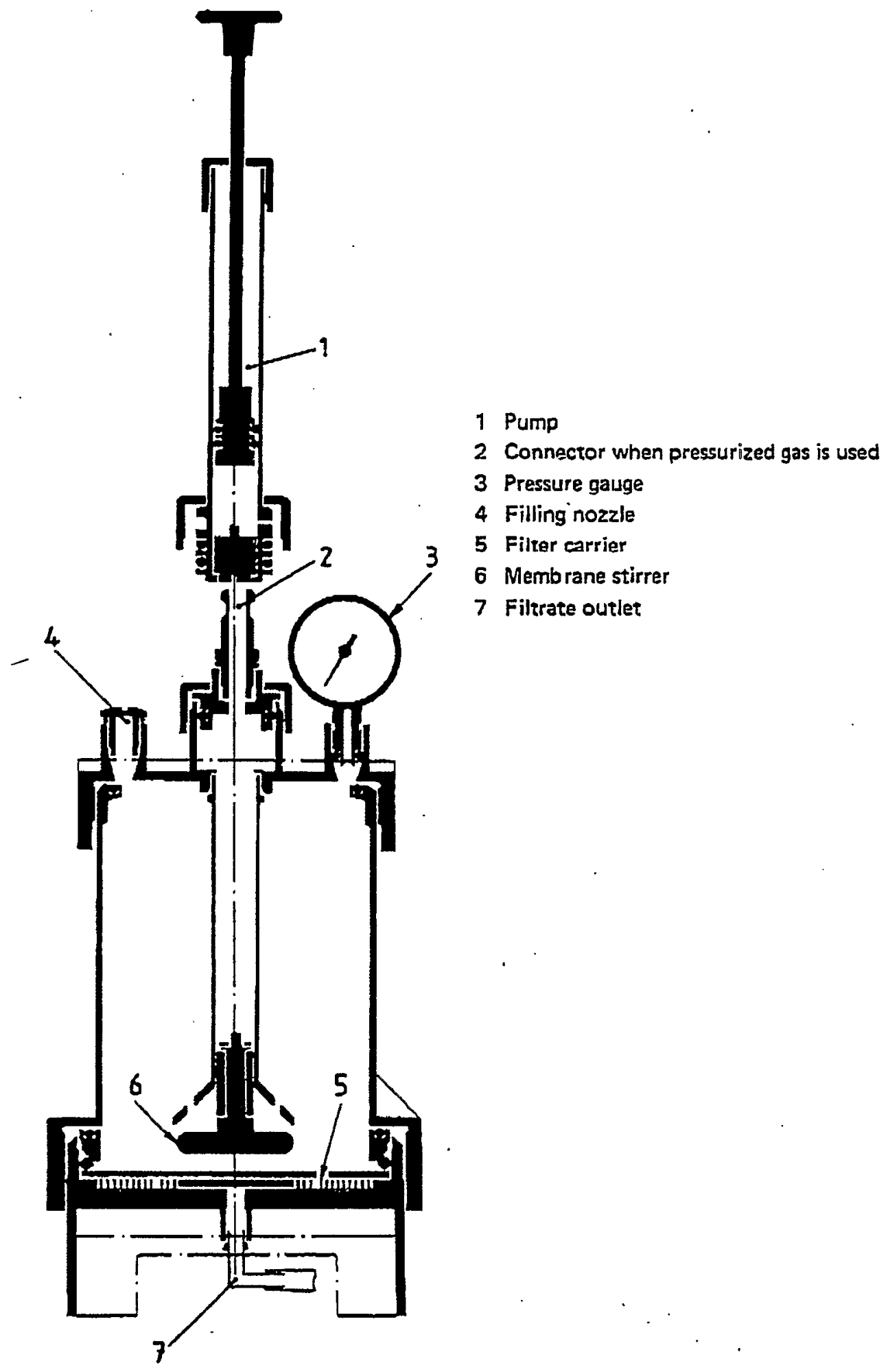

Figure. Pressure filtration using a stirring device 


\section{Sample form for leaching test}

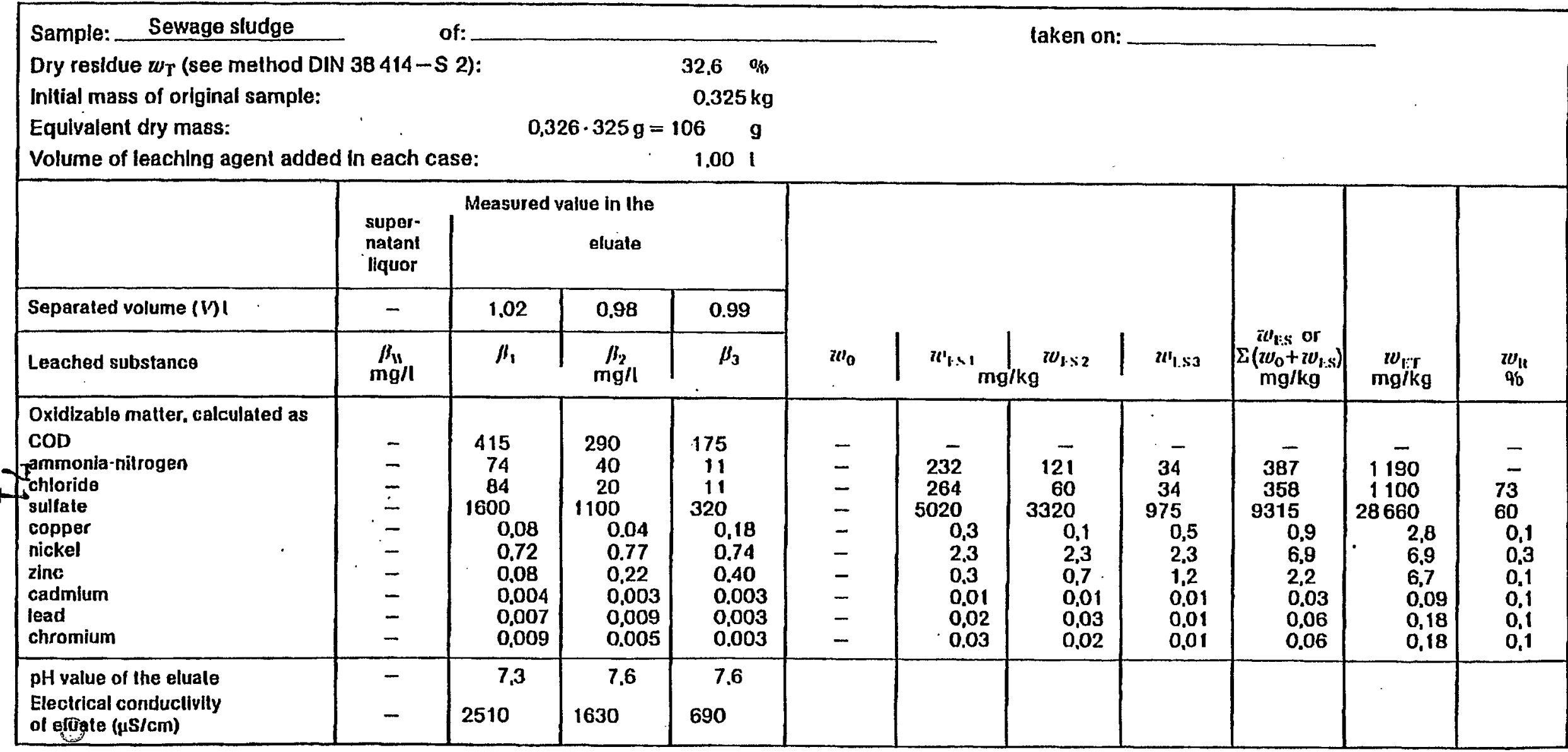

For the user of thls standard, appendix $A$ is not subject to the reproduction restrictlons mentioned in the marginal note. 
Page 6 DIN 38414 Part 4

\section{Standards and other documents referred to}

DIN 19261 pH measurement; terminology relating to measurement methods using galvanic cells

DIN 38404 Part 8 German standard methods for the examination of water. waste water and studge; physical and physico-chemical characteristics (group $\mathrm{C}$ ): determination of electrical conductivity (C B)

DIN 38414 Part 2 German standard methods for the examination of water, waste water snd sludge (group S); determination of water content and of dry residue and solids coment (S 2)

(1] Richtlinien für das Vorgehen bei physikalischen und chemischen Untersuchungen im Zusammenhang mit der Beseitigung von Abfällen der Länderarbeitsgemeinschaft Abfellbeseitigung (Code of practice for procedure to be followed in physical and chemical examinations relating to the disposal of waste of the Laender Joint commitre on waste disposal): Bestimmung der Eluierbarkeit von festen und schlammigen Abfällen mit Wasser (EW/77) (Determination of the leachability of solid and sludge-like wastes by water). Hösel/Kumpf. Technische Vorschriften für die Abfallbeseirigung (Technical rules for waste disposal), Erich-Schmidt-Verlag. No. 11-150 ff.

[2] German standard methods for the examination of water, waste water and sludge; group $S$, sludge and sediments, sampling (S 1).

[3] Klärschfammverordnung (Decree on sewage sludges) of 25 June 1982, Bundesgesetzblatt (Federal Law Gazette) 1982. Part 1, pp. 734-739.

[4] Richtlinien für das Voryehen bei physikalischen und chemischen Untersuchungen im Zusammenhang mit der Beseitigung von Abfallen der Länderarteitsgemeinschaft Abfallbeseitigung: Entnahme und Vorbereitung von Proben aus festen, schlammigen und flüssigen Abfällen (PN2/78) (Sampling and preparation of samples from solid, sludge-like and liquid wastes) and Grundregeln für die Entnahme von Proben aus Abfällen und abgelagerten Stoffen (PN2/78K) (Principles for sampling from wastes and dumped materiall. Hösel/Kumpi. Technische Vorschriften für die Abfal/. beseizigung, Erich-Schmidt-Verlag, No. 11-150 ff.

[5] Ringversuche zur Bestimmung der Eluibrbarkeit von Abfällen und Sch/ämmen mit Wasser (Interalaboratory tests for determining the leachability of wastes and sludges by water). v. Ammon, F. and Dietz, F. Z. Wasser, Abwasserforsch.. volume 74, 2, Pp. 51-60 (1981).

\section{Explanatory notes}

The present standard contains the German standard method "Determinazion of leachability by water" prepared jointly by the Normenausschuß Wasserwesen of DIN and Study group Wasserchemie of the Gesellschaft Deurscher Chemiker. Apart from such jointly prepared methods, all the standard methods prepared by Study group Wasserchemie and contained up to now in the loose-leaf publication "German standard methods for the examination of water, waste water and sludge" will be successively incorporated in the body of German standards, so that, after a transition period, all the standard methads will be available as DIN Standards. Standard methods published as DIN Standards are obtainable from Beuth Veriag GinbH either individually or grouped in volumes. The above-mentioned loose-leaf publication, containing the standard methods, will also continue to be published by Verlag Chemie GmbH, Weinheim.

Standards or draft standards bearing the group title "German standard methods for the examination of water, waste water and sludge" are classified under the following categories (main titles):

General data (group A)

(DIN 38402 )

Physical and physico-chemical characteristics (group C)

(DIN 38404 )

Anions (group D)

(DIN 38 405)

Cations (group E)

(DIN 38406 )

Jaintly determinable substances (group F)

(DIN 38407 )

Gaseous constituents (group G)

(DIN 38 408)

Summary indices of actions and substances (group H)

(DIN 38409 )

Microbiological methods (group K)

(DIN 38411 )

Test methods using water organisms (group L)

(DIN 38412 )

Individual components (group P)

(DIN 38413 )

Sludge and sediments (group S)

(DIN 38414$)$

Information on Parts of this standard that have already been published can be obtained from the offices of the Normen. ausschu\& Wassenwesen of DIN Deurschas Institut für Normung e. V., tol. (030) 26 01-423. or Beuth Verlag GmbH. Post. fach $1107 . D-1000$ Berlin 30.

\section{International Patent Classification}

G 01 N 33-13 


\section{APPENDIX D}

Exports from and Imports to the U.S. Under International and Bilateral Agreements 
SUPPORTING STATEMENT FOR

- EPA INFORMATION COLLECTION REQUEST \#1647.03

"EXPORTS FROM AND IMPORTS TO

THE UNITED STATES UNDER INTERNATIONAL AND

BILATERAL WASTE AGREEMENTS"

$* * * 11 / 01 / 2000 * * *$

74 


\section{CONTENTS}

1. IDENTIFICATION OF THE INFORMATION COLLECTION $\ldots \ldots \ldots \ldots \ldots$

1 (a) Title and Number of the Information Collection . . . . . . . . . 1

1 (b) Short Characterization $\ldots \ldots \ldots \ldots \ldots \ldots$

2. NEED FOR AND USE OF THE COLLECTION $\ldots \ldots \ldots \ldots \ldots \ldots$

2(a) Need and Authority for the Collection . . . . . . . . . . . 5

2(b) Practical Utility and Users of the Data . . . . . . . . . . . . 6

3. NONDUPLICATION, CONSULTATIONS, AND OTHER

COLLECTION CRITERIA $\ldots \ldots \ldots \ldots \ldots \ldots \ldots \ldots \ldots$

3(a) Nonduplication . . . . . . . . . . . . . . . . . . . 6

3(b) Public Notice . . . . . . . . . . . . . . . . . . . . . 7

3(c) Consultations . . . . . . . . . . . . . . . . . . 7

3(d) Effects of Less Frequent Collection . . . . . . . . . . . . . 7

3(e) General Guidelines . . . . . . . . . . . . . . . . . . . . . . . 7

3(f) Confidentiality . . . . . . . . . . . . . . . . . . . 8

- 3 (g) Sensitive Questions ...................... . . 8

4. THE RESPONDENTS AND THE INFORMATION REQUESTED . . . . . . . 8

4(a) Respondents and SIC Codes . . . . . . . . . . . . . . . 8

4 (b) Information Requested . . . . . . . . . . . . . . . 9

5. THE INFORMATION COLLECTED--AGENCY ACTIVITIES, COLLECTION METHODOLOGY,

AND INFORMATION MANAGEMENT $\ldots \ldots \ldots \ldots \ldots \ldots \ldots \ldots$

5 (a) Agency Activities . . . . . . . . . . . . . . . . . . . . . . 11

5(b) Collection Methodology and Management . . . . . . . . . . 12

5(c) Small Entity Flexibility . . . . . . . . . . . . . . . . . . . . . . 12

5(d) Collection Schedule . . . . . . . . . . . . . . . . . . . 12

6. ESTIMATING THE COST AND BURDEN OF THE COLLECTION . . . . . 12

6(a) Estimating Respondent Burden . . . . . . . . . . . . . . . . . . . . . . . . 12

6(b) Estimating Respondent Costs . . . . . . . . . . . . . . . . . . 14

6(c) Estimating Agency Burden and Cost . . . . . . . . . . . . . . . 16

6(d) Estimating the Respondent Universe and Total Burden and

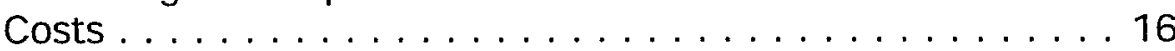

6(e) Bottom Line Burden Hours and Costs . . . . . . . . . . . . . 16

6 (f) Reasons for Change in Burden . . . . . . . . . . . . 17

6 (g) Burden Statement . . . . . . . . . . . . . . . . . . . 17 


\section{IDENTIFICATION OF THE INFORMATION COLLECTION}

\section{1 (a) Title and Number of the Information Collection}

The title of this ICR (ICR \#1647.03) is "Exports from and Imports to the United States Under International and Bilateral Waste Agreements."

\section{1(b) Short Characterization}

On March 30, 1992, the Organization for Economic Cooperation and Development (OECD) adopted Council Decision C(39)92/FINAL on the Control of Transfrontier Movements of Wastes Destined for Recovery Operations ("OECD Decision"). The U.S., a member of the OECD, supported the OECD Decision; therefore, the OECD Decision is legally binding upon the United States Government. At the time the OECD Decision was adopted, member countries noted that most countries would find it necessary to change domestic regulations to implement the OECD Decision, although most modifications would be minor. To implement this legally binding Decision in the U.S., it was necessary for the U.S. Environmental Protection Agency (EPA) to modify certain regulations under the Resource Conservation and Recovery Act (RCRA). As a result, EPA developed a Final Rule to codify the requirements of the OECD Decision as it is implemented in the U.S. in 40 CFR Part 262, subpart $\mathrm{H}^{1}{ }^{1}$ It is important to note that the new rule effectively modified the existing requirements for hazardous waste exports and imports to incorporate the additional requirements of the OECD Decision. The regulations are necessary to create requirements that are enforceable against U.S. hazardous waste exporters and importers.

Aside from the OECD Convention, the United States also imposes requirements on U.S. exports and imports of hazardous wastes to and from other countries at 40 CFR part 262 , subpart $E$ for exports and at subpart $F$ for imports.

It is important to note that this ICR calculates the burden associated with waste exports from and imports to the U.S. under the OECD Decision (40 CFR Part 262, subpart $H)$. This "OECD-only" burden is presented in separate exhibits in Section 6 of this supporting statement (see Exhibits 6.1a and 6.2a). This ICR also calculates the burden associated with U.S. exports and imports of hazardous wastes to and from other countries (non-OECD). This burden is presented along with the OECD burden in other exhibits in Section 6 (see Exhibits 6.1 and 6.2). The existing (non-OECD) export and import requirements (40 CFR Part 262, subparts $E$ and $F$ ) already required Notifications of Intent to Export and manifests for exports and imports. Therefore, the "OECD-only" analysis in this ICR considers only the incremental burdens and costs associated with the minimal additional information collection requirements imposed by the OECD Decision. The analysis that includes exports and imports under the

${ }^{1}$ Although there are requirements for foreign entities pursuant to the OECD Decision, this ICR estimates only the burdens to the U.S. regulated community and EPA. This is because the OECD Decision itself establishes the requirements for foreign entities. The rule codifying the OECD Decision in the U.S. (under RCRA authority) establishes requirements only for the regulated community within the United States. 
OECD Decision plus other hazardous waste exports and imports ("OECD-plus") also considers only the incremental burdens associated with the OECD Decision, but applies them to a broader universe of shipments (i.e., non-OECD exports and imports). In this way, the burden figures and costs calculated for "OECD-plus" are somewhat misleading, since nonOECD shipments need not conform to the OECD Decision requirements.

The burden and costs estimated for the OECD-only scenario are far lower, due to the limited number of exports from and imports to the U.S. under the OECD Decision. However, these numbers reflect an accurate estimation of the burden associated with the OECD requirements.

The OECD Decision identifies an extensive array of wastes that are subject to a graduated system of procedural and substantive controls when they are moved across national borders within the OECD. ${ }^{2}$ The applicable control scheme for any particular waste depends on the pre-established placement of a waste on one of three lists: green, amber, or red. Green-list wastes are subject to no additional controls under the OECD Decision beyond those imposed on normal international commercial shipments. Amber-list wastes either: (1) move on a shipment-by-shipment basis requiring prior written notification and consent (either written or tacit) from the importing and transit countries (if any); or (2) move to a facility that is pre-approved by the importing country to accept that waste type with prior written notification only. In both cases, the waste must be accompanied by a tracking document and shipped under a legally binding contract, chain of contracts, or equivalent arrangements (where the notifier and the receiving facility are part of the same corporate entity). Red-list wastes are handled in the same manner as amber-list wastes except that prior written consent from importing and transit countries is always required and no facilities are preapproved to accept red-list wastes. Wastes not identified on any list are subject to red-list controls if they are identified or defined as a hazardous waste using a concerned country's (exporting, importing, and transit, if any) national procedures (e.g., laws and regulations); otherwise, they move as green-list wastes. ${ }^{3}$

Many of the wastes identified on the amber and red lists are, in fact, categories of wastes rather than specific waste streams (e.g., wastes from the formulation, production, and use of paints). OECD member countries are allowed to use their respective national procedures (e.g., RCRA) to determine which specific waste streams are subject to the

${ }^{2}$ OECD member countries currently include Australia, Austria, Belgium, Canada, Czech Republic, Denmark, Finland, France, Germany, Greece, Hungary, Iceland, Ireland, Italy, Japan, Korea, Luxembourg, Mexico, the Netherlands, New Zealand, Norway, Poland, Portugal, Spain, Sweden, Switzerland, Turkey, the United Kingdom, and the United States.

${ }^{3}$ An OECD work group, comprised of Member country delegates, is in the final stages of re-negotiating the legally binding international agreement, or "Council Decision", which facilitates trade in waste recyclables among developed countries. The renegotiation of the Council Decision will alter somewhat, the current procedural and substantive controls governing waste movement across national borders within the OECD. The OECD Member countries are expected to formally approve this revised international agreement in 2001. The agreement will not enter into force for the U.S. until relevant RCRA regulations are revised to reflect the OECD agreement. 
OECD Decision. Under U.S. national procedures, those hazardous wastes subject to Federal manifesting requirements under RCRA, using the definition of hazardous waste found in the Federal regulations (40 CFR 261.3), are covered by EPA's regulations codifying the OECD Decision. The Agency's interpretation of the scope of coverage of the OECD Decision (hazardous wastes subject to RCRA manifesting requirements under Federal regulations) applies only to controls imposed within the jurisdiction of the U.S. Persons exporting wastes from the U.S. to other OECD countries also have to comply with any additional requirements imposed by the importing and transit countries, in accordance with the domestic laws of those countries, which is the status quo.

On April 12, 1996 (61 FR 16289), the newly modified regulations codifying the OECD Decision procedures replaced existing RCRA export/import regulations found in 40 CFR Part 262 , subparts $E$ and $F$ only for those hazardous wastes destined for recovery within the scope of the OECD Decision. Those hazardous wastes not within the scope of the OECD Decision remain subject to the previously existing RCRA export/import requirements in 40 CFR Part 262, subparts $E$ and $F$. Wastes not within the scope of the OECD Decision include all hazardous wastes moving to:

- : Non-OECD member countries, and

- $\quad$ OECD member countries for treatment and disposal).

In addition, it is important to note that it is EPA's interpretation that the RCRA regulations codifying the terms of the OECD Decision are applicable only to hazardous waste destined for recovery that is:

1. Subject to the RCRA manifest requirements under the Federal regulations when it is sent for recovery, and

2. Sent to or received from an OECD member country. ${ }^{4}$

The collection of information from U.S. exporters and U.S. importers was an existing process under RCRA prior to the April 12, 1996 rulemaking. However, the regulations codifying the OECD Decision had the net effect of increasing the burden of information collection imposed on EPA and U.S. exporters and importers of hazardous wastes. This increased burden is not defined as a "significant regulatory action" under section 3(f) of Executive Order 12866, "Regulatory Planning and Review."

Under non-OECD hazardous waste export regulations, U.S. exporters of hazardous waste must complete and transmit to EPA a Notification of Intent to Export hazardous waste for each shipment unless the notice is a general, annual notice for multiple shipments

${ }^{4}$ Although Canada and Mexico are members of the OECD, the United States has separate bilateral agreements covering transboundary movements of waste with both Canada and Mexico. Therefore, while the requirements of 40 CFR Part 262, subpart H do not apply to U.S. exports and imports to and from Canada and Mexico, this ICR does consider the burden associated with shipments to and from Canada and Mexico, as well as other countries with which the U.S. maintains a bilateral waste trade agreement. 
of the same hazardous waste to the same recovery facility (40 CFR Part 262, subpart E). The OECD Decision did not significantly change this requirement, but does require the submittal of additional information as part of the Notification of Intent to Export. These new requirements are discussed in Section 4(b) of this ICR. No additional recordkeeping burden is imposed by the OECD Decision; recordkeeping requirements continue to be the same as requirements imposed under existing export regulations.

Under the Part 262, subpart E export regulations, U.S. exporters also must complete and transmit a Uniform Hazardous Waste Manifest. The OECD Decision requires exporters of hazardous waste to complete and transmit a tracking document. ${ }^{5}$ Some information required in the tracking document exceeds that presently required for the hazardous waste manifest. Most of the additional information required for the tracking document under the OECD Decision is information necessary for the OECD Notification of Intent to Export. A tracking document is required each time an export shipment of hazardous waste is initiated.

Under the non-OECD hazardous waste import regulations, U.S. hazardous waste management facilities regulated under 40 CFR Part 264 or 265 must notify EPA at least four weeks prior to the date of receipt of hazardous waste imports. Importing facilities must confirm receipt of the shipment by sending a signed copy of the manifest to the generator, e.g., foreign generator or U.S. importer (40 CFR Part 262, subpart F). The OECD Decision also requires recovery facilities importing hazardous waste into the U.S. to return signed copies of the tracking document to the foreign exporter and competent authorities of the concerned countries (exporting, importing, and transit, if any). The OECD Decision did not significantly change the previously existing requirements, but required the signing and transmission of additional copies of the tracking document and an expedition of this process (three working days instead of 30 days).

The information collection burden imposed under both the OECD Decision and for U.S. hazardous waste exports to and from other countries, involves approximately 816 U.S. exporters and 746 U.S. importers. The annual cost associated with the additional OECD requirements in the first year covered by this ICR is estimated to be $\$ 441,360$ for U.S. exporters and $\$ 38,582$ for U.S. importers.

${ }^{5}$ Although the OECD Decision requires the use of a tracking document, the OECD only recommends forms for notification and tracking purposes. Neither the OECD nor the U.S. requires their use. Therefore, OECD member countries are allowed to use any document, provided all of the required information is contained in the document. If OECD decides to require the use of OECD forms, EPA will codify this requirement and assess the burden. 


\section{NEED FOR AND USE OF THE COLLECTION}

\section{2(a). Need and Authority for the Information Collection}

Authority to promulgate the April 12, 1996 rule is found in sections 2002(a) and $3017(a)(2)$ and (f) of the Solid Waste Disposal Act, as amended by the Resource Conservation and Recovery Act, and as amended by the Hazardous and Solid Waste Amendments, 42 U.S.C. $\$ 6901$ et seq.

The Final Rule codifying the OECD Decision was necessary to ensure implementation of the OECD Decision, which is considered legally binding on the United States under Articles 5(a) and 6(2) of the OECD Convention, 12 U.S.T. 1728. In addition, the OECD Decision and the rule implementing the OECD Decision ensure that exports and imports of recoverable hazardous waste between the U.S. and OECD member countries may proceed even though the U.S. is not yet a "Party" to the Basel Convention on the Control of Transboundary Movements of Hazardous Wastes and Their Disposal. The Basel Convention entered into force on May 5, 1992 for countries that had ratified it by that date. The Convention prohibits trade of Basel-covered wastes between Parties and Non-parties, unless a bilateral, multilateral, or regional agreement or arrangement exists in accordance with Article 11 of the Convention. The OECD Decision satisfies the requirements of Article 11 of the Basel Convention because it is a pre-existing multilateral agreement compatible with the environmentally sound management of wastes as required by the Basel Convention.

Therefore, the revisions to the RCRA hazardous waste export and import regulations, which are necessary to implement the OECD Decision, make it possible for the U.S. to continue exporting and importing Basel-covered wastes for recovery to and from OECD countries. The European Union's implementation of regulations for Basel and OECD became effective on May 6, 1994.

Although the OECD Decision is neither a statute nor a court order, it has similar impacts. Courts recognize international agreements as part of the law of the U.S. and as supreme over the law of the states. The State Department has determined that this OECD Decision is an international agreement binding on the U.S. under the terms of the OECD Convention. The U.S. had an obligation under that Convention to implement the OECD Decision as quickly as possible. Other OECD member countries may refuse to accept U.S. shipments of waste for recovery that do not conform to the OECD Decision. Such countries also may refuse to allow wastes to be exported to the U.S. if the U.S. cannot carry out its duties under the OECD Decision.

The State Department determined that the OECD Decision is not "self-cxccuting" and therefore regulations are necessary to give its provisions the effect of law. In other words, the OECD Decision does not by itself impose any obligations directly on citizens of the U.S. Instead, by consenting to the OECD Decision, the United States Government agrees to enact legislation or promulgate regulations necessary to ensure that the U.S. can uphold the agreement. EPA and the State Department determined that no new legislation was needed because RCRA authorizes EPA to promulgate requirements for individual importers and exporters of hazardous waste that are needed to implement the OECD Decision. 
The OECD Decision sets out very specific requirements for shipments of recoverable hazardous waste. EPA codified in the Code of Federal Regulations language that mirrors the OECD Decision to establish certain requirements that are enforceable against importers and exporters (40 CFR Part 262, subpart H).

\section{2(b) Practical Utility and Users of the Data}

The Office of Enforcement and Compliance Assurance, U.S. EPA, uses the information provided by each U.S. exporter and U.S. importer to determine compliance with the applicable RCRA regulatory provisions. In addition, the information is used to determine the number, origin, destination, and type of exports from and imports to the U.S. for tracking purposes and for reporting to the OECD. This information also is used to assess the efficiency of the program.

\section{NONDUPLICATION, CONSULTATIONS, AND OTHER COLLECTION CRITERIA}

\section{3(a) Nonduplication}

Except as described below, the OECD Decision does not result in the collection of duplicate data. Although some of the information required for the hazardous waste manifest and the tracking document is substantively the same, up to six pieces of additional information are required for the tracking document. In addition, these two documents serve different purposes. A signed copy of the hazardous waste manifest, which is not valid beyond U.S. borders, is dropped off at the U.S. Customs check point when the shipment leaves the U.S. to verify pertinent information, including point of departure, date, destination, and contents of the shipment. The tracking document must accompany the shipment until it reaches the foreign recovery facility. The signed tracking document is subsequently returned to EPA and the U.S. exporter to acknowledge receipt of the shipment in accordance with the OECD Decision.

In certain cases, some of the information on the tracking document also may be collected by the Department of Commerce in its Census Bureau form titled "Shipper's Export Declaration" (15 CFR Part 30). This form, which is required for all shipments that have a value in excess of $\$ 1,500$, must be filed at the U.S. port of exit, similar to the current export requirements. However, the information contained in the Census Bureau's form is not adequate for EPA's purpose of tracking and identifying the export of hazardous waste from the U.S. For example, the wastes are identified by tariff codes that are less precise than the waste codes required by the tracking document.

Because the OECD Decision applies only to hazardous waste destined for recovery, it is likely that some of the wastes may have a value in excess of $\$ 1,500$. EPA believes that the economic interest served by allowing recovery operations to continue within the OECD and the interest in protecting human health and the environment served by the tracking document outweigh the potential minor costs to a small number of exporters that may have to complete the Census Bureau form in addition to the tracking document. 
When the regulations codifying the OECD Decision were published on April 12, 1996 (61 FR 16289), EPA promulgated the requirements without first providing notice and opportunity for public comment. Under the Administrative Procedure Act (APA), 5 U.S.C. 553 (b)(B), an agency may forgo notice and comment in promulgating a rule when the agency finds that such procedures are impracticable, unnecessary, and/or contrary to the public interest. EPA found that notice and comment procedures were unnecessary in connection with promulgating the OECD Decision because EPA was precluded from modifying the rule in any meaningful way in response to public comment. The requirement to implement the Decision virtually as written derived from the legally binding commitment made by the U.S. with the other OECD countries on implementing the Decision. As a result, the April 12, 1996 rulemaking is analogous to a codification of statutory requirements, where an agency assumes the nondiscretionary function of simply translating requirements into regulatory form.

On November 1, 2000, EPA published a notice in the Federal Register to inform the public that this proposed and continuing ICR, entitled "U.S. Exports and Imports of Hazardous Wastes", was being submitted to OMB for review and approval. The burden and cost figures presented in the Federal Register notice correspond to the "OECD-plus" scenario analyzed in this ICR and include exports and imports under the OECD Decision plus other bilateral waste agreements.

\section{3(c)}

\section{Consultations}

EPA played a significant role in negotiating the U.S.' position in the OECD Decision. EPA benefitted from extensive industry involvement and support from such groups as the Institute for Scrap Recycling Industries, Aluminum Association, International Precious Metals Institute, National Forest and Paper Association, U.S. Chamber of Commerce, American Chemistry Council (then Chemical Manufacturers Association), World Resources Company, American Zinc Association, Cadmium Council, Non-ferrous Metal Producers Committee, National Mining Association, and the Zinc Corporation of America. Other Federal agencies involved included the State Department and the Department of Commerce.

\section{Effects of Less Frequent Collections}

The Agency believes that the tacit consent and general notification provisions for amber-listed waste are the minimum necessary to ensure compliance with domestic statutory and international requirements. The tacit consent and general notification provisions are a reduction in burden. Any further reduction in the information collection requirements would hinder the Agency from effectively tracking the disposition of hazardous waste.

\section{3(e) General Guidelines}

This information collection follows all of OMB's "General Guidelines for Information Collections." However, OMB's general guidelines require EPA to justify any reporting 
requirements imposed more frequently than quarterly. Under the rules codifying the OECD Decision, copies of the tracking document are required to be sent to the Agency within 3 working days of receiving the shipment. It is possible that the timing of import shipments to the U.S. could trigger the obligation of importers to forward tracking documents to EPA more frequently than on a quarterly basis. There is, however, no accurate or dependable method to predict how often this would occur under the OECD Decision, since the shipments are tied solely to market conditions and patterns of the hazardous waste import/export business.

Within three working days of receiving the Notification of Intent to Export hazardous waste to the United States, EPA is required to transmit the Notification of Acknowledgment of Receipt to the competent authority(ies) of the foreign exporting country. This requirement codifies a provision of the OECD Decision that is binding on the United States Government as a signatory nation. EPA has no discretion to modify this response time requirement as it is set forth in the OECD Decision. Further, the practical effect of changing to a three-day response time results in the expedition of the shipping of these wastes and helps maximize the efficiency of the hazardous waste recovery process to the benefit of the regulated community.

The Agency will comply with all applicable provisions of Section 3007(b) of RCRA and 40 CFR Part 2, subpart B, and 40 CFR 260.2. These regulations define EPA's general policy on the public disclosure of information.

3(g) Sensitive Questions

No questions of a sensitive nature are included in any of the information collection or management requirements.

\section{THE RESPONDENT AND THE INFORMATION REQUESTED}

\section{4(a) Respondents' SIC Codes}

Businesses with the following SIC codes potentially are affected by this effort:

28 Chemicals and allied products

29 Petroleum refining and related industries

33 Primary metal industries

34 Fabricated metal products, except machinery and transportation equipment

35 Industrial and commercial machinery and computer equipment

36 Electronic and other electrical equipment and components, except computer equipment

37 Transportation equipment

38 Measuring, analyzing, and controlling instruments

39 Miscellaneous manufacturing industries

49 Electronic, gas, and sanitary services 


\section{4(b) Information Requested}

The information requirements imposed on respondents under the OECD Decision are basically the same as the requirements previously imposed under the general export and import requirements of 40 CFR Part 262, subparts $E$ and $F$, except for the additional information items described below. ${ }^{6}$

\section{(i) Data Items}

The following information, which is required by the OECD Decision, is in addition to the information required for non-OECD exports and imports, under 40 CFR Part 262. subparts $E$ and $F$, respectively:

\section{U.S. Exporters:}

Export Notification (40 CFR 262.83):

\section{- $\quad$ Fax number}

- $\quad$ Serial number/identifier of notification form

- Intended carrier(s) and/or agents

- Countries of export, import, and transit and relevant competent authorities

- Certification of the existence of written contract, chain of custody, or equivalent arrangement with consignee, between exporter and importer

- $\quad$ Certification that the information is complete and correct

- Certification of financial guarantee if required by any concerned country (importing and transit).

Tracking Form (40 CFR 262.84):

- $\quad$ Fax numbers of the export notifier, consignee, and carrier

- Technologies employed by the recovery facility

${ }^{6}$ For the purposes of this ICR, under the OECD Decision it is assumed that only amber-listed wastes are exported or imported for recovery. The Agency believes that most of the RCRA wastes subject to Federal manifesting are amber-listed wastes. The number of red-listed waste shipments are probably very small because the U.S. has banned the export of some of the wastes (e.g., PCBs) and other countries similarly have instituted restrictions on some red wastes. In addition, most red-listed wastes are not as amenable to recovery as amber-listed wastes, and thus, are unlikely to be shipped under this OECD Decision. 
- Means and mode of transport, including types of packaging

- Countries of export, import, and transit and relevant competent authorities

- $\quad$ Frequency of shipment (single or general notification).

Certification of Contracts (40 CFR 262.85):

(This is not an additional burden because it has long been standard business practice.)

\section{U.S. Importers:}

The rule codifying the OECD Decision did not impose any significant new or additional information collection requirements on U.S. importers of hazardous waste destined for recovery. However, U.S. recovery facilities that import hazardous waste are required to sign additional copies of the tracking document and transmit them to the appropriate parties within three working days instead of the previously required 30 days [see $\$ \$ 264.71$ (d) and 265.71(d)].

(ii) Respondent Activities

\section{U.S. Exporters:}

- Obtain and read the regulations codifying the OECD Decision and assess applicability

- Complete the additional information for the Notification of Intent to Export

- $\quad$ Complete the additional information for the tracking document.

\section{U.S. Importers:}

- Obtain and read the regulations codifying the OECD Decision and assess applicability

- $\quad$ Sign and transmit the additional copies of the tracking document to EPA, competent authority of exporter country, and competent authority of transit country (if applicable)

- $\quad$ Expedite the response time (three working days) to transmit copies of the signed tracking document to the foreign exporter, EPA, competent authority of exporter country, and competent authority of transit country (if applicable).

\section{THE INFORMATION COLLECTED--AGENCY ACTIVITIES, COLLECTION METHODOLOGY, AND INFORMATION MANAGEMENT}

The following subsections discuss how EPA collects the information, what activities, if any, EPA performs after receiving the information, and how EPA manages the information 
that it collects. Only those additional information collection and management activities required by the OECD Decision (performed by EPA) are considered in this section of the supporting statement.

\section{5(a) Agency Activities}

The OECD Decision requires the Agency to perform the following additional information collection and management activities. These activities are in addition to the baseline (non-OECD) information collection and management requirements already imposed by RCRA for hazardous waste exports and imports. ${ }^{7}$

\section{Exports From the U.S.:}

- Receive and record the Acknowledgment of Receipt from the importing country

- Receive and record the Tracking Document received from the foreign recovery facility.

Imports To the U.S.:

- Transmit an Acknowledgment of Receipt to the foreign exporter, competent authority of the foreign exporting country, and competent authority of transit country(ies) if applicable

- Receive and record the Tracking Document received from the U.S. recovery facility.

7 The quantifiable benefit to EPA in implementing the OECD Decision is the reduced burden cost to EPA to implement the exporter procedures required under the OECD Decision. The Agency is relieved of having to forward the importing country's Acknowledgment of Consent or denial to the U.S. exporter. 
As with the information collection activities under the non-OECD hazardous waste export and import program, the collection and management of the information submitted to EPA via the Notification of Intent to Export, tracking documents, and Acknowledgments of Receipt is stored by EPA in file cabinets and/or electronically to be compiled in an annual status report. In addition, this information is collected and stored for possible future use in enforcement actions.

\section{5(c) Small Entity Flexibility}

In promulgating the rule codifying the OECD Decision, EPA evaluated the impact on regulated small entities. The decision to export or import hazardous waste is voluntary. Thus, no business, small or otherwise, is required to export or import its hazardous waste. Therefore, there is no mandatory burden on the regulated community, including small businesses. Furthermore, for small businesses that do choose to export or import hazardous waste, EPA exempted conditionally exempt small quantity generators (less than 100 kilograms per month) from the requirements of the rule.

5(d) - Collection Schedule

Under the rule codifying the OECD Decision, Notification of Intent to Export submissions and tracking documents are generated and sent to EPA on a random, occurrence-specific basis for which there is no formalized schedule. Once these events do occur, notifications must be sent to EPA within 45 days prior to initiating waste exports, and tracking documents must be sent to EPA by U.S. recovery facilities within three working days of receipt of imported wastes.

\section{ESTIMATING THE COST AND BURDEN OF THE COLLECTION}

6(a) Estimating Respondent Burden

\section{(1) Requirements for Exports of Hazardous Waste from the U.S.}

The OECD Decision imposes incremental burdens on U.S. exporters of hazardous waste destined for recovery. These burdens result from the activities discussed in Section 4(b)(ii)--reading the regulations, completing the Notification of Intent to Export, and completing the tracking document. The burden and costs associated with the few additional activities imposed on U.S. importers are shown in Exhibits 6.1 and 6.1a (all Exhibits are presented at the end of Section 6).

Data on exports were obtained from EPA's Office of Enforcement and Compliance Assurance (OECA). The level of certainty associated with available export data is high, except for per-company shipment estimates. The level of certainty associated with the number of per-company shipment estimates is low because of the use of brokering agents that may represent multiple companies. 
The affected universe of U.S. exporters and export shipments of hazardous waste from the U.S. as a result of the OECD Decision (and other bilaterals) includes the following:

- U.S. Exporters:

The precise total number of U.S. exporters affected by the OECD Decision cannot be determined. This is because it is difficult to account for the number of companies that use waste brokers who may trade several companies' wastes, and who file notices and annual export reports for wastes for multiple generators (exporters). However, the number of exporters who filed a Notification of Intent to Export to OECD countries only in 1999 was 44. The total number of companies in 1999 that filed a Notification of Intent to Export to either an OECD country or a country covered by a bilateral agreement was 816 . For the purposes of this ICR, these numbers of exporters are used to estimate burden.

- $\quad$ Export Shipments:

Based on data obtained from the Office of Enforcement and Compliance Assurance, the number of export shipments from the U.S. to OECD countries only is estimated to be 1,320. The number of export shipments to OECD countries and to other countries under bilateral agreements (including Canada and Mexico) is estimated to be 25,000 .

\section{(2) Requirements for Imports of Hazardous Waste to the U.S.}

The OECD Decision imposes only minor, incremental burdens on U.S. importers of hazardous wastes destined for recovery. These burdens stem from those few activities identified in Section 4(b)(ii)--reading the regulations, signing the various copies of the tracking document, and transmitting the signed copies within three working days rather than 30 . The Agency recognizes that there is an increased burden to U.S. importers associated with the expedited response time for signing and transmitting the completed tracking document (30 days reduced to three working days). However, because there is no additional labor effort, paperwork burden, recordkeeping, reporting, or capital costs associated with this decrease in response time, there is no reasonable, accurate cost burden that can be estimated for this effort. 'It is assumed that such costs are understood intuitively to be slight in relation to other requirements imposed by the OECD Decision. The burden and costs associated with the few additional activities imposed on U.S. importers are shown in Chart 6.2.

The affected universe of U.S. importers and hazardous waste import shipments to the U.S. as a result of the OECD Decision (and other bilaterals) includes the following:

- U.S. Importers:

Based on data from OECA, there were 746 U.S. importers in 1999. This includes U.S. facilities importing wastes from OECD countries, as well as from other countries under bilateral agreements. 34 importers received wastes only from OECD countries in 1999.

- Import Shipments:

OECA has no information on the number of import shipments originating in all 
countries, so it was assumed that each of the 746 importers receives four (4) shipments per year, for a total of 2,984 annual import shipments. OECA provided information that one U.S. facility regularly imports wastes from another OECD country and estimated the annual number of OECD import shipments to be approximately 350 shipments per year. For purposes of this ICR, these numbers of U.S. importers and import shipments are used to estimate burden.

\section{6(b)}

\section{Estimating Respondent Costs}

As shown in Chart 6.1, the estimated annual incremental costs incurred by U.S. companies exporting hazardous waste to an OECD country include costs associated with the time necessary to:

- $\quad$ Obtain and read the regulations and assess applicability (new entrants only)

- Complete a Notification of Intent to Export hazardous waste

- $\quad$ Complete the Tracking Document

As shown in Chart 6.2, the estimated incremental costs incurred by U.S. recovery facilities importing hazardous waste include costs associated with the time necessary to:

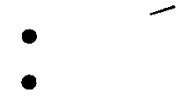

Sign and transmit copies of the tracking document

Reduce response time ( 3 working days as compared to 30 days) to transmit a signed copy of a tracking document

EPA estimates an average hourly respondent cost of $\$ 73$ for managerial staff, $\$ 53$ for technical staff, and $\$ 27$ for clerical staff. These rates were used in the most recent version of the Land Disposal Restrictions ICR (EPA ICR \#1442.17). To derive these figures, EPA consulted the Handbook of U.S. Labor Statistics, Second Edition, and the EPA report Estimating Costs for the Economic Benefits of RCRA Noncompliance. These publications summarize the base hourly rates for various labor categories in U.S. firms. EPA then applied an overhead factor of 2.3 for non-legal staff and 3.0 for legal staff to derive the loaded hourly rates. Loaded rates include salary, benefits, and other overhead.

There are no significant start-up costs associated with this ICR. With respect to operation and maintenance costs, the tracking document requirements for U.S. importers of hazardous waste (i.e., recovery facilities transmitting additional copies of the tracking document), the Agency assumes that the tracking document is sent by telefax. The telefax is a one-page copy of the tracking document. Currently, 70 percent of all hazardous waste imports to the U.S. originate in Canada. Deriving the most conservative cost estimates assumes that 70 percent of the telefaxed documents are sent to Canada at a cost of $\$ 0.11$ per minute; the remaining 30 percent of the faxed documents are assumed to be sent to Australia (the most distant OECD member country from the U.S. mainland borders) at a cost of $\$ 0.13$ per minute. (These rates are based on peak rates for private businesses that spend $\$ 25$ or more each month.) Based on these data, a weighted average per fax cost of $\$ 0.11$ was used. This assumes that it takes one minute to fax each page of the tracking document. The annual total telefax costs are approximately $\$ .35$ per importer, for a total estimated operation and maintenance cost of $\$ 1,015$ per year. 
Additional EPA information collection and management responsibilities under this rulemaking involve only administrative functions. Therefore, no management or technical cost figures are included in this ICR. The EPA clerical labor rate used to estimate costs to the Agency is $\$ 18.32$. This labor rate, used to estimate incremental annual costs, was used in the most recent ICR for the Land Disposal Restrictions program (EPA ICR \#1442.17).

In 1999, 95 percent of all hazardous waste exports from the U.S. were to Canada, which did not involve a transit country. Although exports to other countries may require the use of a transit country, the precise number is unknown. However, to estimate the maximum possible burden, it is assumed that all exported shipments of hazardous waste not going to Canada (5 percent) are transported through a transit country. Therefore, it is assumed that a maximum of 1,250 export shipments (25,000 shipments $\times 5$ percent) require the receipt and recording by EPA of an Acknowledgment of Receipt from the competent authority in the transit country. As explained earlier, completion of a Notification of Intent to Export is required annually for each shipment of one type of waste sent to the same recovery facility, but not required with every shipment of like waste.

As stated previously, the total number of import shipments to the U.S. in 1999 from OECD and other countries was 746. Thus, for the purposes of this ICR, this number of import shipments is used to estimate Agency burden associated with importer provisions.

With regard to the tracking document requirements for U.S. importers of hazardous waste (i.e., importer facilities sending additional copies of the tracking document), the Agency is assuming that the Tracking Document is sent by telefax. The telefax is a onepage copy of the Tracking Document. Currently, 70 percent of all hazardous waste imports to the U.S. originate in Canada. Deriving the most conservative cost estimates assumes that 70 percent of the telefaxed documents are sent to Canada at a cost of $\$ 0.12$ per minute; the remaining 30 percent of the faxed documents are assumed to be sent to Australia (the most distant OECD member from the U.S. mainland borders) at a cost of $\$ 0.11$ per minute. These rates are based on current rates for government agencies. Based on these data, a weighted average per fax cost of $\$ 0.12$ was used. This assumes that it takes one minute to fax each page of the Tracking Document. 
The Agency used its substantial experience in developing and implementing the existing RCRA regulatory program for estimating the burden hours associated with the various information collection and management activities required by the OECD Decision.

6(d) Estimating the Respondent Universe and Total Burden and Cost

In estimating the respondent universe, EPA used data from the Office of Enforcement and Compliance Assurance (OECA). These data indicate that 816 Notices of Intent to Export were filed in 1999 for exports to OECD and other countries. Only 44 such notices were filed for exports to OECD countries alone. Similarly, OECA provided data indicating that 746.importers received shipments from OECD and other countries in 1999, while 34 received imports from $\mathrm{OECD}$ countries alone.

Using these numbers to estimate burden, the total annual burden and cost for U.S. exporters and importers under the OECD Decision and other bilaterals is 9,334 hours and $\$ 479,942$. The total annual burden and cost under the OECD Decision alone is 607 hours and $\$ 30,856$.

6(e) Bottom Line Burden Hours and Costs

"OECD-plus" Scenario

The total annual burden for all U.S. exporters of hazardous waste impacted by the OECD Decision and other bilaterals is 8,349 burden hours (10.23 hours per exporter). The total burden hours for all U.S. importers of hazardous waste impacted by the OECD Decision and other bilaterals is 985 burden hours ( 1.32 hours per importer). The total annual combined bottom-line burden hours and costs for U.S. importer and U.S. exporter respondents equal 9,334 burden hours and \$479,942 (see Exhibit 6.1).

The total annual burden associated with EPA implementing the OECD Decision for exports of hazardous waste to OECD and other countries is 6,454 hours. The total annual burden for EPA to implement the OECD Decision for waste imports from OECD and other countries is 1,492 hours. The total annual Agency cost for U.S. exporters is $\$ 118,237$. The total annual Agency cost for U.S. importers is $\$ 27,696$. The total combined annual Agency burden and cost for respondents is 7,946 hours and \$145,933 (see Exhibit 6.2).

\section{"OECD-only" Scenario}

The total annual burden for all U.S. exporters of hazardous waste affected by the OECD Decision is 491 burden hours ( 11.16 hours per exporter). The total annual burden for all U.S. importers of hazardous waste affected by the OECD Decision is 116 burden hours (3.4 hours per importer). The total annual combined bottom-line burden hours and costs for U.S. exporter and importer respondents (OECD-only) equal 607 hours and $\$ 30,856$ (see Exhibit 6.1a).

The total annual burden associated with EPA implementing the OECD Decision for 
exports is 341 hours. The total annual burden for EPA to implement the OECD Decision for waste imports is 175 hours. The total annual Agency cost for U.S. exporters is $\$ 6,247$ and, for importers, $\$ 3,348$. The total combined annual Agency burden and cost for respondents under the OECD Decision is 516 hours and $\$ 9,595$.

6(f) Reasons for Change in Burden

The rule codifying the OECD Decision imposes minimal new information collection requirements on U.S. companies that export and import hazardous waste destined for recovery. As a result of these requirements, the total burden for all respondents has increased. The change in burden is a direct result of the OECD Decision and the U.S. becoming a signatory to the OECD Decision.

\section{6(g) Burden Statement}

Public reporting burden for the collection of information under the OECD Decision plus other bilateral agreements is estimated to average 10 hours for exporters and 1 hour for importers. The reporting burden under the OECD Decision alone is estimated to average 11 hours for exporters and 3 hours for importers. The reason for the significant discrepancies between exporter and importer burden in this ICR is due mainly to the fact that this analysis does not consider any importer burden associated with reading the regulations. The number of importers has decreased since the last ICR was developed, so it was impossible to assign this burden to the new entrants to the system. There are fewer requirements for importers than for exporters, but the actual difference in paperwork burden is probably less than that reflected by this analysis.

There is no change in recordkeeping requirements; therefore, no additional burden associated with increased recordkeeping was calculated. The calculated burden includes the time for reviewing the rule, completing any required forms such as the Notification of Intent to Export hazardous wastes and tracking documents, and associated administrative labor hours for the actual transmission of these documents to their proper locations, as specified by the rule codifying the OECD Decision. 
Send comments regarding these burden statements or any other aspect of this collection, including suggestions for reducing the burden, to the following locations:

Director, Office of Environmental Information

U.S. Environmental Protection Agency

1200 Pennsylvania Ave, N.W.

Washington, DC 20460

and:

Desk Office for EPA

Office of Information and Regulatory Affairs

Office of Management and Budget

Washington, DC 20503 